Portland State University

PDXScholar

\title{
Collaboration and Evaluation in Urban Sustainability and Resilience Transformations: the Keys to a Just Transition?
}

Liliana Elizabeth Caughman

Portland State University

Follow this and additional works at: https://pdxscholar.library.pdx.edu/open_access_etds

Part of the Environmental Policy Commons, Environmental Studies Commons, Higher Education Commons, Place and Environment Commons, and the Sustainability Commons Let us know how access to this document benefits you.

\section{Recommended Citation}

Caughman, Liliana Elizabeth, "Collaboration and Evaluation in Urban Sustainability and Resilience Transformations: the Keys to a Just Transition?" (2020). Dissertations and Theses. Paper 5471. https://doi.org/10.15760/etd.7343

This Dissertation is brought to you for free and open access. It has been accepted for inclusion in Dissertations and Theses by an authorized administrator of PDXScholar. Please contact us if we can make this document more accessible: pdxscholar@pdx.edu. 
Collaboration and Evaluation in Urban Sustainability and Resilience Transformations:

The Keys to a Just Transition?

by

Liliana Elizabeth Caughman

A dissertation submitted in partial fulfillment of the requirements for the degree of

Doctor of Philosophy

in

Earth, Environment and Society

\author{
Dissertation Committee: \\ Vivek Shandas, Chair \\ Melissa Haefner \\ Jon Fink \\ Jennifer Allen
}

Portland State University

2020 
(C) 2020 Liliana Elizabeth Caughman 


\begin{abstract}
Climate has changed and will continue changing; city populations are swelling as urbanization continues to accelerate; extreme environmental events like heat waves and floods are becoming more severe and more common; and the climate justice movement is rapidly gaining momentum. It in this context that municipal governments find themselves urgently seeking solutions to transition cities from extractive, vulnerable, and unjust to sustainable, resilient, and equitable. The task is complex and will require systemic transformations across interconnected social, environmental, and economic infrastructures. Emerging theories regarding how to govern such massive changes suggest Transition Management strategies and the values of a just transition. Taken together, these approaches aim to build pathways from our current system to a new one, without leaving anyone behind. Unfortunately, there is little known about which strategies, processes, and practices will support the management and implementation of urban sustainability and resilience just transition agendas. Therefore, this dissertation explores the role of partnerships and collaborations as well as monitoring and evaluation in facilitating and accelerating equitable urban sustainability and resilience transformation, and concludes with the establishment of just transformative capacity.
\end{abstract}




\section{Dedication}

To my beloved mother-in-law, Jeanne McGinnis. To my wise mentor, Americ Azevedo. To everyone we have lost too soon. To everyone who has lost someone that inspired them to be a better version of themselves. 


\section{Acknowledgements}

This is a dissertation about collaboration and transformation, and it itself was made through these processes. The ideas put forth in this paper are not mine alone, and I owe so much to my countless co-producers of knowledge. I am also incredibly lucky to have been financially, emotionally, and intellectually supported by so many in order to complete this work. Thank you, everyone.

First, I must acknowledge my advisor Dr. Vivek Shandas for bringing me to Portland State University. Without him, I would not have pursued a PhD. His supportive yet laid-back approach to advising was the perfect fit for me; he somehow knew exactly how I would thrive and put the pieces in place for me to seize the occasion.

Next, I must thank The Institute for Sustainable Solutions, and especially Director Fletcher Beaudoin, for bringing me on to their team and giving me the opportunity to conduct my research. This dissertation would be impossible without your unrelenting dedication to innovation and systemic change, and your belief in my abilities to contribute to this work.

I also must recognize my academic colleagues from Arizona State University, the Global Consortium for Sustainability Outcomes (GCSO), and The Urban Resilience to Extremes (UREx) Sustainability Research Network. I offer a huge thank you to Dr. Lauren Withycombe Keeler for being a fantastic mentor to me and showing me what it means to be a successful woman in academia. I thank GCSO for providing me context for my research, and for incubating a rich landscape of capacity-building partnerships in which I could participate and learn. Last, I send my appreciation to the extended UREx 
team, and especially to Dr. Thad Miller for including me as an honorary member in countless events and conversations.

The City of Portland and particularly members of the Disaster Resilience and Recovery Action Group (DRRAG), and the Climate Action Team at the Bureau of Planning and Sustainability also greatly contributed to my success. The opportunity for hands-on and real-world learning proved more important than anything I could have read in a book. In return, I can only hope that my contributions have helped our beautiful city move towards a just transition to a more resilient and sustainable place.

The emotional support from my family and friends also helped propel me through this process. They consoled me as I suffered several losses and hardships during my tenure as a $\mathrm{PhD}$ student, and were always there to celebrate the countless accomplishments, too. For this I send my unyielding love to my wife Megan, my parents, my brother, and my whole family. I also feel incredibly grateful for my friends, especially Dorothy Horn, who welcomed me into social gatherings and soon became my most trusted comrade.

Finally, thank you: to my dissertation committee for passing me; to Dr. Melissa Haefner for nerding-out with me about Environmental Justice; to Beth Gilden for being a confidant; to Michele Crim for inspiration and opportunity; to Alisa Kane for lunches, kombuchas, and listening; to Jenny Serpa for not forgetting about me, and getting me a job post-graduation; and to my cat, Nova, for being there with me through all the gloomy Portland days. 
Table of Contents

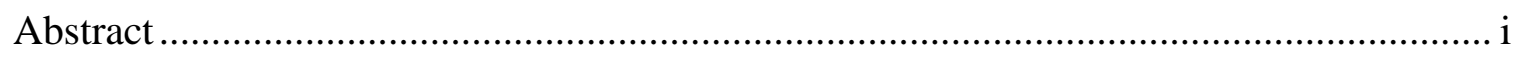

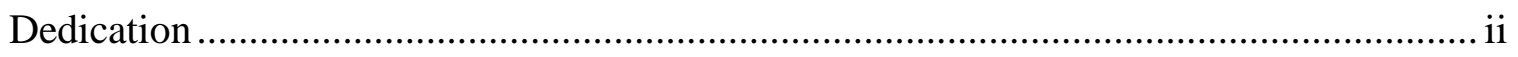

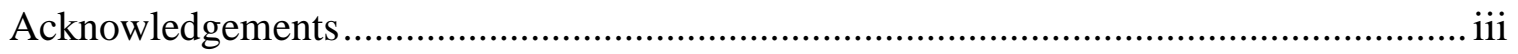

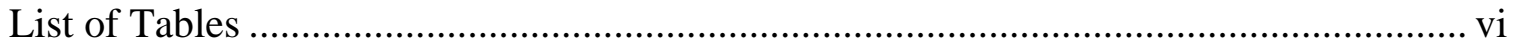

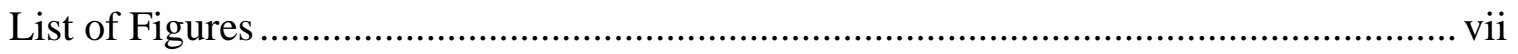

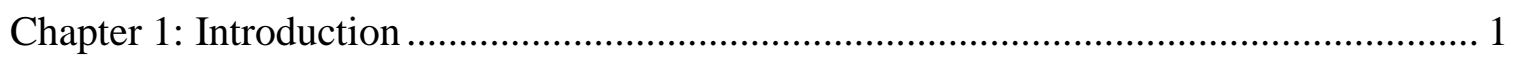

Chapter 2: Characterization of Partnerships and Collaborations in Urban Resilience Plans

Chapter 3: Real-Time Evaluation of City-University Partnerships for Sustainability and Resilience

Chapter 4: From Pragmatic Projects to Reflective Relationships: Evolving Dynamics in

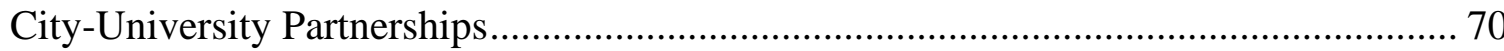

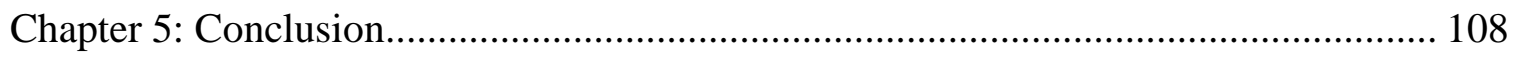

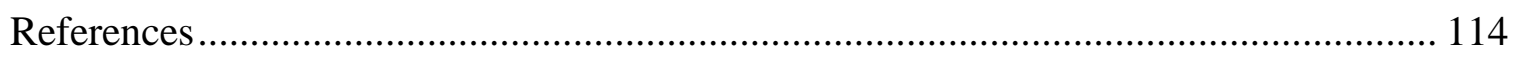

Appendix A: Personal and Academic Reflections ..................................................... 129

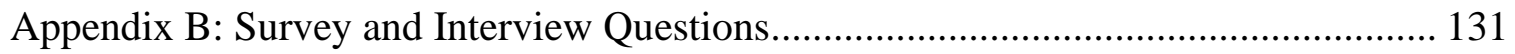




\section{List of Tables}

Table 1. List of all urban resilience plans produced in the United States through the 100 Resilient Cities project. ......................................................................................... 16

Table 2. Description of the coding scheme developed via analysis of the $100 \mathrm{RC}$ documents. 18

Table 3. a) Symbols and associated meanings the describe how often a category was defined; b) A breakdown of each actor group and how often partnership focus area, other actors, processes, and futures were defined.

Table 4. Actor groups and the most common codes mentioned in relation to partnership

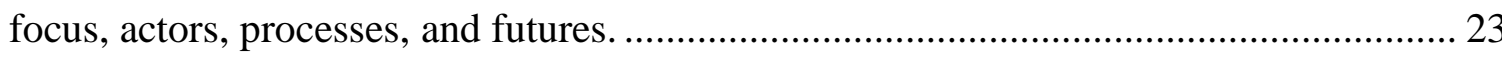

Table 5. Process categories and most commonly co-occurring themes.......................... 24 Table 6. This table shows three modes of partnership structures, their attributes, and the

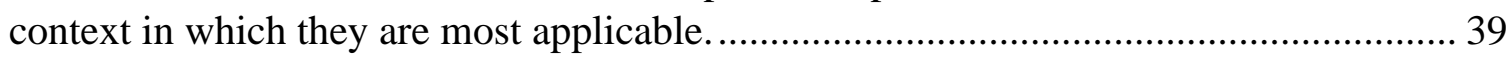

Table 7. Shows each CUP, the actors involved, and the stated goals............................ 78 Table 8. Chart showing how project functioning impacted the partnership across sites.. 92 Table 9. Chart showing how partnership functioning impacted the projects across sites. 93 Table 10. Chart showing how combined knowledge of the project-partnership cycle and application of real-time evaluation informed management strategies and produced specific outcomes across sites 


\section{List of Figures}

Figure 1 Diagram showing one proposed framework for just transitions from an extractive economy to a living economy......................................................................... 4 Figure 2. Co-occurrence of codes and theme groups with mentions of partnership and collaboration. 18

Figure 3. Health is the most common code mentioned related to the focus area of the

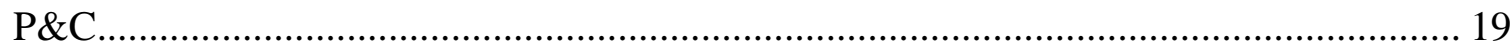

Figure 4. Count of all codes mentioned related to the actors of a P\&C. ......................... 20

Figure 5. Flow chart describing the iterative process of focus group sessions to develop the evaluation scheme and application of the draft evaluation scheme.

Figure 6. Chart describing three core areas of collaborative project evaluation

(foundation, actions, and impact) and how they build upon each other throughout the project timeline.

Figure 7. Chart describing ICES assessment categories and how they relate to the mode and attributes of the partnership.

Figure 8. Example "score sheet" for a comparison of partners' perspective of project functioning. Here, the city and university have mostly aligned perspectives regarding the strength of the foundation but see things differently when it comes to the actions. This should prompt discussion that explores this difference in perception and generates solutions.

Figure 9. Example timeline for application of FAIICES scheme. Evaluations occur just before/after key milestones and events that impact the CUP. Results from the evaluation should be immediately compiled and used for real-time management and decision-

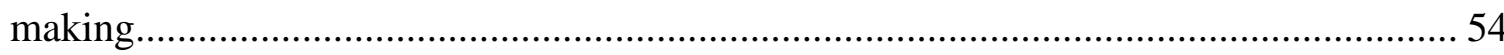

Figure 10. a) Example case study timeline; b \& c) example case study "scorecards" ... 76 Figure 11. Overview of the UNAM/Mexico City CUP project timeline with key milestones and actions. 81

Figure 12. Overview of the Leuphana/Luneburg CUP project timeline with key milestones and actions. 83

Figure 13. Overview of the PSU/Portland CUP project timeline with key milestones and actions. 85

Figure 14.Overview of the KIT/Karlsruhe project timeline with key milestones and actions.

Figure 15. Overview of the ASU/Tempe CUP project timeline with key milestones and actions. 88

Figure 16. The partnership project cycle and positive feedback loop. 95

Figure 17. The project-partnership cycle spiraling towards changes in transformative capacity; a) Positive results from projects and partnerships reinforce each other and lead to positive gains in transformative capacity; b) Negative impacts from dysfunctional projects and partnerships reinforce each other and lead to negative change in transformative capacity 


\section{Chapter 1: Introduction}

"This is about a just transition away from the fossil fuel economy as a whole, and into a renewable energy economy for all of us" - Kandi Mosset of the Indigenous Environmental Network on why she is fighting against the Dakota Access Pipeline

Local governments are at the forefront of planning for and responding to climate change impacts like sea level rise and extreme environmental events; and they are responsible for ensuring related policies are produced and implemented in equitable ways. Over the last two decades, municipalities across the United States have undertaken climate change risk and vulnerability assessments, developed climate change adaptation plans, and have embarked on designing resilient cities - both as stand-alone policies and as part of broader sustainability and climate action strategies (Collins 2016).

Unfortunately, progress has been largely incremental, and benefits and burdens of sustainability and resilience initiatives are rarely distributed evenly across the population. As climate change continues at an ever-increasing rate and social movements demand action, municipal agencies are attempting to implement mechanisms to rapidly transition to carbon neutral and climate resilient cities in equitable and just ways.

Transition management (TM) is a governance strategy that has been proposed to help navigate such large-scale transformations in socio-technical and socio-ecological systems. It prioritizes using long term thinking to inform short-term policy making and considers drivers and impacts across domains, actors, and scales. Additionally, TM focuses on learning-by-doing and doing-by-learning and hopes to bring about both system innovation and system improvement while keeping a wide selection of options open (Rotmans, Kemp, \& Van Asselt, 2001). Methodologically, TM recommends 
reflexivity via evaluation and constant learning (Kemp \& Loorbach, 2006); use of scenarios to keep options open and prevent lock-in (Loorbach, 2010a; Sondeijker, Geurts, Rotmans, \& Tukker, 2006); and building coalitions that support safe places for experimentation and innovation (Nevens, Frantzeskaki, Gorissen, \& Loorbach, 2013). Finally, TM suggests roles for individual actors and institutions across society, and specifically advises that governments can and should assume a leading role in Transition Management by inspiring collective learning, formulating a vision, and encouraging other actors to participate (Rotmans et al., 2001).

While the TM approach has been praised for its ability to generate innovative solutions, it has been criticized for its lack of attention to equity considerations like social justice and power dynamics (Scholz, 2017; Shove \& Walker, 2007). As equity has rightfully emerged as a leading priority in climate policy development and implementation, applying TM to sustainability and resilience might be both a challenge and a risk. With the critiques of TM in mind, it is crucial to design and implement Transition Management activities in ways that mitigate challenges and limit harm.

To combat problems of power dynamics, and attain equity and justice, municipal governments and urban community members alike are embracing the emerging field of just transitions. Just transitions aim to outline and follow an equitable pathway from the current state to one that is carbon neutral and climate resilient. The just transition literature combines insights and practices from fields like environmental justice, energy justice, and climate justice, and integrates them with the concept of transformative change in socio-technical-ecological systems (Goddard \& Farrelly, 2018; Healy \& Barry, 2017; Heffron, Mccauley, \& Heffron, 2017; Smith, Scott Frey, \& Gellert, 2018). Just 
transitions vary from TM in several ways, but perhaps most importantly, just transitions place value on the processes by which outcomes are achieved, not only transformational outcomes themselves.

Informed by the environmental justice and labor movements, there is a developing vision for a just transition framework and strategy (figure 1). This has largely been advanced through work led by frontline communities - an intersectional group consisting primarily of people of color, low-income individuals, members of the working class, and youth. Just transition activists and supporters aim to facilitate the transition from an extractive economy to a living economy, and often speak of "stopping the bad and building the new" (Helle \& Scarenha S -Swan, 2017). Within the just transition framework, policy makers must acknowledge that sustainability and resilience transitions are innately political, and therefore difficult political trade-offs are part of the process (Newell \& Mulvaney, 2013). It specifically focuses on procedural and distributive justice in transitions, prioritizing inclusive participation in the processes of designing and influencing transitions, and fair distribution of positive and negative outcomes. 


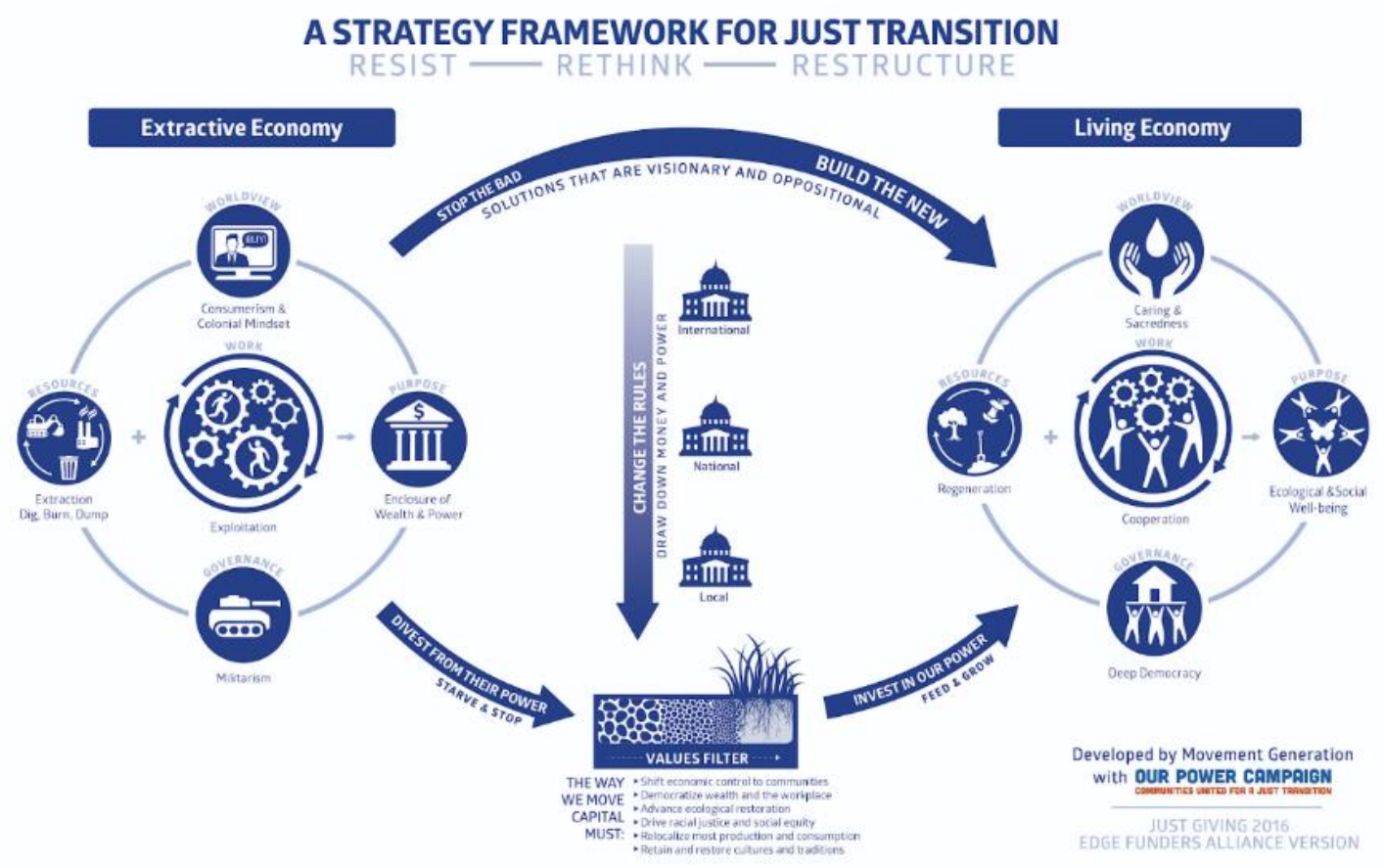

Figure 1 Diagram showing one proposed framework for just transitions from an extractive economy to a living economy.

For example, Australia is attempting a transition from coal to solar energy. They are specifically using a Transition Management (TM) approach to achieve lasting changes to the energy system (Goddard \& Farrelly, 2018; Heffron et al., 2017). However, this TM approach failed to recognize how the transition to clean energy may cause social, economic, and environmental harm to specific groups and regions. For instance, many Aboriginal communities rely on coal as the basis of their socio-economic well-being (Goddard \& Farrelly, 2018). Additionally, the raw materials needed for solar panels would need to be mined either in protected natural areas in the Australian desert or conflicted regions of Africa and the Middle East (Goddard \& Farrelly, 2018; Heffron et al., 2017). The original transition trajectory and plan contained no mention of these people or places and had no strategy for mitigating these ill impacts, therefore potentially perpetuating the same systems of oppression and consumption that led to the climate 
crisis in the first place. Implementing a just transition approach where many voices are included from the beginning and decision-making power is distributed could allow for more holistic solutions to be developed that are more likely to lead to the type of transformative systemic change Transition Management desires.

Many cities around the US are now explicitly and implicitly stating that they aim to achieve carbon neutrality and climate resilience, with goals of improving equity outcomes along the way. The specific terminology of aiming for a "just transition" is only beginning to emerge, but stated goals across climate change, sustainability, and resilience plans suggest a just transition is indeed desired. This is most readily visible within the movement for a "Green New Deal", which aims to tackle climate change and economic inequality simultaneously through government sponsored jobs and investments in the renewable energy industry. Although this legislation has only just been introduced at the federal level, similar programs are already starting to take hold in cities. For instance, Portland, Oregon recently passed the Portland Clean Energy Fund (PCEF), a $1 \%$ tax on large corporations in the city that will generate roughly $\$ 6$ million per year for green jobs and infrastructure that specifically support communities of color and lowincome residents (https://www.portlandoregon.gov/revenue/78324). Members of the PCEF coalition and the related policy documents themselves specifically call for the new program to catalyze a local just transition; this is likely the first of many similar programs that will arise across US cities. To guide this work, organizers and policy makers alike need to know the processes and strategies that best support just transitions.

Although current research into just transitions in practice is limited, there is a plethora of data from climate justice, environmental justice, and transition management 
literature that speaks to possible strategies and practices that may support attainment of a just transition. Two common themes that arise include 1) the need for people to work together across institutions, disciplines, and social groups; and 2) the need for continual learning, feedback, and adjustment. Therefore, distinct processes for fruitful partnership and collaboration (to bring people together), as well as monitoring \& evaluation (to support learning), need to be further developed and better understood so that they can play an appropriate role in the attainment of just transitions.

Recent sustainability and resilience policies and plans are shifting towards transdisciplinary and partnership-based approaches (Evans \& Phelan, 2016). Municipal plans across the United States and around the world contain calls to action that necessitate undertaking transformative sustainability and resilience work that increasingly relies on cross-sectoral and inter-institutional partnerships (i.e. between cities, universities, NGOs, and community organizers) that can help dismantle institutional barriers and path-dependencies so that more innovative and holistic solutions can be achieved (Lozano, 2007). Partnerships and collaborations are thought to support sustainability and resilience transitions by building capacity and increasing resources, challenging existing institutional designs, and accelerating knowledge sharing (Lozano, 2007; Ramaswami et al., 2018). Furthermore, the just transition framework puts partnerships and collaboration at the core of several strategies, proposing that, if done well, collaboration can lead to more dispersed power and equitable outcomes for oft marginalized groups (Gajda, 2004; Luederitz, Schäpke, et al., 2017). Unfortunately, partnerships and collaborations for resilience, sustainability, and ultimately, just 
transitions, do not always achieve their desired outcomes or impacts; they must be carefully managed, studied, and mediated to achieve success.

Monitoring and evaluation (M\&E) provide a vital mechanism to assess and manage progress, while contributing to the evidence base for learning what works, for whom, and in what context (Spearman \& McGray, 2011). To determine sustainability and resilience programmatic success and alignment with the framework and values of a just transition, it is necessary to determine what outcomes should look like when they are achieved and develop indicators and metrics for measurement. M\&E plays a critical role in promoting successful sustainability and resilience planning by providing a powerful tool to help practitioners manage their work and provides insight that can deepen understanding of community need and demonstrate accountability to stakeholders (Dinshaw, Fisher, Mcgray, Rai, \& Schaar, 2014; Fisher, Dinshaw, Mcgray, Rai, \& Schaar, 2015; Spearman \& McGray, 2011). However, despite the need for such measures, there are many documented challenges and barriers to sufficient $\mathrm{M} \& \mathrm{E}$ and thus it is not widely undertaken (Baker, Peterson, Brown, \& McAlpine, 2012; Woodruff \& Stults, 2016). This lack of M\&E implementation is especially concerning when considering the need to understand if real transformations are taking place, and if policies are fulfilling the commonly cited goals of reducing institutional inequities and prioritizing and empowering community- which is required for a just transition.

The research presented in this dissertation examines three distinct ways that transformative urban resilience and sustainability work relates to either partnership and collaboration or monitoring and evaluation. Chapter 2 examines resilience planning documents from US cities to understand how partnership and collaboration is being 
defined and how often it is being sought as an implementation method. Chapter 3 develops a method for the monitoring and evaluating transformative sustainability and resilience partnerships. Chapter 4 examines case-studies of five international sustainability and resilience partnerships and aims to understand how partnership relations and project outcomes are connected. Finally, the conclusion chapter looks across the research and uncovers insights that can help community organizers, private and public institutions, researchers, and all interested parties better understand the ways in which partnership and collaboration and monitoring and evaluation can support a just transition to sustainable and resilient urban societies. 
Chapter 2: Characterization of Partnerships and Collaborations in Urban Resilience Plans

\begin{abstract}
As urbanization continues and the impacts of climate change escalate, city governments are finding themselves responsible for the resilience of large populations. To cope, increasing numbers of municipalities are developing urban resilience plans. These documents often articulate partnerships and collaborations (P\&Cs) as key strategies for urban resilience implementation. Several studies posit that $\mathrm{P} \& \mathrm{Cs}$ enhance urban resilience capacity by 1) increasing connectivity and reducing excessive compartmentalization, and 2) operationalizing equity through deep engagement. Although specific case studies of resilience-related collaborative practices are well documented in urban resilience literature, little is known about the proliferation of $\mathrm{P} \& \mathrm{C}$ strategies collectively. Questions remain regarding the characterization of P\&Cs by practitioners, including: who are the actors, and what are the topics, processes, and visions of collaboration for urban resilience? This paper explores urban resilience partnerships via a thematic content analysis of Resilience Strategy documents produced in US cities through the 100 Resilient Cities project. It aims to describe how urban resilience $\mathrm{P} \& \mathrm{Cs}$ are being articulated in practice and offer insight into $\mathrm{P} \& \mathrm{Cs}$ ' relationship to connectivity and equity. A better characterization of urban resilience $\mathrm{P} \& \mathrm{C}$ implementation will provide a platform for evaluation of $\mathrm{P} \& \mathrm{C}$ strategies and offer opportunities to assess their efficacy.
\end{abstract}


Introduction

As the global climate continues to warm, human populations must contend with increasing numbers of extreme environmental events, and the social and economic damage they leave in their wake. It has been formally recognized that adapting to climate change impacts in an anticipatory and planned manner is crucial to the wellbeing of communities across the globe (Moloney, Scott, \& Macdonald, 2018). This is illustrated in Goal 13 of the United Nations Sustainable Development Goals (SDGs), which calls for "urgent action to combat climate change and its impacts" (United Nations 2017), as well as in the 2015 Paris Agreement which established a goal for "enhancing adaptive capacity, strengthening resilience and reducing vulnerability to climate change..." (UNFCCC 2015, Article 7.7a, p.6). Additionally, there has been philanthropic support for accelerating a global resilience agenda, which can be seen in initiatives like the Rockefeller Foundation's 100 Resilient Cities (100RCs) project which helped 74 cities across the globe hire Chief Resilience Officers and write urban resilience plans (Spaans \& Waterhout, 2016).

Globally and in the United States, governments across scales have developed a plethora of climate resilience related policies and plans to build adaptive capacity and implement actions to reduce risk and vulnerability (Adger, Arnell, \& Tompkins, 2005). Local governments and urban municipalities have been particularly active, since the prevailing notion is that climate change resilience initiatives should be local and context specific (Baker et al. 2012; Measham et al. 2011). Additionally, municipal governments 
are feeling increased pressure to develop climate adaptation and resilience solutions as urban populations continue to rise. By 2050, when climate change impacts are likely to be felt at full force, more than two-thirds of the world's population, over 7 billion people, will be living in cities (Ritchie \& Roser, 2018). It is in this context that a rush to develop comprehensive urban resilience plans has emerged, as well as a thriving area of academic research.

While the definition of urban resilience remains contested in academic circles, cities have widely adopted the concept, finding it a useful construct for anticipating and mitigating the shocks and stressors related to climate change. In the realm of urban planning, several methods and mechanisms for achieving urban climate resilience have emerged, often articulated in the form of planning documents. Local governments tend to base their plans on their own unique context and challenges, which also leads them to their own specific definition of urban resilience that explains "resilience for whom and to what? When? Where? And why?" (Meerow \& Newell, 2016). Generally, urban climate resilience plans aim to help cities build their capacity to withstand and/or adapt to disruptive events, including chronic stresses (i.e. aging infrastructure, socio-economic disparities, and environmental degradation) and acute shocks (i.e. sea level rise, earthquakes, floods) (Meerow, Pajouhesh, \& Miller, 2019).

Across applied urban resilience literature, distinct attributes of and strategies for implementing urban resilience have emerged. One of the most central themes is the development, use, and enhancement of inter-institutional and cross-disciplinary partnerships and collaborations (P\&Cs) (Chi, Williams, Chandra, Plough, \& Eisenman, 
2015; Drakaki \& Tzionas, 2017; Marana, Labaka, \& Sarriegi, 2018). These P\&Cs can be formal or informal and span a range of configurations but require that individuals and/or organizations come together for a common goal. Interestingly, $\mathrm{P} \& \mathrm{Cs}$ are related to the concept of urban resilience in several ways: they can be viewed as an intrinsic quality of urban resilience, a strategy for implementing urban resilience, and/or an indicator of increased urban resilience itself.

Intrinsically, urban resilience is sometimes considered to be a "boundary object" or "bridging concept" that resonates with a wide variety of social worlds and as a result can bring together different stakeholders and disciplines (Brand \& Jax, 2007; Meerow, 2017). When thinking about cities as complex systems that require management across countless different specialties, cultures, and perspectives, the malleable definition of resilience can act as a natural unifying force. This same definitional malleability can also cause confusion and is often critiqued (MacKinnon \& Derickson, 2013; Tierney, 2015). However, despite concerns, there are several examples of the concept of urban resilience being used to bring people together via partnerships and collaborations (P\&Cs) to tackle multifaceted problems in transdisciplinary ways.

For instance, in Portland, Oregon, a cross-bureau and inter-institutional partnership was formed to better understand infrastructure vulnerabilities and recovery strategies for the city. In this case, Portland State University administrators and researchers came together with city leaders from the bureaus that work on water, sewer, environmental services, sustainability, and disaster management. Although defined differently by all participants, the term resilience united the team and strengthened their 
resolve to work together, leading to an integrated infrastructure resilience planning session and formation of an ongoing cross-bureau collaborative team in the city (Caughman et. al, in press).

Further, forming and utilizing P\&Cs offers several advantages as an urban resilience implementation strategy, especially in terms of enhancing equity through collaborative governance and meaningful engagement. Recent work has argued that, if done well, the collaborative practices that are often articulated via P\&Cs in urban resilience planning can help facilitate procedural, recognitional, and distributive justice (Meerow et al., 2019). This deep engagement between government and community facilitates resilience by bettering the distribution of goods and services (i.e. infrastructure and environmental amenities), enhancing respect between groups (i.e. honoring group experience and history), and by opening the doors for participation in decision-making processes (i.e. co-writing plans) (Meerow et al., 2019; Schlosberg, 2003).

Additionally, the act of bringing groups together is a reinforcing concept which in turn supports increased levels of urban resilience itself, via increased connectivity. When considering cities within a systems framework, collaborative approaches to urban resilience planning reduces the number of "policy silos" and can mitigate the counterproductive outcomes that arise from treating interrelated problems in isolation (Coaffee \& Clarke, 2015). Alternatively, via collaborative urban resilience planning, linked networks can be formed that build multi-scale connectivity, enhance system redundancy, and facilitate physical and social bonds that can be relied upon in extreme events. 
For instance, imagine that a city water bureau decides to become resilient in isolation (i.e. strengthening pipes and determining what parts of the city should get water service turned on first after a disaster). Without collaborating with other bureaus to understand the full network of interconnected infrastructure and social systems, this increase in resilience will likely be done in vain. Instead, it is vital that the water bureau coordinate with the department of transportation to know which roads will be functional to get to the pipes; they should also work with the office of equity to understand which communities and populations are most vulnerable and in need of service. Without these collaborative efforts, individualized water system resilience planning work could lead to less overall resilience in the city. If the bureaus were to work together instead, a stronger network of infrastructure and social services could be produced; as well as better rapport and communication between individuals.

Examples like this, and many other types of partnerships and collaborations $(\mathrm{P} \& \mathrm{Cs})$ are deeply ingrained into urban resilience planning and implementation in a multitude of ways. In fact, a recent study of resilience planning documents from US cities showed that " $85 \%$ of strategies described partnering with external organizations and stakeholders to create and implement actions," (Fitzgibbons \& Mitchell, 2019). Despite this staggeringly high number, academic studies of P\&Cs' relationship to urban resilience tend to focus only on individual case studies that document specific partnership initiatives (Acosta et al., 2018; Chi et al., 2015; Drakaki \& Tzionas, 2017; Marana et al., 2018). To date, there has been no work that looks comprehensively at the proliferation of urban resilience P\&Cs. Questions remain regarding the characterization of P\&Cs by 
practitioners, including: who are the actors, and what are the topics, processes, and visions of collaboration for urban resilience?

This paper explores urban resilience $\mathrm{P} \& \mathrm{Cs}$ via a thematic content analysis of urban resilience planning documents produced in US cities through the 100RCs project. It aims to describe how urban resilience P\&Cs are being articulated in practice and offer insight into P\&Cs' relationship to connectivity and equity. This takes the form of two research questions: Are specific thematic areas related to collaborations consistently represented in the resilience plans? And what are the characteristics of the collaborative processes, actors, and topics in the plans? A better characterization of urban resilience $\mathrm{P} \& \mathrm{C}$ implementation will provide a platform for evaluation of $\mathrm{P} \& \mathrm{C}$ strategies and offer opportunities to assess their efficacy.

Methods

This study examines the urban resilience plans and strategies of US cities and their characterization of partnerships and collaborations (P\&Cs). This is achieved via a thematic content analysis of all 16 of the 100RC strategy documents produced in US cities (table 1). The documents were analyzed using principles from grounded theory and thematic content analysis with the aim of understanding how urban resilience practitioners are characterizing P\&Cs. 


\begin{tabular}{|c|c|c|c|}
\hline City & Plan Title & Length & Date released \\
\hline Tulsa, Oklahoma & $\begin{array}{l}\text { Resilient Tulsa: An equitable, action- } \\
\text { oriented, and collaborative roadmap for } \\
\text { all of Tulsa. }\end{array}$ & 69 pages & June 2018 \\
\hline $\begin{array}{l}\text { San Francisco, } \\
\text { California }\end{array}$ & $\begin{array}{l}\text { Resilient San Francisco: Stronger } \\
\text { today, stronger tomorrow }\end{array}$ & 71 pages & April 2016 \\
\hline $\begin{array}{l}\text { Pittsburgh, } \\
\text { Pennsylvania }\end{array}$ & $\begin{array}{l}\text { ONE PGHL Resilient Pittsburgh; } \\
\text { Pittsburgh's Resilience Strategy: } \\
\text { Together we move forward as one } \\
\text { Pittsburgh }\end{array}$ & 61 pages & March 2017 \\
\hline Oakland, California & $\begin{array}{l}\text { Resilient Oakland: Collaborative. Data- } \\
\text { driven. Equitable. }\end{array}$ & 62 pages & October 2016 \\
\hline St. Louis, Missouri & Preliminary Resilience Assessment & 19 pages & March 2018 \\
\hline Norfolk, Virginia & Norfolk’s Resilience Strategy & 60 pages & October, 2015 \\
\hline $\begin{array}{l}\text { New Orleans, } \\
\text { Louisiana }\end{array}$ & $\begin{array}{l}\text { Resilient New Orleans: Strategic } \\
\text { actions to shape our future city }\end{array}$ & 90 pages & August 2015 \\
\hline El Paso, Texas & Resilient El Paso & 114 pages & February 2018 \\
\hline $\begin{array}{l}\text { Los Angeles, } \\
\text { California }\end{array}$ & Resilient Los Angeles & 91 pages & March 2018 \\
\hline $\begin{array}{l}\text { New York, New } \\
\text { York }\end{array}$ & $\begin{array}{l}\text { One New York: The plan for a strong } \\
\text { and just city }\end{array}$ & 354 pages & April 2015 \\
\hline Dallas, Texas & Resilient Dallas & 79 pages & June 2018 \\
\hline Boulder, Colorado & City of Boulder Resilience Strategy & 52 pages & April, 2016 \\
\hline Berkeley, California & $\begin{array}{l}\text { Resilience Strategy: A strategic } \\
\text { preparedness plan for Berkeley, a } \\
\text { community known for inclusiveness } \\
\text { and innovation }\end{array}$ & 56 pages & April 2016 \\
\hline Chicago, Illinois & $\begin{array}{l}\text { Resilient Chicago: A plan for inclusive } \\
\text { growth and a connected city }\end{array}$ & 162 pages & February 2019 \\
\hline $\begin{array}{l}\text { Boston, } \\
\text { Massachusetts }\end{array}$ & $\begin{array}{l}\text { Resilient Boston: An equitable and } \\
\text { connected city }\end{array}$ & 154 pages & July 2017 \\
\hline Atlanta, Georgia & $\begin{array}{l}\text { Resilient Atlanta: Actions to Build an } \\
\text { Equitable Future }\end{array}$ & 78 pages & November 2017 \\
\hline
\end{tabular}

Table 1. List of all urban resilience plans produced in the United States through the 100 Resilient Cities project.

To characterize an observed phenomenon, a description of its distinctive nature and/or features must be generated. To characterize P\&Cs specifically, several frameworks articulate that it is vital to understand what the partnerships focus on, who is involved, why they are being used, and how the process takes place (Faulkner, Ayers, \& 
Huq, 2015; Lasker, Weiss, \& Miller, 2001; Woodland \& Hutton, 2012a). Therefore, these driving questions were used as a framework for analysis. The urban resilience planning documents were closely read to find sections where the documents discussed partnerships and/or collaborations, and this identified text was used for analysis.

Several codes were inductively developed and then sorted into sub-theme and overall category groups (table 2). Five district category groups emerged: actors (who is involved in the partnership action), process (how the partnership is implemented), focus (what is the topic area of the partnership), and futures (why the partnership was occurring). Co-occurrence tables were generated to better understand the full context of the proposed $\mathrm{P} \& \mathrm{Cs}$, as well as a cross-city comparison to draw out the most prevalent similarities and differences in approach across the United States.

\begin{tabular}{|c|c|c|c|}
\hline $\begin{array}{l}\text { Category } \\
\text { Group }\end{array}$ & Sub-themes & Codes & Details \\
\hline Focus & $\begin{array}{l}\text { Environmental; Social; } \\
\text { Technical; Economic; } \\
\text { Other }\end{array}$ & $\begin{array}{l}\text { Extreme Environmental } \\
\text { Events; Disaster; Ecosystem; } \\
\text { Education; Culture; Energy; } \\
\text { Environment; Equity; Justice; } \\
\text { Health; Housing; } \\
\text { Infrastructure; Jobs; } \\
\text { Workforce; School; } \\
\text { Technology; Transportation; } \\
\text { Mobility; Water; Other }\end{array}$ & $\begin{array}{l}\text { Describes the topic area of } \\
\text { the stated partnership or } \\
\text { collaboration. } \\
\text { The 'what' }\end{array}$ \\
\hline Actors & $\begin{array}{l}\text { Government; } \\
\text { Community; } \\
\text { Academia; Industry; } \\
\text { Hospital; Other }\end{array}$ & $\begin{array}{l}\text { City; Bureau; Department; } \\
\text { Municipal; Government; } \\
\text { Agency; Community; } \\
\text { Neighborhood; College; } \\
\text { University; Business; } \\
\text { Industry; Hospital; Church; } \\
\text { Other }\end{array}$ & $\begin{array}{l}\text { Describes who is involved in } \\
\text { the stated partnership or } \\
\text { collaboration. } \\
\text { The 'who' }\end{array}$ \\
\hline Processes & $\begin{array}{l}\text { Planning; Engagement; } \\
\text { Evaluation/Monitoring; } \\
\text { Process (general); } \\
\text { Research; Other }\end{array}$ & $\begin{array}{l}\text { Planning; Plans; Policy; } \\
\text { Outreach; Engagement; } \\
\text { Assessment; Monitor; } \\
\text { Evaluate; Study; Data; } \\
\text { Research; Report; Scenario; } \\
\text { Workshop; Activity; Other }\end{array}$ & $\begin{array}{l}\text { Describes the processes } \\
\text { involved in implementing the } \\
\text { partnership or collaboration. } \\
\text { The 'how' }\end{array}$ \\
\hline
\end{tabular}




\begin{tabular}{|c|c|c|c|}
\hline Futures & $\begin{array}{l}\text { Vision; } \\
\text { Transformation; } \\
\text { Transition; Other }\end{array}$ & $\begin{array}{l}\text { Vision; Visioning; } \\
\text { Transformation; System } \\
\text { Change; Transition; Futures; } \\
\text { Other }\end{array}$ & $\begin{array}{l}\text { Describes systemic changes } \\
\text { and visions of the future to be } \\
\text { achieved via partnership and } \\
\text { collaboration or visions of } \\
\text { partnership and collaboration } \\
\text { itself. } \\
\text { The 'why' }\end{array}$ \\
\hline
\end{tabular}

Table 2. Description of the coding scheme developed via analysis of the $100 \mathrm{RC}$ documents.

Results

Analysis showed that across the 16 resilience planning documents, partnerships and collaborations (P\&Cs) were mentioned over 2000 times. When P\&Cs are discussed, the most commonly co-occurring codes fall into four separate theme groups. In order of prevalence, these themes are: focus (the topic area of the partnership), actors (who is involved in the partnership action), process (what occurs in the partnership), and vision (the futures and purpose of the partnership) (figure 1).

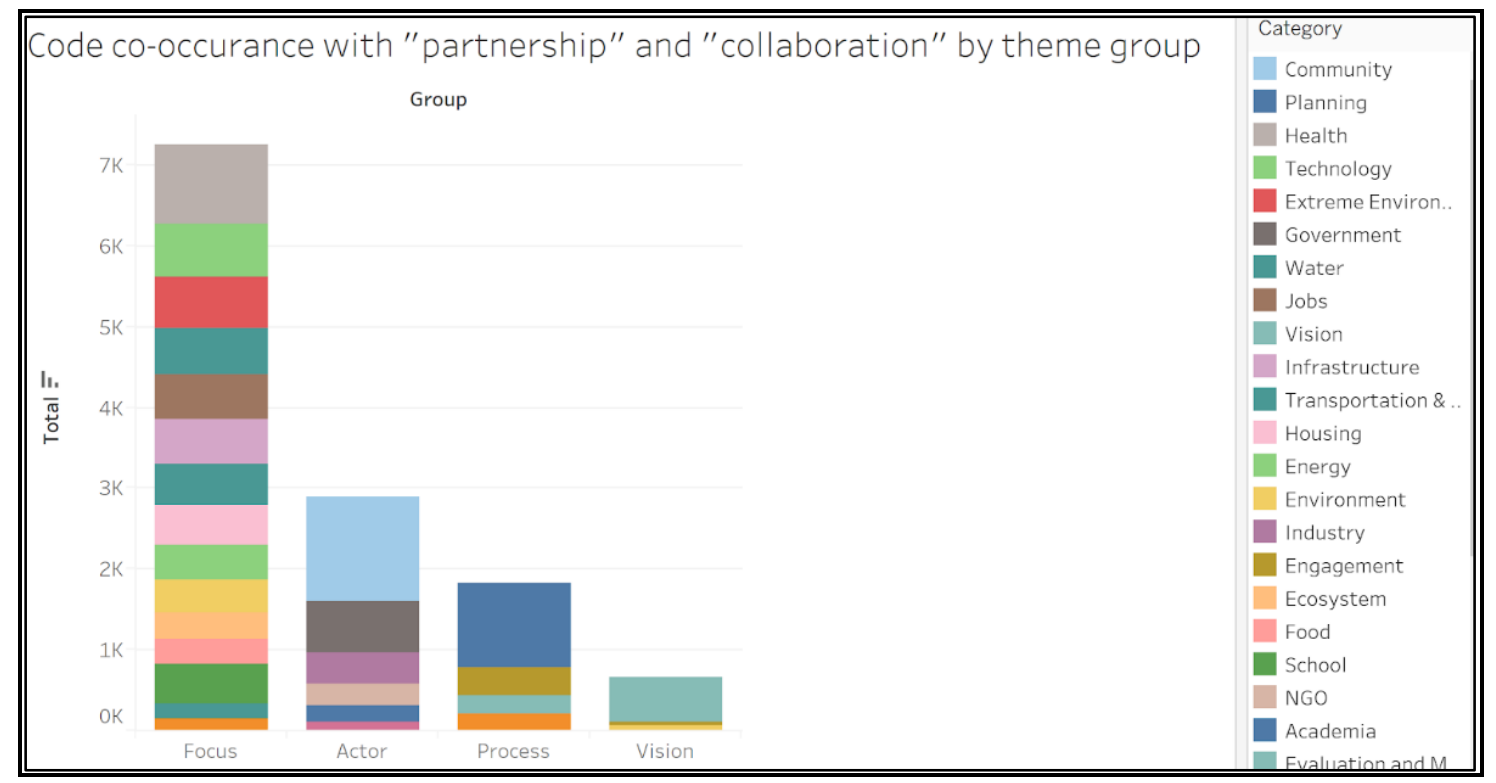

Figure 2. Co-occurrence of codes and theme groups with mentions of partnership and collaboration. 
When looking at occurrences by category, it is clear that partnerships and collaborations are most commonly discussed in relation to the focus or topic area of the work, and less often define the specific actors, processes, or transformative futureoriented visions involved. However, each theme offers insight into the ways in which practitioners are characterizing urban resilience partnerships, and as such results from each category are explored in further detail below.

\section{P\&C Focus- The What}

Analysis revealed that nearly all

mentions of $\mathrm{P} \& \mathrm{Cs}$ in the urban resilience

planning documents noted a specific topic area

for the work. In total, 16 topic areas emerged, with a focus on health being most prevalent.

The 16 focus areas were, in order of

prevalence: Health, technology, disaster,

water, jobs, infrastructure, transportation and

mobility, housing, energy, environment,

ecosystem, food, school, education, equity/justice, and culture. Health was noted as a focus area for P\&Cs roughly 1000 times, with all other topics being mentioned between 100 to 700 times (figure 3 ).

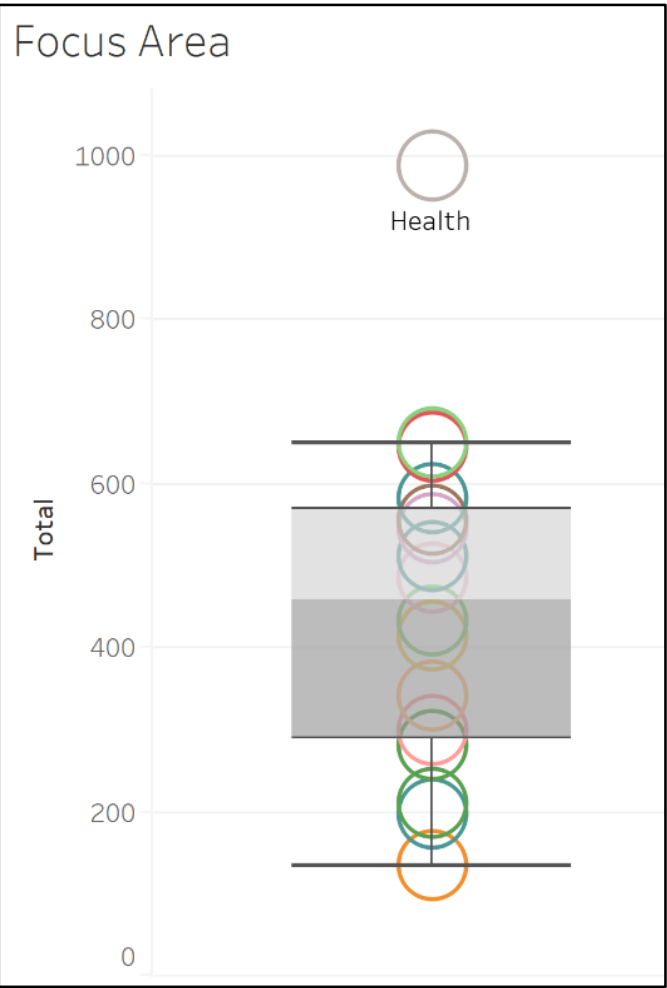

Figure 3. Health is the most common code mentioned related to the focus area of the $P \& C$. 
P\&Cs focused on health tended to be cross-cutting with several other focus areas, as can be seen in this quote: “...Chicago's multi-pronged approach acts as a platform on which local residents of various backgrounds can work creatively together towards more equitable decisions about Chicago's built environment through the collaboration of public health, climate resilience, and the arts." Similarly, a large majority of the P\&Cs had mentioned more than one focus area at a time.

$\mathrm{P} \& \mathrm{C}$ Actors - The Who

When actors are mentioned in relation to partnership and collaboration, community is mentioned far more often than any other actor group (figure 3). This shows that when practitioners are discussing urban resilience P\&Cs they are often imagining community involvement. Due to this articulation, urban resilience $\mathrm{P} \& \mathrm{C}$ s can be seen as a community engagement strategy. However, for each group of actors, a distinct breakdown of focus areas, other actors, processes, and visioning emerges.

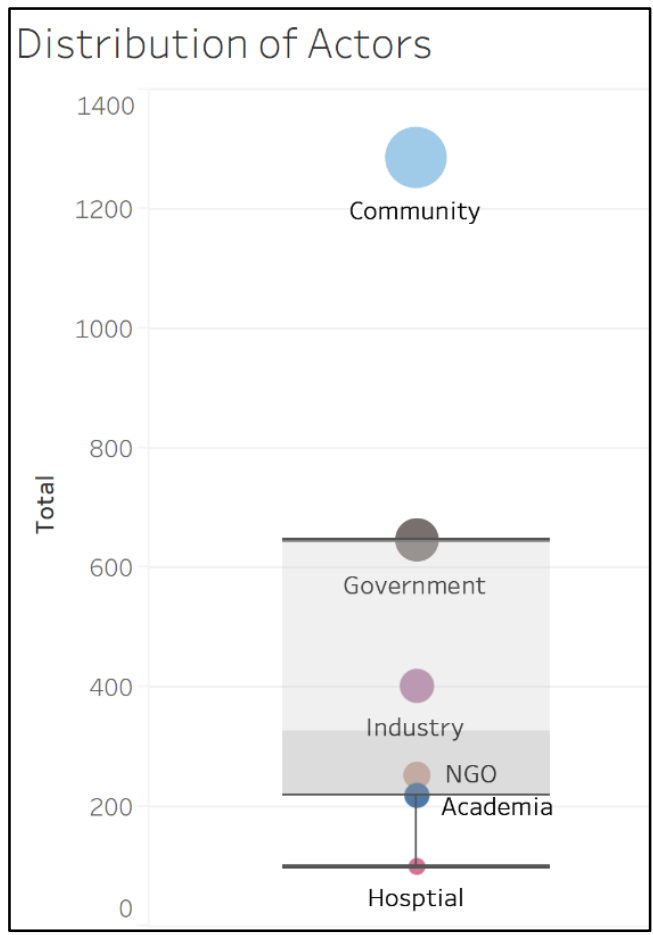

Figure 4. Count of all codes mentioned related to the actors of a $P \& C$.

This highlights the structure of desired urban resilience partnerships and collaborations.

Looking at the distributions of co-occurrences for each actor group, a few key findings emerge. For instance, when exploring community as an actor, partnerships focus 
on a broad distribution of topics; occur between community, government, and industry; and the processes for collaboration are discussed as often as actors involved. For each actor groups, a similar sort of signature pattern of $\mathrm{P} \& \mathrm{C}$ format arises. These findings are summarized in tables 3 and 4.

a)

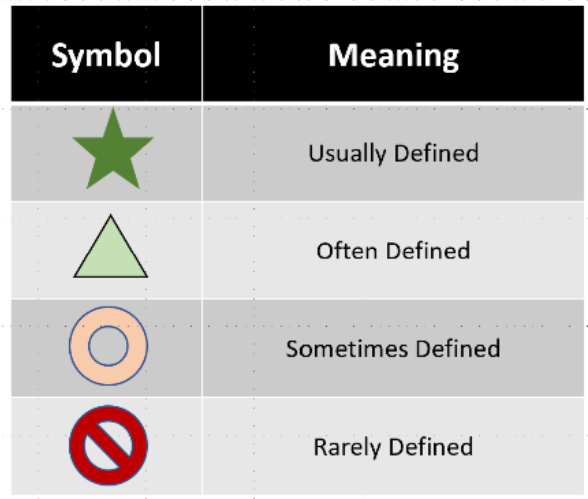

b) 


\begin{tabular}{|c|c|c|c|c|}
\hline & Focus & Actor & Process & Futures \\
\hline Academia & حي & (0) & $\triangle$ & \\
\hline Community & 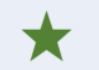 & (0) & & \\
\hline Government & 人 & (0) & $\triangle$ & ) \\
\hline Hospital & 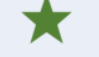 & (0) & & \\
\hline Industry & 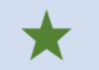 & $\triangle$ & (O) & \\
\hline NGO & 众 & $\triangle$ & (0) & \\
\hline
\end{tabular}

Table 3. a) Symbols and associated meanings the describe how often a category was defined; $b$ ) A breakdown of each actor group and how often partnership focus area, other actors, processes, and futures were defined.

\begin{tabular}{|c|c|c|c|c|}
\hline & Focus & Actor & Process & Futures \\
\hline Academia & $\begin{array}{l}\text { Health; } \\
\text { Technology }\end{array}$ & $\begin{array}{l}\text { Community; } \\
\text { Government }\end{array}$ & $\begin{array}{l}\text { Planning; } \\
\text { Research }\end{array}$ & Vision \\
\hline Community & $\begin{array}{l}\text { Health; } \\
\text { Technology; Jobs }\end{array}$ & $\begin{array}{l}\text { Government; } \\
\text { Industry }\end{array}$ & $\begin{array}{l}\text { Planning; } \\
\text { Engagement }\end{array}$ & $\begin{array}{l}\text { Vision; } \\
\text { Transformative }\end{array}$ \\
\hline Government & $\begin{array}{l}\text { Health; } \\
\text { Technology; }\end{array}$ & $\begin{array}{l}\text { Community; } \\
\text { NGO }\end{array}$ & $\begin{array}{l}\text { Planning; } \\
\text { Engagement }\end{array}$ & $\begin{array}{l}\text { Vision; } \\
\text { Transition }\end{array}$ \\
\hline Hospital & Health & $\begin{array}{l}\text { Community; } \\
\text { Academia }\end{array}$ & Planning & Vision \\
\hline Industry & $\begin{array}{l}\text { Health; } \\
\text { Technology; } \\
\text { Disaster; Jobs; } \\
\text { Energy; } \\
\text { Infrastructure; } \\
\text { other }\end{array}$ & $\begin{array}{l}\text { Community; } \\
\text { Government }\end{array}$ & $\begin{array}{l}\text { Planning; } \\
\text { Engagement }\end{array}$ & $\begin{array}{l}\text { Vision; } \\
\text { Transformative }\end{array}$ \\
\hline NGO & Health; Culture & $\begin{array}{l}\text { Government; } \\
\text { Community }\end{array}$ & $\begin{array}{l}\text { Planning; } \\
\text { Engagement }\end{array}$ & $\begin{array}{l}\text { Vision; } \\
\text { Transformative }\end{array}$ \\
\hline
\end{tabular}


Table 4. Actor groups and the most common codes mentioned in relation to partnership focus, actors, processes, and futures.

These charts show that, collectively, focus areas and other actors are defined far more often than the processes of visions of the future related to any given $\mathrm{P} \& \mathrm{C}$. Additionally, the results show how certain actors are often mentioned as partnering together, but only on specific tasks (i.e. government/all other actors take on planning; academia/community take on research).

P\&C Process - The how

Analysis of the 100RC documents also showed how practitioners describe the processes that resilience partnerships and collaborations (P\&Cs) will undertake. Five process categories emerged, which include, in order of prevalence: planning, engagement, evaluation and monitoring, research, and process (general). Planning was noted as the most dominant process, mentioned alongside P\&Cs over 1000 times (almost more than the number of times all other processes were mentioned, combined). Planning was most often talked about in relation to community, health, disaster, water, jobs, transportation, and visioning. Table 5 summarizes the results from each process category.

\section{Process Category Co-occurring themes}

\begin{tabular}{l|l} 
Planning & Actors: Community \\
Topics: Health, disaster, water, jobs, transportation, infrastructure \\
\hline Futures: Visioning
\end{tabular}




\begin{tabular}{|c|c|}
\hline & Processes: Planning \\
\hline $\begin{array}{l}\text { Evaluation and } \\
\text { Monitoring }\end{array}$ & $\begin{array}{l}\text { Actors: Community } \\
\text { Topics: Health, technology, infrastructure, disaster, environment, water } \\
\text { Processes: Planning }\end{array}$ \\
\hline Research & $\begin{array}{l}\text { Actors: Academia, community } \\
\text { Topics: Technology, health, transportation, housing, jobs } \\
\text { Processes: Planning }\end{array}$ \\
\hline Process (general) & Topics: Technology, housing, equity/justice \\
\hline
\end{tabular}

Table 5. Process categories and most commonly co-occurring themes.

P\&C Futures- The why

Of all categories, futures, or "the why" of P\&Cs was mentioned the least. Futures captures where the documents describe systemic changes and visions of the future to be achieved via partnership and collaboration or visions of partnership and collaboration itself. Three main sub-themes emerged, including vision (in general), and then, less often mentioned, but more specifically, transitions and transformations. Mentions of visions typically accompanied community and government actors and planning processes. Meanwhile, discussions of transitions were more often related to the topic areas of transportation and mobility and disaster; and transformation was related to the topic of health with the actor of community.

\section{Cross-city Comparison}

Overall, the City of Los Angeles mentioned P\&Cs more than any other city. Additionally, Los Angeles connected mentions of P\&Cs to specific focus areas and mentioned related processes more than any other city. However, Chicago strongly 
outpaced all other cities when it came to defining actors involved in P\&Cs, and visions of the future that drive $\mathrm{P} \& \mathrm{C}$ urban resilience work.

When normalizing the data so that document length does not impact the findings, a different picture emerges. The cities of St. Luis and Boulder lead in defining actors when mentioning P\&Cs, doing so over $50 \%$ of the time. El Paso leads in defining processes and procedures associated with $\mathrm{P} \& \mathrm{Cs}$, which happens in their document roughly $40 \%$ of the time. Atlanta and Norfolk lead in defining the focus areas and topic of P\&Cs, specifying this information nearly $50 \%$ of the time. Finally, even when the data is normalized, Chicago continues to lead in defining futures related to $\mathrm{P} \& \mathrm{C}$ work, closely followed by Boston; they are the only cities to mention this more than $15 \%$ of the time.

\section{Discussion}

The results of the document analysis offer insight into how urban resilience partnerships and collaborations (P\&Cs) are being characterized and articulated by practitioners in planning documents. The analysis shows that $\mathrm{P} \& \mathrm{Cs}$ are defined broadly, taking several forms to meet a wide variety of objectives. This analysis suggests that urban resilience $\mathrm{P} \& \mathrm{Cs}$ are indeed acting as boundary objects with the aim of engagement across social groups, but the details of the P\&Cs are rarely articulated which is potentially problematic for their implementation and success.

Topically, the P\&Cs mentioned in the documents spanned a wide range of focus areas. This spread is unsurprising due to the disciplinary-defying nature of urban resilience itself. It appears that $\mathrm{P} \& \mathrm{Cs}$ are being suggested as planning and 
implementation strategies across all urban resilience topic areas and the sheer number of P\&Cs mentioned across all cities highlights their relevance to urban resilience planning as a whole. This supports the notion that the diverse definitions and understandings of urban resilience form a sort of boundary object, where social actors from widely varying perspectives can see their interests represented within the idea. While this might be advantageous in terms of bringing people together to form $\mathrm{P} \& \mathrm{Cs}$ and could potentially increase connectivity, thus enhancing resilience, it also poses serious challenges.

Research on P\&Cs shows that they are most successful at reaching their intended outcomes when the initiatives have well-defined shared goals, agreed upon processes, and appropriately chosen actors. Unfortunately, these details were rarely delineated across the planning documents. This can be seen, for example, in the fact that the most commonly cited process for P\&Cs articulated in the planning documents was to make additional plans. This "plan to plan" approach is sometimes appropriate, but also may indicate that the proposed $\mathrm{P} \& \mathrm{C}$ is no more than a suggestion that has not been fully considered for its applicability, usefulness, or buy-in. Therefore, it is unclear if all of the P\&Cs mentioned within the documents are serious endeavors, or simply well-intentioned ideas that will likely never materialize.

Additionally, this lack of specificity could inhibit the actualization of equity in urban resilience implementation. Across all documents, community organizations and individual members of specific communities were the most commonly proposed actors for participation in P\&Cs. This highlights the fact the P\&Cs are often seen by plan writers (primarily government officials) as community engagement methods. While this 
could lead to more collaborative governance that supports the well-being and prosperity of commonly under-severed groups like people of color, and low-income residents, these outcomes are not guaranteed. Social justice, environmental justice, and community-led participatory planning literature consistently demonstrates that achieving procedural, recognitional, and distributive justice requires transparency, trust, and follow-through. Considering the high number of community-based P\&Cs proposed in these documents and the general lack of specification, there is concern that several of these P\&Cs could perpetuate harm, rather than mitigate it.

Successful implementation of P\&Cs for equitable, just, and generally successful outcomes also require close attention to the outcomes and impacts of the work. Processes that support accountability, adjustment, and learning must be included in the $\mathrm{P} \& \mathrm{C}$ process. Unfortunately, descriptions of monitoring and evaluation approaches were incredibly sparse across all the P\&Cs mentioned throughout the $100 \mathrm{RC}$ documents. This again causes concern about the efficacy of the proposed P\&Cs and their ability to enhance equity in urban resilience.

Finally, P\&Cs may not be the most appropriate implementation strategies for all aspects of urban resilience. The immense number of $\mathrm{P} \& \mathrm{Cs}$ as urban resilience strategies seen throughout these documents is over-promising at best and could lead to severe community fatigue at worst. It is hard to imagine that all of the proposed P\&Cs will be given the time, resources, and energy needed to be actualized; and there is an assumption that community organizations and individuals would like to engage in urban resilience 
partnerships. These problems can quickly compound other equity challenges, leading to failed P\&Cs, continued injustice, and ultimately little improvement in urban resilience.

It may be advantageous for urban resilience planners and practitioners to more deeply consider the application of P\&Cs. While P\&Cs have huge potential for enhancing equitable urban resilience implementation, they require real forethought, commitment, and resources. Document analysis revealed that characterizations P\&Cs often failed to describe "the why" behind the work; or in other words, they failed to communicate whether critical thought and reasoning contributed to the decision to use P\&Cs. Few mentioned how the P\&Cs would contribute to a proposed future state of enhanced urban resilience, or related them to visions of larger urban transformations or societal transitions. Perhaps deeper consideration of why P\&Cs should be used in a particular context will lead to fewer, but more comprehensive and attainable P\&Cs being proposed and developed.

\section{Conclusion}

Partnerships and collaborations (P\&Cs) are increasingly being identified by cities as mechanisms for implementing urban resilience. This study confirms results from other reports that find partnerships and collaborations are mentioned alongside other resilience strategies more often than any other approach. As the desire to form and implement P\&Cs continues to grow, it is becoming increasingly important to understand what exactly $\mathrm{P} \& \mathrm{C}$ means in the context of urban resilience. Just like the term resilience itself, partnership and collaboration can have different meanings depending on the context, 
which can be benign, harmful, or helpful. This article explores how municipal practitioners in the United States are characterizing P\&Cs within their urban resilience planning documents. Understanding and categorizing the who, what, when, and why of P\&Cs for urban resilience provides a deeper understanding of how these strategies are being described and offers a starting point for further research into urban resilience P\&Cs, including how they are tangibly actualized outside of planning documents.

\section{Works Cited}

Acosta, J. D., Burgette, L., Chandra, A., Eisenman, D. P., Gonzalez, I., Varda, D., \& Xenakis, L. (2018). How Community and Public Health Partnerships Contribute to Disaster Recovery and Resilience. Disaster Medicine and Public Health Preparedness, 12(5), 635-643. https://doi.org/10.1017/dmp.2017.130

Adger, W. N., Arnell, N. W., \& Tompkins, E. L. (2005). Successful adaptation to climate change across scales. Global Environmental Change, 15, 77-86.

https://doi.org/10.1016/j.gloenvcha.2004.12.005

Brand, F. S., \& Jax, K. (2007). Focusing the meaning(s) of resilience: Resilience as a descriptive concept and a boundary object. Ecology and Society. The Resilience Alliance. https://doi.org/10.5751/ES-02029-120123

Chi, G. C., Williams, M., Chandra, A., Plough, A., \& Eisenman, D. (2015). Partnerships for community resilience: perspectives from the Los Angeles County Community 
Disaster Resilience project. Public Health, 129(9), 1297-1300.

https://doi.org/10.1016/j.puhe.2015.07.004

Coaffee, J., \& Clarke, J. (2015, June 11). Viewpoint: On securing the generational challenge of urban resilience. Town Planning Review. Liverpool University Press. https://doi.org/10.3828/tpr.2015.16

Drakaki, M., \& Tzionas, P. (2017). Community-based social partnerships in crisis resilience: a case example in Greece. Disaster Prevention and Management: An International Journal, 26(2), 203-216. https://doi.org/10.1108/DPM-09-2016-0190

Faulkner, L., Ayers, J., \& Huq, S. (2015). 6 Meaningful Measurement for CommunityBased Adaptation, (147). https://doi.org/10.1002/ev.20133

Fitzgibbons, J., \& Mitchell, C. L. (2019). Just urban futures? Exploring equity in "100 Resilient Cities.” World Development, 122, 648-659. https://doi.org/10.1016/J.WORLDDEV.2019.06.021 Lasker, R. D., Weiss, E. S., \& Miller, R. (2001). Partnership Synergy: A Practical Framework for Studying and Strengthening the Collaborative Advantage. Milbank Quarterly, 79(2), 179-205. https://doi.org/10.1111/1468-0009.00203

MacKinnon, D., \& Derickson, K. D. (2013). From resilience to resourcefulness. Progress in Human Geography, 37(2), 253-270. https://doi.org/10.1177/0309132512454775 
Marana, P., Labaka, L., \& Sarriegi, J. M. (2018). A framework for public-private-people partnerships in the city resilience-building process. Safety Science, 110, 39-50. https://doi.org/10.1016/J.SSCI.2017.12.011

Meerow, S. (2017). The Contested Nature of Urban Resilience: Meaning and Models for Green Infrastructure and Climate Change Adaptation Planning. Retrieved from https://deepblue.lib.umich.edu/handle/2027.42/138739

Meerow, S., \& Newell, J. P. (2016). Urban resilience for whom, what, when, where, and why? Urban Geography, 1-21. https://doi.org/10.1080/02723638.2016.1206395

Meerow, S., Pajouhesh, P., \& Miller, T. R. (2019). Social equity in urban resilience planning. Local Environment, 24(9), 793-808.

https://doi.org/10.1080/13549839.2019.1645103

Moloney, S., Scott, H., \& Macdonald, F. (2018). Tracking progress on climate change: Developing a tool for monitoring and evaluation for local governments How well are we adapting? View project Adaptation for Recovery project evaluation View project Tracking progress on climate change: developing a tool for monitoring and evaluation for local governments. Retrieved from https://www.researchgate.net/publication/327172586 Ritchie, H., \& Roser, M. (2018). Urbanization - Our World in Data. Retrieved February 28, 2020, from https://ourworldindata.org/urbanization

Schlosberg, D. (2003). The Justice of Environmental Justice: Reconciling Equity, recognition, and participation in a political movement. Retrieved January 6, 2019, from 
https://books.google.com/books?hl=en\&lr=\&id=EumtnLONgAAC\&oi=fnd\&pg=PA77\& dq=Schlosberg,+David+(2003).+The+Justice+of+Environmental+Justice:+Reconciling+ Equity,+recognition,+and+participation+in+a+political+movement\&ots=bqc2jM6O77\&s ig=L5ZayQ307KyZzbZ16q2hrh

Spaans, M., \& Waterhout, B. (2016). Building up resilience in cities worldwideRotterdam as participant in the 100 Resilient Cities Programme Building up resilience in cities worldwide-Rotterdam as participant in the 100 Resilient Cities Programme. https://doi.org/10.1016/j.cities.2016.05.011

Tierney, K. (2015). Resilience and the Neoliberal Project: Discourses, Critiques, Practices-And Katrina. https://doi.org/10.1177/0002764215591187

Woodland, R. H., \& Hutton, M. S. (2012). Evaluating Organizational Collaborations. American Journal of Evaluation, 33(3), 366-383. https://doi.org/10.1177/1098214012440028 
Chapter 3: Real-Time Evaluation of City-University Partnerships for Sustainability and Resilience

Liliana Caughman $^{1,3}$, Lauren Withycombe Keeler $^{2}$, Fletcher Beaudoin ${ }^{1}$

${ }^{1}$ Institute for Sustainable Solutions, Portland State University

${ }^{2}$ School for the Future of Innovation in Society, Arizona State University

${ }^{3}$ College of Liberal Arts and Sciences, Portland State University

\begin{abstract}
Cities face many challenges in their efforts to create more sustainable and resilient urban environments for their residents. Among these challenges is the structure of city administrations themselves. Partnerships between cities and universities are one way that cities can address some of the internal structural barriers to transformation. However, cityuniversity partnerships do not necessarily generate transformative outcomes, and relationships between cities and universities are complicated by history, politics, and the structures the partnerships are attempting to overcome. In this paper, focus groups and trial evaluations from five city-university partnerships in three countries are used to develop a formative evaluation tool for city-university partnerships working on challenges of urban sustainability and resilience. The result is an evaluative tool that can be used in real-time by city-university partnerships in various stages of maturity to inform and improve collaborative efforts. The paper concludes with recommendations for creating partnerships
\end{abstract}


between cities and universities capable of contributing to long-term sustainability transformations in cities.

\section{Introduction}

The future of global sustainability and the future of cities are tightly connected. Cities are home to more than half of the world's population and must play a critical role in mitigating climate change and adapting to its impacts to allow residents to thrive. In fact, one of the 17 SDGs specifically mentions the role of cities and urban areas, and the need for urban sustainability transformation, and several others focus heavily on cities. Cities currently emit over $70 \%$ of all global carbon dioxide emissions ("C40," 2020) . Therefore, establishing and maintaining tight urban carbon budgets is key to meeting emissions and warming goals set out by the Paris agreement, the International Panel and Climate Change (IPCC), and UN Sustainable Development Goals (SDGs) (Acuto, Parnell, \& Seto, 2018). Cities are increasingly feeling the effects of extreme weather and are particularly vulnerable because of their frequent proximity to coasts, floodplains, and dry areas. For instance, extreme wildfires have become a global phenomenon and cities from California to Australia are facing compounding struggles from the fires that seem to worsen every year (Acuto et al., 2018; Nauslar, Abatzoglou, \& Marsh, 2018; Nolan et al., 2020; Science News, 2019). In the 2019-2020 fire season megafires burned across Australia, scorching over 25 million acres of land, killing roughly a billion animals, and destroying nearly 2,000 homes. In California's 2018 fire season, there were over 58,000 wildfires, with the Paradise fire incinerating an entire town and killing 85 people. In 2019, utility companies throughout 
California chose to preemptively shut off electricity for over 500,000 residents for fear of similarly devastating fires. This urgency is echoed in calls to focus sustainability research and practice on the sustainability transformation of cities and regions (Wolfram, Borgström, \& Farrelly, 2019).

Sustainability problems such as climate change are complex and require innovative systemic solutions that span disciplines and institutions and are often slow to manifest (Loorbach, 2010b). These complex problems require transformation, or "radical, systemic shifts in values and beliefs, patterns of social behavior, and multilevel governance and management regimes" (Olsson, Galaz, \& Boonstra, 2014b) . Municipal governments are attempting to mitigate and prepare for complex climate and energy challenges by creating sustainability and resilience agendas, which typically take the form of planning documents, civic mandates, and associated policy and programmatic actions (Keeler et al., 2019a). Local governments, including municipalities, counties and regions, are primarily responsible for addressing climate change impacts, decarbonizing transit systems, transitioning to renewable energy, ensuring food access, and building more resilient and sustainable communities. However, they are often limited by institutional design, organizational logic, limited cross-jurisdictional coordination, and a general lack of skill and capacity for dealing with the uncertain and fast-changing nature of sustainability and resilience challenges (Keeler et al., 2019a; Polk, 2015). Municipal plans and policy initiatives necessitate and often explicitly call for cross-sectoral and inter-institutional partnerships and collaborations (i.e. between cities, businesses, universities, NGOs, and community organizations) that can help dismantle institutional barriers and path- 
dependencies so that more innovative and holistic solutions can be achieved (Lozano, 2007). For instance, in an analysis of the Rockefeller Foundation's 100 Resilient Cities strategy documents, partnerships and collaborations were the most commonly cited planning, development, and implementation strategy across US cities (Caughman, n.d.). Additionally, Partnerships and collaborations with other institutions, like universities, have become increasingly important because they can help cities and other municipal governments address complex challenges, develop innovative solutions by operating across departments and jurisdictions and build capacity for sustainability problem solving.

Sustainability science and related fields (e.g. climate science, environmental science) continue to call for greater transdisciplinarity and applied research to increase the rate and real-world impact of discovery for urban sustainability and resilience (Caughman, 2017; Lang et al., n.d.; Simmons et al., 2015; Withycombe Keeler, Beaudoin, \& Caughman, n.d.). A 2018 Nature article recognized the urgent need for research on the intersection of cities and climate change (Acuto et al., 2018). The article, and a subsequent publication from the National Science Foundation (NSF), called for increased understanding of "sustainable urban systems science", and deeper partnership between researchers, policymakers, and practitioners to co-create knowledge and solutions together (Ramaswami et al., 2018). This research underscores the need for collaboration that supports innovation and transformation at the local level that can be shared and scaled globally.

City-university partnerships (CUPs) are emerging as mechanisms for the development, implementation and assessment of sustainability and resilience measures - creating the environment for sustainability science research to be more tightly coupled with 
sustainability problem-solving by urban policymakers (G. Trencher, Bai, Evans, McCormick, \& Yarime, 2014; Withycombe Keeler et al., 2018). Across the world, increasing numbers of CUPs are forming to support a range of climate change and sustainability-oriented work. For example, in the US, Smart City San Diego is a partnership between a university, municipality, utility company, and non-profit organization aimed at accelerating a regional transition to a green economy (G. P. Trencher, Yarime, \& Kharrazi, 2013). The Sustain-Lite project is a partnership in Singapore between a university, the local government, and a private business, responding to predicted growth of trade and commerce in Asia, and developing knowledge and tools for supply chain innovation (G. P. Trencher et al., 2013). Keeler and colleagues (2016) describe utilizing city university partnerships across the North America, Europe, and Asia to transfer and scale solutions to sustainability problems (Withycombe Keeler et al., 2016). CUPS are rapidly developing at a global scale. For instance, the Educational Partnerships for Innovation in Communities - Network (EPIC-N) which unites local governments and communities with universities, now has 37 members spanning four continents, nine countries, and continues to grow ("Who's in the Network - EPIC-N,” n.d.).

While CUPs have structural similarities, e.g. they all include some form of agreement between researchers or administrators from universities and city administrators to formally collaborate, the partnerships operate in different modes. CUPs established to address complex sustainability problems such as climate change can be understood as falling into one of three modes: routine, strategic, or transformative, summarized in Table 1 (Margerum, n.d.; Teitel, 2012; Withycombe Keeler et al., n.d.). Routine partnerships are 
transactional and consultant-based; limited joint efforts that are suited for static and straight-forward problems (e.g. the City of Portland and Portland State University working together to develop a map of street trees) (Butcher, Bezzina, \& Moran, 2011; Kula-Semos, 2009). Strategic partnerships focus on co-creation with both the city and university partners contributing to the goals and design of the collaboration. Such partnerships are often addressing more complicated problems that are value-laden and have multiple solutions (e.g. Tempe, Arizona working with ASU to design and implement a process to create a climate action plan) (Salimova, Vatolkina, \& Makolov, 2014; Withycombe Keeler et al., n.d.). Transformative partnerships are formalized, with deep cross-institutional learning and mission alignment; these are well-suited for complex or wicked problems that include long-term goal setting, contested solution spaces and regular evaluation and updating of developed solutions (e.g. the holistic partnership between University of British Columbia and the city of Vancouver working to accelerate and navigate urban sustainability transitions) (Butcher et al., 2011; Kula-Semos, 2009; Swartz \& Triscari, 2011; Warren \& D., 2018). There is an increasing need for these kinds of transformative partnerships given the growing awareness and pressure to make progress on complex issues. Understanding which partnership mode a CUP is operating within lays the foundation for evaluating a CUP for, among other things, coherence between partnership goals and partnership structure.

\begin{tabular}{ccc}
\hline Partnership Modes & Attributes & Context \\
\hline Routine & Transactional, consultant-based or fee- & Straight-forward problems \\
& $\begin{array}{c}\text { for-service; Loose exchanges; One-sided } \\
\text { deliverables; Limited joint efforts; One- }\end{array}$ & $\begin{array}{c}\text { i.e. community organization } \\
\text { manager working with a }\end{array}$ \\
\hline
\end{tabular}


off projects; Often based on individual (rather than institutional) relationships

Loose partnership; Shared vision and

Strategic desire to co-create; Often externally focused researcher to develop maps of street trees

\section{Complicated problems}

i.e. Business organization and city department collaborating on the development and implementation of initiatives for minority-owned businesses

\section{Complex problems}

Formalized partnerships; Deep crossinstitutional learning and mission alignment; Focused on internal and external systemic change i.e. City, university, and community coming together to develop holistic equityfocused climate adaptation plan

Table 6. This table shows three modes of partnership structures, their attributes, and the context in which they are most applicable.

Developing effective monitoring and evaluation (M\&E) techniques for all modes of CUPs is a vital component for intervention implementation, management, learning, and adjustment; for transformative CUPs it is imperative. Iterative $\mathrm{M} \& \mathrm{E}$ of interventions provides real-world decision-making strategies for administrators, while also delivering comparable data for long-term research and analysis (Luederitz, Sch, et al., 2017; Reed, Fraser, \& Dougill, 2006). Appropriate development and implementation of CUP specific M\&E tools can fulfil the real need to assess new and ongoing efforts and offer recommendations for improvement.

The partnership evaluation literature across several fields of study provides some common indicators for successful partnerships and collaborations. However, there is little 
guidance regarding specific strategies for CUPs seeking transformative sustainability and resilience outcomes. In general, partnerships and collaborations tend to be assessed based on: trust and trust-building; understanding context; shared history; mutual respect and understanding; member attitudes and beliefs; member satisfaction; processes, organization, and decision-making; communication; determination of goals and objectives; financial and human resources; and leadership (Greenwald \& Zukoski, 2018; Marek, Brock, \& Savla, 2015; Woodland \& Hutton, 2012b). However, there remains a need to guide partners in how to implement evaluative practices, relate assessment to outcomes, or integrate findings into ongoing partnership management, especially in the case of large institutions coming together for prolonged change. Additionally, further clarity is needed regarding how the general indicator categories of partnership assessment apply to the specific context of partnerships between cities and universities pursuing transformational sustainability outcomes.

Therefore, this paper aims to develop a research-based evaluation scheme for CUPs working on urban sustainability and resilience transformations. The article chronicles the development of an evaluation scheme to plan, monitor, and optimize CUPs for transformative resilience and sustainability outcomes. In so doing, the paper answers the following research questions: How can city-university partnerships be assessed for their capacity to contribute to long-term sustainability and resilience transformation? Specifically, what should be evaluated, who should be involved in the evaluation, and at what frequency? And how is this knowledge formatively integrated into CUPs for their improvement? The research questions are answered through a combination of focus groups 
and evaluation design and application and results include a step-by step guide for real-time sustainability and resilience CUP evaluation.

Methods

The research team utilized an exploratory and confirmatory iterative focus group methodology as a knowledge elicitation technique to develop an operationalized evaluation scheme for city-university partnerships (CUPs) working on urban resilience and sustainability initiatives (Kitzinger, 1995; Massey \& Wallace, 1991; Tremblay, Hevner, \& Berndt, 2010). The focus groups were made up of experts currently involved in the development of transformative sustainability and resilience CUPs and were used to inform possible formative evaluation approaches, indicators, and tools. This consisted of three focus group meetings: one to develop the baseline schema, the second to refine the schema, and the final to reflect on the schema (Figure 1). Between each focus group session, the evaluation technique was applied to the CUP initiatives being undertaken by focus group participants as part of a participatory evaluation technique (Rodríguez-Campos, 2012; Whitmore, 1998).

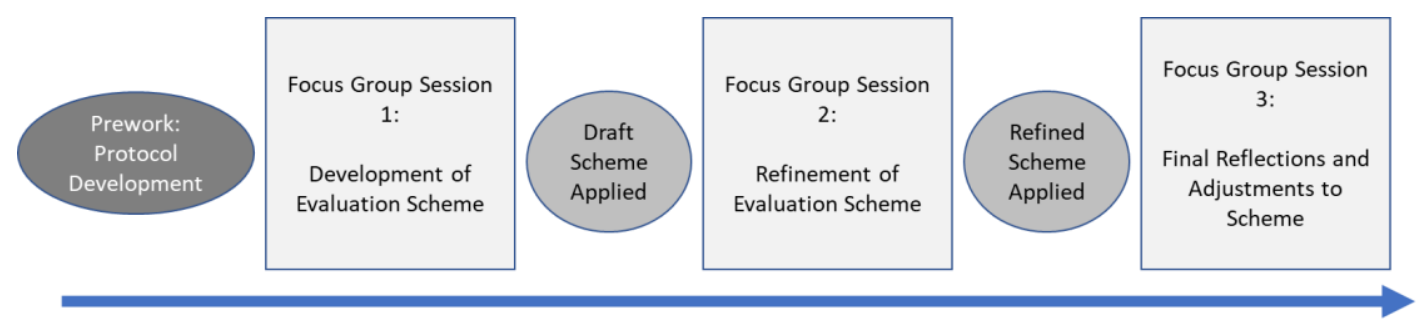

Figure 5. Flow chart describing the iterative process of focus group sessions to develop the evaluation scheme and application of the draft evaluation scheme. 
Focus groups functioned as generative workshops, bringing multiple experts together in one space, and using guiding questions to prompt development of tools, considerations, and opportunities for CUP evaluation. In particular, the groups were asked to think about indicators, metrics, and functional approaches for evaluation based upon their knowledge and skills. The researchers took notes at the focus group sessions which were compiled and sorted to uncover metrics and indicators that met criteria from three prominent collaboration evaluation frameworks: 1) the Collaboration Evaluation and Improvement Framework (CEIF) (Brown, Feinberg, \& Greenberg, 2012), 2) the Relationships, climate, and expectations (RCE) framework, and 3) the Extent of collaboration (EC) framework (Greenwald \& Zukoski, 2018). These findings were then compared to existing literature on transition management and transformative partnerships, specifically, the principals for transferring partnership-based sustainability and resilience solutions across contexts (Withycombe Keeler et al., 2018). Finally, metrics and indicators were fit into the deployment strategy developed by the focus group participants to create the proposed CUP evaluation framework.

Expert knowledge elicitation focus groups were used for this research because they capitalize on communication between research participants in order to generate data. Compared to other types of group interviews, focus groups explicitly use group interaction as part of the method, therefore, people are encouraged to talk to each other, ask questions, exchange anecdotes and comment on each other's experiences and perspectives (Kitzinger, 1995). Focus group methodologies are particularly useful for exploratory and applied 
research; identifying avenues of interest as new fields begin to emerge and when academic literature is thin.

A focus group was developed using a purposive sampling technique. Participants were chosen based upon their experiences in transformative sustainability and resilience CUP development and implementation, connection to inter-institutional partnership initiatives, and experience in research, evaluation, or monitoring of sustainability and resilience related interventions. All participants were currently actively engaged in the implementation of self-described transformative sustainability or resilience initiatives through a CUP at the time of the focus groups, so iterations of the developed formative evaluation scheme could be directly applied.

The individuals selected for focus group participation contained academics and practitioners from five cities around the globe: Portland, Oregon, USA; Mexico City, Mexico; Leuphana, Germany; Karlsruhe, Germany; and Tempe, Arizona, USA. While not statistically representative, this group offered a wide range of experiences and expertise related to sustainability and resilience CUP planning, implementation, and transition management useful for the development of an operationalized evaluation scheme.

The goal of the first focus group session was to determine a starting point for the research and development of a formative evaluation approach for urban sustainability and resilience initiatives that utilize CUPs. There were 10 attendees in the group which consisted of: graduate students, post-docs, faculty members, and practitioners from local government. Attendees were from Germany, Mexico, and the United States. The focus 
group session was semi-structured, with researchers posing questions and participants responding free form to the questions and to the responses of the other participants.

The session consisted of exploring open-ended questions and prompts, related to how participants currently managed and evaluated their sustainability and resilience CUP work, and what was working well, or experiencing challenges. Questions were used to guide the conversation and to prompt generative and comparative discussion among the participants. Notes were taken and analyzed to develop answers to the questions, which were then combined with best-practices literature (as described above) to develop a formative evaluation scheme. The first version of the evaluation scheme was then applied by the researchers to the focus group participants' initiatives.

The goal of the second focus group session was to present findings from the first version of the formative evaluation scheme and elicit feedback from the group to refine the scheme. The focus group session was loosely facilitated by the researchers and consisted of exploring open-ended questions and prompts related to the performance of the draft evaluation scheme, how well it represented the work, how findings could be integrated into CUP management, and what might need to be changed. Results from this session were compiled and used to create a refined version of the evaluation scheme, which was subsequently applied by researchers to the participant's initiatives.

The goal of the final focus group session was to present findings from the application of the refined version of the evaluation scheme and elicit feedback from the group to reflect upon and finalize the scheme. The focus group session was loosely facilitated by the researchers and consisted of exploring open-ended questions and prompts related to the 
accuracy, usefulness, and overall design of the evaluation scheme. Findings from the session were consolidated and used as final refinements to the evaluation scheme.

Results

The focus group sessions and iterative process of evaluation development, deployment, and refinement resulted in a scheme that can be used to assess city-university partnerships (CUPs) for their capacity to contribute to long-term sustainability and resilience transformation. Specifically, results indicated: 1) what should be evaluated, 2) who should be involved in the evaluation, 3) how evaluation data is collected and disseminated, and 4) the frequency at which evaluation should occur. Finally, the results highlight how knowledge generated through the evaluation process can be formatively integrated into CUP management for their improvement.

An in-depth description of the proposed CUP evaluation scheme is described below. It begins with answering the practical questions of who, what, when, where, and why to evaluation. It concludes with a simple step-by-step guide to implement the evaluation.

\subsection{Indicators and Measures: What to evaluate and why}

The focus group sessions and trial evaluations showed that assessing CUP progress requires understanding participant perceptions of both outcome-based and relational aspects of the partnership. Therefore, the proposed scheme includes two domains for evaluation: 1) perceptions of the collaborative project and 2) perceptions of the partnership itself. It is advantageous to gauge the status of these two domains separately, and then 
integrate knowledge between them for a holistic understanding of the dynamics of the CUP.

When evaluating perceptions of the collaborative project, three core areas, supported by several reinforcing indicators, are assessed. This is referred to as the Foundation, Actions, Impacts (FAI) assessment of CUP project development, implementation, and outcomes. FAI assessment uses short surveys and informal interviews to gauge participant perceptions related to each indicator (process details elaborated upon in sections 3.2 and 3.3). Each of the three core areas are described in further detail below:

1. Foundation - Measures CUP participants' perceptions of interest, competency, and capacity related to project undertaking. Seeks to understand feelings towards own organization and partner organization.

2. Actions - Assesses perceived ability of all partners to plan and implement projectrelated change interventions in a co-created and co-managed way.

3. Impact - Evaluates the perceived achievement of project goals and identification of opportunities for future work.

The FAI components are additive over the course of CUP project development and implementation (Figure 2). Findings indicate that when there are deficiencies in one of the earlier stages (for example, lack of interest in the foundation stage), it becomes increasingly difficult for the CUP project to thrive in later stages. By applying the FAI evaluation scheme, such deficiencies can be illuminated and mitigated. Additionally, if progress on 
the initiative becomes stalled or problematic, using this diagnostic tool can help direct where corrective action should be taken. It can also help identify where support is needed and aid the formulation of goals and plans to better match the evolving circumstances.

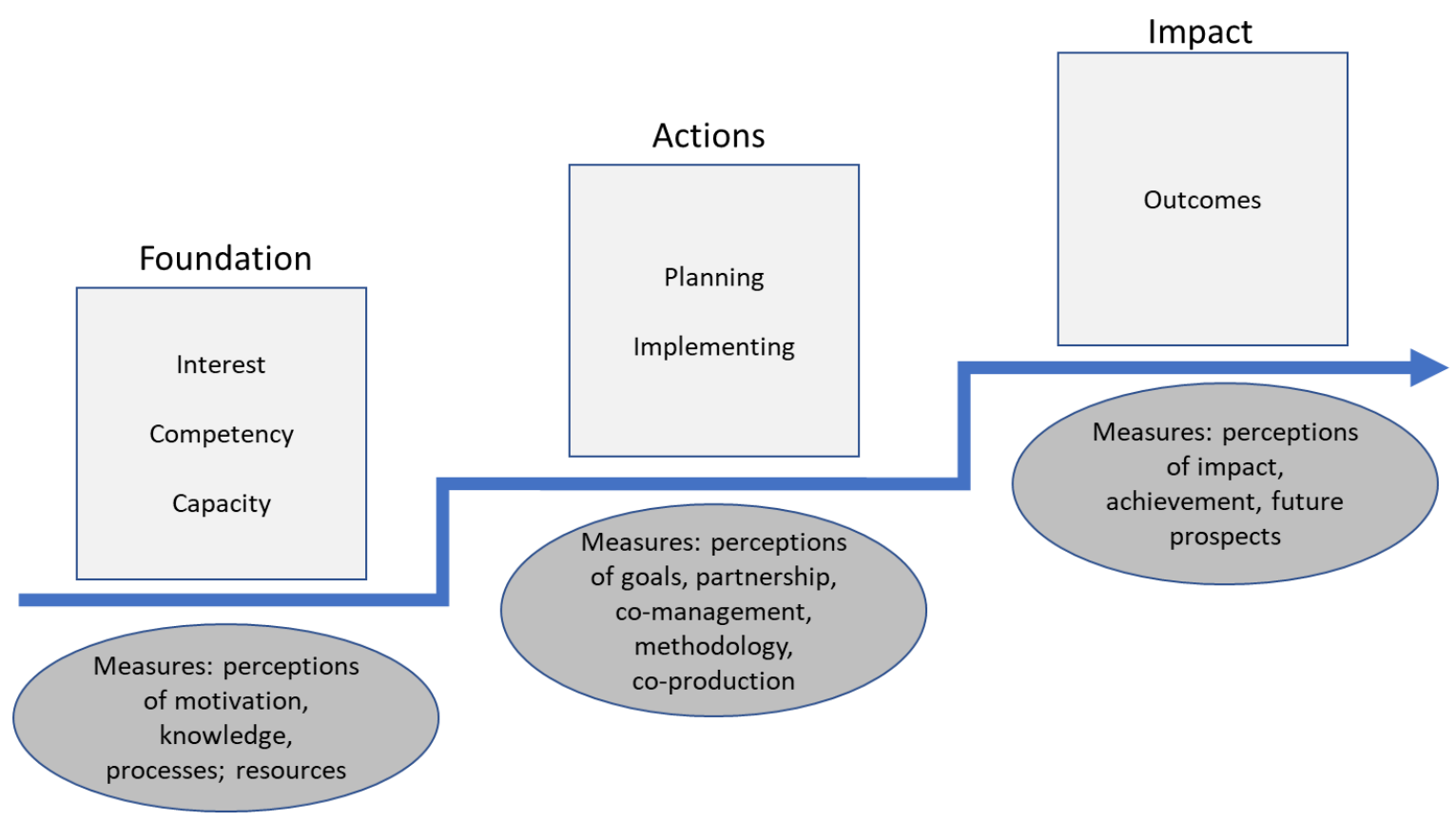

Figure 6. Chart describing three core areas of collaborative project evaluation (foundation, actions, and impact) and how they build upon each other throughout the project timeline.

The second domain of evaluation measures participant perceptions of partnership functioning. This is used to understand partnership-specific dynamics, that may or may not be directly related to the current collaborative project. This part of the evaluation can help identify the partnership mode being utilized by the CUP and help participants match their partnership structure to the types of problems they hope to solve and their individual institutional contexts. For instance, if the CUP has transformative aims but the partnership is operating in the routine mode, then the assessment can be used to identify the mismatch 
and inform methods to shift modes. To measure partnership functioning, the Interpersonal Context and Empowering Supports (ICES) assessment can be used. The following aspects are considered ICES assessment indicators:

- Interpersonal Context: Measures participant perceptions of collaborative history between institutions, interest to engage, demonstrated motivation to engage, and mutual understanding of need. Seeks to understand perceptions of both own organization and partner organization.

- Empowering Supports- Assesses perceived and/or actual formalization of partnership, mechanism for partnership, and resources committed on all sides of partnership.

The results of the ICES assessment are compiled to describe the current typology of the partnership and its level of functioning (Figure 3). Findings are divided into three categories, low, medium, and high ICES. Each category relates to a partnership typology, which can be used to understand how well the partnership structure is aligned with desired projects and real-world outcomes. It can also expose when there is malalignment between perceptions of the partnership from different individuals or organizations. This allows for transparent conversations regarding the durability, efficacy, and purpose of the CUP. 

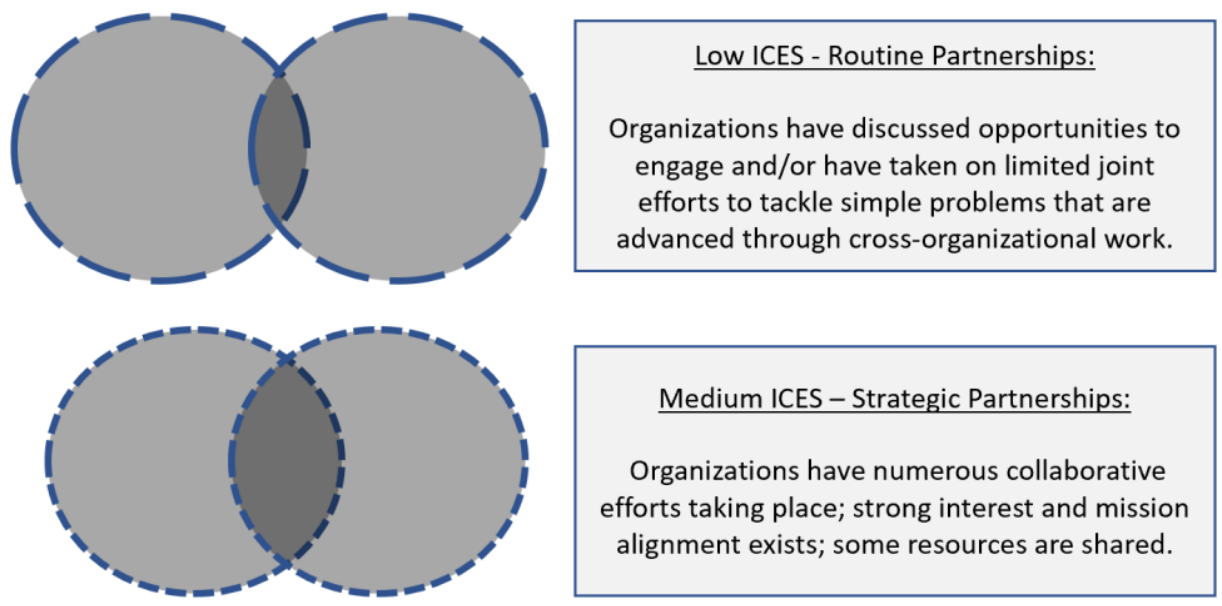

Medium ICES - Strategic Partnerships:

Organizations have numerous collaborative efforts taking place; strong interest and mission alignment exists; some resources are shared.

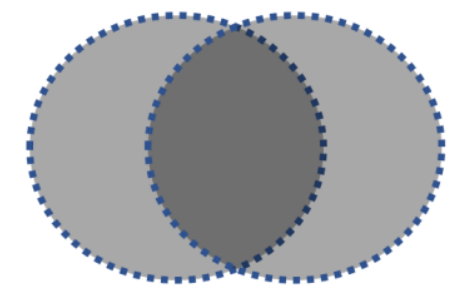

High ICES - Transformative Partnerships:

Organizations have a clear framework for collaboration and dedicated resources to making the partnership work; collaborative efforts are co-created and have a strong influence on strategies within both organizations.

Figure 7. Chart describing ICES assessment categories and how they relate to the mode and attributes of the partnership.

Taken together, the Foundation, Actions, Impacts and Interpersonal Context and Empowering Supports (FAIICES, pronounced 'faces') evaluation scheme provides vital information regarding CUP structure and functioning from both a project-based and relationship-based perspective. It offers a mechanism for understanding how partnerships evolve in relationship to project milestones. The FAIICES scheme can be used to find points where the overall CUP system is lacking or out-of-balance, allowing CUP administrators to target efforts in those specific areas. Additionally, it can provide insight 
into areas where targeted action to develop the partnership, or evolve partnership typology, can be deployed.

For instance, one side of the partnership may be struggling to achieve goals by itself. Through application of the FAIICES evaluation, this could show up as a low score in the Actions category on the project part of the evaluation, and perhaps deficient resources committed on the partnership side. This highlights an opportunity for intervention in specific areas to make an impact; i.e. by facilitating foundational development in content area knowledge or having a tough conversation about shared resources. These capacitybuilding efforts help develop and align the CUP so that action can flow through the system effectively, and project objectives can be adaptively achieved.

\subsection{Actors: Who evaluates and who is evaluated}

The FAIICES evaluation scheme is designed to be participatory and flexible. As a participatory evaluation methodology, it is not meant to be a process where the evaluator is objectively removed, but instead they are an integrated part of the process. This works because the FAIICES scheme is about exploring perceptions of CUP functioning and incorporating findings into CUP management.

Being a participatory method allows for parts of the evaluation methodology to evolve depending on participant needs (especially timing, data collection, dissemination and more - discussed further in $3.3-3.5$ below). Therefore, the evaluator can take many forms: from

collective team-led evaluation, to a specific person on the team leading evaluation, to a semi-removed evaluator who has ties to the initiative, to an outside evaluator with at least 
some knowledge of the initiative. Additionally, the evaluator can be more than one singular person. Adherence to the FAIICES scheme is more important than who leads the evaluation.

However, the evaluator also plays an important role in building the evaluative capacity of the team. As evaluation occurs, the evaluator should be sure that the team is understanding the process, purpose, and usefulness of the evaluation, so that it might be conducted by a different entity in the future. In this way, evaluation can become ingrained in CUP management and the responsibility to evaluate can be shared.

Selecting the correct CUP members to be the subjects of evaluation is a more nuanced task. Not everyone who participates in the CUP needs to participate in the evaluation processes. As little as one person from each partner organization is required to complete the data collection portion. Evaluation participants should be central to the functioning of the CUP on both the relational and project-oriented sides. For most CUPS there are no more than 1-3 key people on each side of the partnership with the insight, power, and positionality needed to be useful for this form of evaluation. The people involved in the evaluation should be the same people who can act on the findings and integrate them into the decision-making and management processes.

\subsection{Tools: How to collect data and disseminate results}

The FAIICES scheme can utilize several forms of data collection. We found that a mixture between short surveys and informal interviews, followed by a safe place to collectively examine results, worked well for the participants. One important feature of 
FAIICES is that it is not rigid; so long as perceptions of the indicators are being gathered, the method in which that occurs is less significant. This is a particularly useful feature when working between multiple institutions. For one side of the partnership, short, pointed surveys with Likert scale answers might best fit into their workflow and norms. Meanwhile, the other side might do better with informal, consultative interviews that get to an understanding of the indicators in a more conversational way. However, they are gathered, compiling the results and fitting them to the FAIICES indicators allows for a subjective, yet informative, comparison between perspectives.

This is a qualitative evaluation tool and evaluators are tasked with interpreting the results from interviews, surveys, etc. and matching them as best they can to the FAIICES attributes. Having a visual representation of results aids understanding and integration of results (see Figure 4 for an example score sheet and visual aid). When sharing the results, it is important to note the qualitative and subjective nature of the findings and note that they should be interrogated and explored. The notion of ambiguity in the results can stimulate more creative thinking and problem-solving in CUP participants. 


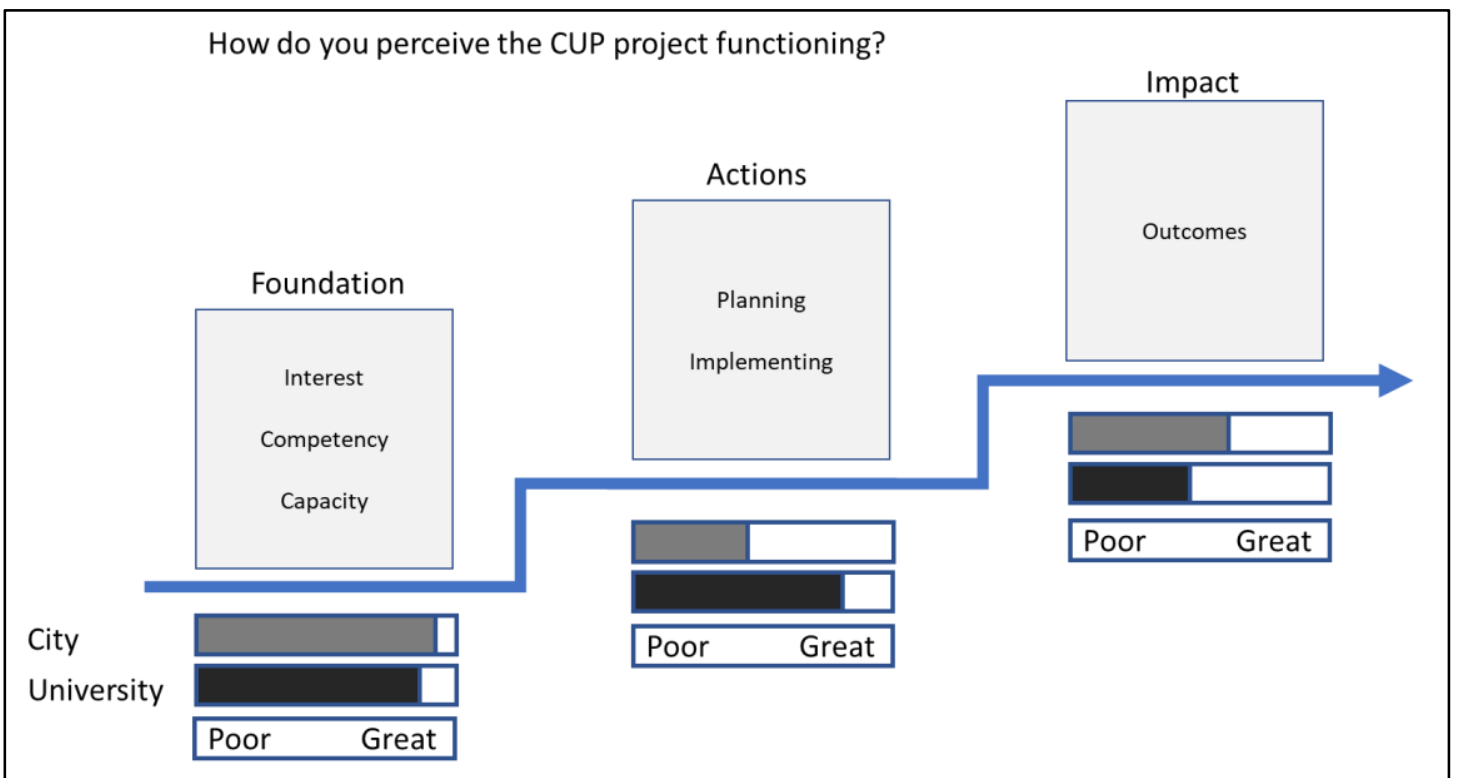

Figure 8. Example "score sheet" for a comparison of partners' perspective of project functioning. Here, the city and university have mostly aligned perspectives regarding the strength of the foundation but see things differently when it comes to the actions. This should prompt discussion that explores this difference in perception and generates solutions.

While only a few people need to actively participate in providing data for the FAIICES analysis, the results of the evaluation can be disseminated more broadly. CUPs vary widely regarding number of people involved, so dissemination practices need to be developed for specific context. If there is a core team of people who meet regularly to work on the CUP initiative, we recommended sharing results at one of these meetings. Here, through active dialogue and discussion, FAIICES findings can be inspected, scrutinized, and affirmed; hopefully leading to the generation of new goals and strategies for improved partnership management and project implementation.

\subsection{Timing: When and how often to evaluate}


Appropriate timing of the FAIICES evaluation is one of the most vital results of this study. The FAIICES scheme should be used iteratively and inform real-time decisionmaking. Depending on the context of the CUP, the evaluation should be completed about two to four times per project cycle. The timing of evaluation should revolve around key milestones or events, that way findings can be used immediately; results help both reflectively, and for future management decisions (Figure 5). This concept of participatory real-time evaluation has not often been used for CUPs, or other urban sustainability and resilience work. Development and testing of the FAIICES framework showed tangible potential for this approach to be seamlessly integrated into CUP partnership and project management.

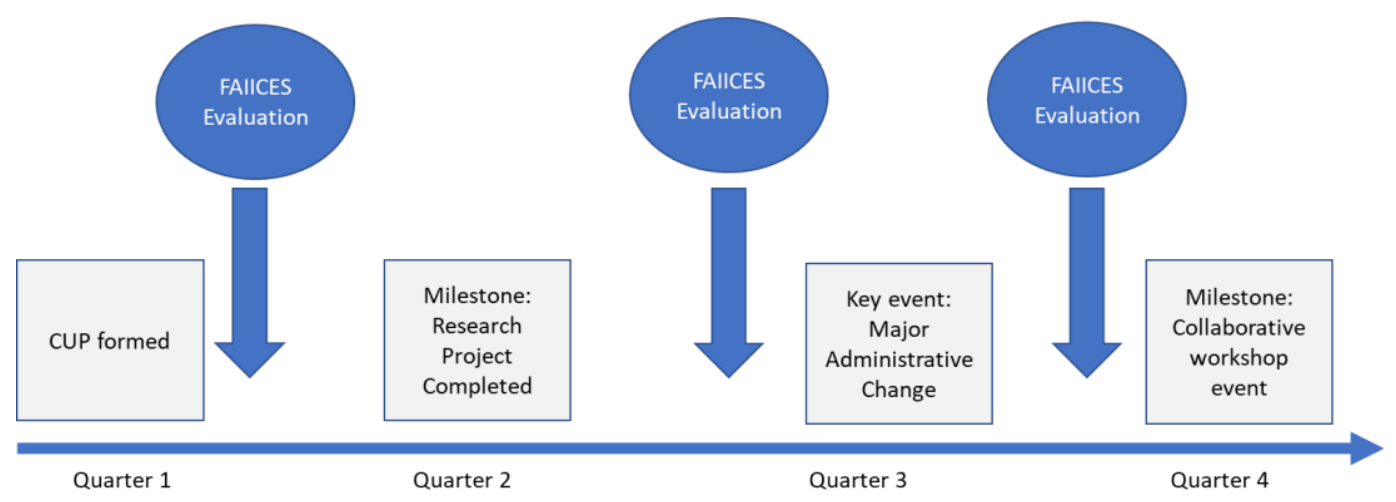

Figure 9. Example timeline for application of FAIICES scheme. Evaluations occur just before/after key milestones and events that impact the CUP. Results from the evaluation should be immediately compiled and used for real-time management and decision-making.

\subsection{Knowledge Integration: Using evaluative results in real-time}

As mentioned throughout previous sections, it is imperative for the results of the FAIICES evaluation to be integrated into CUP management and decision-making in real- 
time. The value of the knowledge generated from the evaluation itself does not compare with the value generated through careful exploration and integration of results by CUP administrators. Collaboratively disseminating and investigating the findings from application of the FAIICES scheme helps to bridge gaps in understanding across institutional barriers and norms. Additionally, the process helps spur conversation and dialogue, which ultimately, reinforces mutual understanding and trust.

Knowledge integration from FAIICES often highlights concerns, challenges, and opportunities that CUP participants may not have previously considered. In this way, the evaluation offers insight into leverage-points for higher impact interventions, or elicits strategies for navigating complex political, institutional, and real-world systemic barriers. Continuous, iterative, and strategically timed evaluation can help the CUP evolve and prosper through ever-evolving internal and external circumstances.

\subsection{Implementation: Quick Guide to the FAIICES evaluation scheme}

The FAIICES scheme is simple to begin and can change to suit specific context and needs over time. The follow list is a quick step-by-step guide for getting started on implementing a FAIICES evaluation:

1. Define your city-university partnership - Who is involved, what are your goals, why do you want to undertake this collaborative work?

2. Choose an evaluator - Determine whether you want to collaboratively conduct the evaluation, or if you want to identify a specific person or people on your team or entity outside your team to undertake the evaluator role. 
3. Pick your evaluation participants - Choose at least one central figure from each partner institution to participate in the evaluation. These people should understand both the relational and outcomes-oriented sides of the partnership. They will be the subjects of data collection.

4. Determine data collection methods - Decide whether open-ended surveys, Likert scales, informal interviews, or focus group sessions will be best for your participants (and feel free to get creative or adjust over time). Develop questions and prompts to explore participants' perceptions of project foundation, actions, and impact as well as the partnership's interpersonal context and empowering supports (see section 3.1). Example open-ended informal interview questions and guidelines are available for reference in and example open-ended and Likert style survey questions are available in the Appendix.

5. Conduct evaluation - Choose an appropriate time to conduct your evaluation, usually just before or after a key event or milestone (see section 3.4). Get survey/interview responses from your key informants on all sides of the partnership.

6. Analyze and compile data - Data analysis techniques will vary depending on the data collection methods used. Therefore, either quantitatively, qualitative, and/or subjectively compile data to show institution-specific and combined responses for each FAIICES category; depict in a visual format if possible (see Figure 4).

7. Disseminate and discuss - Soon after results have been compiled, schedule a time to collectively examine results. At minimum, the people who participated in the 
evaluation should be present, but this can also be expanded to include the larger CUP team. As a group, (typically led by the evaluator) go through the results, question them, add context, change or reinforce the findings.

8. Integrate results into CUP administration - Have the management team think about any opportunities, challenges, or interesting findings that were exposed by the analysis. Question whether these findings indicate that a change in CUP typology, strategy, or goals is needed. Pay specific attention to places where modifications could lead to a better partnership trajectory, or tangible impacts. Finally, decide if and how to respond to these findings, and adjust CUP practices accordingly.

9. Repeat FAIICES process - Follow the same instructions at the next appropriate evaluation time; you can then also explore how results change over time for deeper understanding of CUP evolution.

\section{Discussion}

This paper outlines a multi-faceted tool for the real-time monitoring and evaluation (M\&E) of sustainability and resilience city-university partnerships (CUPs) derived from analysis of ongoing sustainability and resilience-focused CUPs. The FAIICES evaluation tool is useful for CUPs of all types but is vital for CUPS that aim to be transformative and attain transformational outcomes. The tool offers a mechanism for ongoing data collection on CUPs suitable for future research, and immediate, tangible, useful results for adept management of CUP initiatives as they happen. As municipal governments work towards 
solutions for exceedingly complex sustainability and resilience problems, CUPs are emerging as a strategy to accelerate learning, build capacity, and confront institutional barriers (Keeler et al., 2019a; G. Trencher et al., 2014). Successful CUPs will match the structure of their partnership to their sustainability aspirations. However, there is there is limited research on CUPs to improve their performance. This paper provides the FAIICES evaluation tool as one mechanism to guide the design and management of sustainability and resilience-oriented CUPs, in an effort to improve their contributions to sustainability outcomes.

If a CUP is interested in tackling the complexities of urban resilience and sustainability through long-term collaboration, establishing and maintaining a transformative partnership will be critical. In transformative partnerships, cross-institutional partners retain their identities but are willing to learn from and with each other through prolonged, deep engagement. Partners approach their common purposes in a profoundly collaboratively way and exhibit a greater willingness to promote deeper systemic changes both internally and externally (Butcher et al., 2011; Seitanidi \& Koufopoulos, 2010; Withycombe Keeler et al., n.d.). While not all CUPs need to be transformative, many CUPs that are working on sustainability transformations are not achieving their goals or generating real world outcomes. This may be due, in part, to a mismatch between partnership structure and the specific problems and context. Successful transformative partnership administration calls for understanding how to think systemically and manage within systems. The FAIICES scheme offers users a way to reconcile their current partnership mode with their goals and develop pathways toward alignment. 
How the FAIICESE scheme is implemented matters. Effective implementation must: gauge perceptions of the CUP from all sides of the partnership; explore both relational and outcome-oriented aspects of the CUP; and occur in real-time (i.e. well-timed iterative formative evaluation for adaptive management). Gauging CUP participant's perceptions of and perspectives on the indicator areas of interest proved to be more useful than measuring quantifiable metrics. Our results confirm that for the purposes of agile management and decision-making, perspectives play a critical role. For example, what one partner perceives as interest to engage from their collaborator matters more for relationship development than the actual measurable interest, i.e. impact is greater than intent. Future work should aim to connect methods of quantitative analysis to the FAIICES findings to better understand how the varying indicators relate to CUP outcomes and the qualitative measures used in this approach.

Additionally, our findings show that the project-based component and relationshipbased component of the CUPs should be assessed separately but considered collectively. This is not often done in research on sustainability and resilience collaborations, as most research either focuses solely on project outcomes or solely on the collaboration itself (Ferraris, Santoro, \& Papa, 2018; Wilson et al., 2014). With the FAIICES evaluation scheme, the relationship between these two domains is better understood, and can be used to make decisions that span across the domains. Future research should apply the FAIICES framework with an eye towards understanding the dynamics between the two domains, and how their interplay impacts CUP functioning and outcomes over time. 
One of the biggest value-propositions that is generated by using the FAIICES tool is the ability to both collect data for immediate and longitudinal studies of CUPs while also immediately integrating findings into the CUP development, management, and implementation process. Historically, implementers have tended towards summative evaluation, which entails analysis of results compared to goals at the end of an intervention process used to make a judgement regarding efficacy (Faehnle \& Tyrväinen, 2013; Taras, 2005). Unfortunately, summative assessments often go uncompleted, or they occur after an intervention has ceased, so results cannot be directly integrated into implementation (Guyadeen \& Seasons, 2018). This is in direct contrast to the formative evaluation strategies that have been suggested by the sustainability and resilience transition management literature. It is suggested that complex work should be constantly re-evaluated and re-adjusted (adaptively managed) an iterative way that supports agile decision-making and learning (Luederitz, Schäpke, et al., 2017; Plummer \& Armitage, 2007). Our findings from this study confirm these results.

Finally, while this tool was developed specifically for city-university partnerships that are working on complex urban sustainability and resilience topics, it is possible that it can be useful for a much broader context. The FAIICES tool itself does not ask any resilience or sustainability-related questions; it also is not specific to the constraints of municipal governments or research universities. The metrics are focused on co-management, institutional alignment, and process in such a way that they are likely applicable to a wide range of collaborative efforts, especially those working on exceedingly complex or 
transformative issues. Further work is needed to understand how FAIICES might be applicable to these varying contexts.

\section{Works Cited}

Acuto, M., Parnell, S., \& Seto, K. C. (2018, January 1). Building a global urban science. Nature Sustainability. Nature Publishing Group. https://doi.org/10.1038/s41893-0170013-9

Brown, L. D., Feinberg, M. E., \& Greenberg, M. T. (2012). Measuring Coalition Functioning: Refining Constructs Through Factor Analysis. Health Education \& Behavior, 39(4), 486-497. https://doi.org/10.1177/1090198111419655

Butcher, J., Bezzina, M., \& Moran, W. (2011). Transformational Partnerships: A New Agenda for Higher Education. Innovative Higher Education, 36(1), 29-40. https://doi.org/10.1007/s10755-010-9155-7

C40. (2020). Retrieved January 29, 2020, from https://www.c40.org/why_cities

Caughman, L. E. (n.d.). From theory to practice: Urban resilience partnerships and collaborations. In Prep.

Caughman, L. E. (2017). TRIBAL COLLEGE STUDENT PERSPECTIVES: SUSTAINABILITY EDUCATION CURRICULUM IN STEM. 
Faehnle, M., \& Tyrväinen, L. (2013). A framework for evaluating and designing collaborative planning. Land Use Policy, 34, 332-341. https://doi.org/10.1016/j.landusepol.2013.04.006

Ferraris, A., Santoro, G., \& Papa, A. (2018). The cities of the future: Hybrid alliances for open innovation projects. Futures, 51-60. https://doi.org/10.1016/J.FUTURES.2018.03.012

Greenwald, H. P., \& Zukoski, A. P. (2018). Assessing Collaboration. American Journal of Evaluation, 39(3), 322-335. https://doi.org/10.1177/1098214017743813

Guyadeen, D., \& Seasons, M. (2018). Evaluation Theory and Practice: Comparing Program Evaluation and Evaluation in Planning. Journal of Planning Education and Research, 38(1), 98-110. https://doi.org/10.1177/0739456X16675930

Keeler, L. W., Beaudoin, F., Wiek, A., John, B., Lerner, A. M., Beecroft, R., ... Forrest, N. (2019). Building actor-centric transformative capacity through city-university partnerships. Ambio, 48(5), 529-538. https://doi.org/10.1007/s13280-018-1117-9

Kitzinger, J. (1995). Qualitative research. Introducing focus groups. BMJ (Clinical Research Ed.), 311(7000), 299-302. https://doi.org/10.1136/bmj.311.7000.299

Kula-Semos, M. (2009). Seeking transformative partnerships: schools, university and the practicum in Papua New Guinea. Retrieved from https://researchonline.jcu.edu.au/15463/ 
Lang, D. J., Arnim Wiek, B., Matthias Bergmann, B., Michael Stauffacher, B., Pim Martens, B., Peter Moll, B., ... Christopher Thomas, B. J. (n.d.). Transdisciplinary research in sustainability science: practice, principles, and challenges. https://doi.org/10.1007/s11625-011-0149-X

Loorbach, D. (2010). Transition Management for Sustainable Development: A Prescriptive, Complexity-Based Governance Frameworkg ove_1471 161..184. Retrieved from www.senternovem.nl/energytransition

Lozano, R. (2007). Collaboration as a pathway for sustainability. Sustainable Development, 15(6), 370-381. https://doi.org/10.1002/sd.322

Luederitz, C., Sch, N., Wiek, A., Lang, D. J., Bergmann, M., Bos, J. J., ... Westley, F. R. (2017). Learning through evaluation e A tentative evaluative scheme for sustainability transition experiments. Journal of Cleaner Production, 169, 61-76. https://doi.org/10.1016/j.jclepro.2016.09.005

Luederitz, C., Schäpke, N., Wiek, A., Lang, D. J., Bergmann, M., Bos, J. J., ... Westley, F. R. (2017). Learning through evaluation - A tentative evaluative scheme for sustainability transition experiments. Journal of Cleaner Production, 169, 61-76. https://doi.org/10.1016/J.JCLEPRO.2016.09.005 
Marek, L. I., Brock, D.-J. P., \& Savla, J. (2015). Evaluating Collaboration for Effectiveness. American Journal of Evaluation, 36(1), 67-85. https://doi.org/10.1177/1098214014531068

Margerum, R. D. (n.d.). A Typology of Collaboration Efforts in Environmental Management. https://doi.org/10.1007/s00267-008-9067-9

Massey, A. P., \& Wallace, W. A. (1991). Focus groups as a knowledge elicitation technique: an exploratory study. IEEE Transactions on Knowledge and Data Engineering, 3(2), 193-200. https://doi.org/10.1109/69.87999

Nauslar, N., Abatzoglou, J., \& Marsh, P. (2018). The 2017 North Bay and Southern California Fires: A Case Study. Fire, 1(1), 18. https://doi.org/10.3390/fire1010018

Nolan, R. H., Boer, M. M., Collins, L., Resco de Dios, V., Clarke, H., Jenkins, M., ... Bradstock, R. A. (2020). Causes and consequences of eastern Australia's 2019-20 season of mega-fires. Global Change Biology. Blackwell Publishing Ltd. https://doi.org/10.1111/gcb.14987

Olsson, P., Galaz, V., \& Boonstra, W. J. (2014). Sustainability transformations a resilience perspective. Source: Ecology and Society, 19(4). https://doi.org/10.5751/ES-06799190401 
Plummer, R., \& Armitage, D. (2007). A resilience-based framework for evaluating adaptive co-management: Linking ecology, economics and society in a complex world. Ecological Economics, 61(1), 62-74. https://doi.org/10.1016/J.ECOLECON.2006.09.025

Polk, M. (2015). Transdisciplinary co-production: Designing and testing a transdisciplinary research framework for societal problem solving. Futures. https://doi.org/10.1016/j.futures.2014.11.001

Ramaswami, A., Bettencourt, L., Clarens, A., Das, S., Fitzgerald, G., Irwin, E., ... Tabory, S. (2018). Sustainable Urban Systems: Articulating a Long-Term Convergence Research Agenda.

Reed, M. S., Fraser, E. D. G., \& Dougill, A. J. (2006). An adaptive learning process for developing and applying sustainability indicators with local communities. Ecological Economics, 59(4), 406-418. https://doi.org/10.1016/J.ECOLECON.2005.11.008

Rodríguez-Campos, L. (2012). Advances in collaborative evaluation. Evaluation and

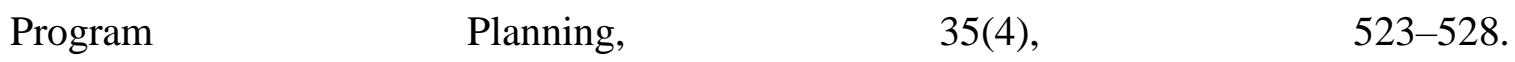
https://doi.org/10.1016/J.EVALPROGPLAN.2011.12.006

Salimova, T., Vatolkina, N., \& Makolov, V. (2014). Strategic partnership: Potential for ensuring the university sustainable development. Quality Innovation Prosperity, 18(1), 107-124. https://doi.org/10.12776/QIP.V18I1.320 
Seitanidi, M. M., \& Koufopoulos, D. N. (2010). Partnership Formation for Change: Indicators for Transformative Potential in Cross Sector Social Partnerships View project. Article in Journal of Business Ethics. https://doi.org/10.1007/s10551-011-0784-2

Simmons, V. N., Klasko, L. B., Fleming, K., Koskan, A. M., Jackson, N. T., Noel-Thomas, S., ... Tampa Bay Community Cancer Network Community Partners, T. B. C. C. N. C. (2015). Participatory evaluation of a community-academic partnership to inform capacitybuilding and sustainability. Evaluation and Program Planning, 52, 19-26. https://doi.org/10.1016/j.evalprogplan.2015.03.005

Sustainable Development Goals .. Sustainable Development Knowledge Platform. (n.d.). Retrieved November 14, 2019, from https://sustainabledevelopment.un.org/?menu=1300

Swartz, A. L., \& Triscari, J. S. (2011). A Model of Transformative Collaboration. Adult Education Quarterly, 61(4), 324-340. https://doi.org/10.1177/0741713610392761

Taras, M. (2005). Assessment - Summative and formative - Some theoretical reflections. British Journal of Educational Studies, 53(4), 466-478. https://doi.org/10.1111/j.14678527.2005.00307.x

Teitel, L. (2012). Childhood Education School/Uníversíty Collaboratíon: The Power of Transformative Partnerships. https://doi.org/10.1080/00094056.2009.10523067 
Tremblay, M. C., Hevner, A. R., \& Berndt, D. J. (2010). The Use of Focus Groups in Design Science Research (pp. 121-143). Springer, Boston, MA. https://doi.org/10.1007/978-1-4419-5653-8_10

Trencher, G., Bai, X., Evans, J., McCormick, K., \& Yarime, M. (2014). University partnerships for co-designing and co-producing urban sustainability. Global Environmental Change, $\quad 28, \quad 153-165$. https://doi.org/10.1016/J.GLOENVCHA.2014.06.009

Trencher, G. P., Yarime, M., \& Kharrazi, A. (2013). Co-creating sustainability: crosssector university collaborations for driving sustainable urban transformations. Journal of Cleaner Production, 50, 40-55. https://doi.org/10.1016/j.jclepro.2012.11.047

Warren, J. D., \& D., J. (2018). The North Carolina Policy Collaboratory: a Novel and Transformative Partnership for Decision-Relevant Science. American Geophysical Union, Fall Meeting 2018, Abstract \#PA43A-08. Retrieved from http://adsabs.harvard.edu/abs/2018AGUFMPA43A..08W

Whitmore, E. E. (1998). Understanding and Practicing Participatory Evaluation. New Directions for Evaluation. Retrieved from https://eric.ed.gov/?id=EJ580835

Who's in the Network - EPIC-N. (n.d.). Retrieved February 13, 2020, from https://www.epicn.org/whos-in-the-network/ 
Will Australia's forests bounce back after devastating fires? | Science News. (n.d.). Retrieved February 13, 2020, from https://www.sciencenews.org/article/australia-forestecosystem-bounce-back-after-devastating-fires

Wilson, S., Campbell, D., Dalemarre, L., Fraser-Rahim, H., Williams, E., Wilson, S., ... Williams, E. (2014). A Critical Review of an Authentic and Transformative Environmental Justice and Health Community — University Partnership. International Journal of Environmental Research and Public Health, 11(12), 12817-12834. https://doi.org/10.3390/ijerph111212817

Withycombe Keeler, L., Beaudoin, F., \& Caughman, L. E. (n.d.). Transformative Parterships for Sustainability. In Prep.

Withycombe Keeler, L., Beaudoin, F., Lerner, A., John, B., Beecroft, R., Tamm, K., ... Lang, D. (2018). Transferring Sustainability Solutions across Contexts through CityUniversity Partnerships. Sustainability, 10(9), 2966. https://doi.org/10.3390/su10092966

Withycombe Keeler, L., Wiek, A., Lang, D. J., Yokohari, M., van Breda, J., Olsson, L., ... Evans, J. (2016). Utilizing international networks for accelerating research and learning in transformational sustainability science. Sustainability Science, 11(5), 749-762. https://doi.org/10.1007/s11625-016-0364-6

Wolfram, M., Borgström, S., \& Farrelly, M. (2019). Urban transformative capacity: From concept to practice. Ambio, 48(5), 437-448. https://doi.org/10.1007/s13280-019-01169-y 
Woodland, R. H., \& Hutton, M. S. (2012). Evaluating Organizational Collaborations. American Journal of Evaluation, 33(3), 366-383. https://doi.org/10.1177/1098214012440028 
Chapter 4: From Pragmatic Projects to Reflective Relationships: Evolving Dynamics in City-University Partnerships

Liliana Caughman ${ }^{1,3^{*}}$, Lauren Withycombe Keeler ${ }^{2}$, Fletcher Beaudoin ${ }^{1}$, Amy M. Lerner $^{4}$, Beatrice John ${ }^{5}$, Abril Cid ${ }^{4}$, Richard Beecroft ${ }^{6}$, Kaidi Tamm ${ }^{6}$, Philip Bernert ${ }^{5}$

\footnotetext{
${ }^{1}$ Institute for Sustainable Solutions, Portland State University

${ }^{2}$ School for the Future of Innovation in Society, Arizona State University

${ }^{3}$ College of Liberal Arts and Sciences, Portland State University

${ }^{4}$ National Autonomous University of Mexico

${ }^{5}$ Leuphana University

${ }^{6}$ Karlsruhe Institute of Technology
}

\section{Abstract}

Cities across the globe are striving to produce viable solutions to pressing urban sustainability and resilience problems. Unfortunately, municipal governments often have insufficient knowledge, capacity, or resources to do it all by themselves. Partnerships between cities and universities have emerged as one mechanism for achieving sustained progress on complex goals. At their best, city-university partnerships (CUPs) can develop strategic actions and interventions that build transformative capacity and support urban transitions; but these outcomes are not always achieved. As CUPs grow in numbers, there is a pressing need to identify their underlying principles and practices, as well as the dynamics between CUP structure and outcomes. Therefore, we studied five cityuniversity pairs across three countries that are co-creating sustainability and resilience 
initiatives. A real-time evaluation technique was used to closely monitor progress, interventions, and impacts. Our work reveals that CUPs thrive when they are more than a series of one-off projects, and instead are intentionally formed with long-term collaboration in mind. This culminates in the development of a new framework for understanding CUP dynamics, based on the positive feedback system of the projectpartnership cycle.

Introduction

Cities are faced with urgent sustainability and resilience challenges, including the need to adapt to climate change while reducing carbon emissions and building resilient infrastructure and sustainable communities. The complex challenges posed by climate change do not confine themselves to the structures of city administrations or the cadence of planning processes; they require action outside the normal operations of city governments. City governments are designed to be stable and consistent entities, which can often serve residents well, but in the context of a rapidly changing world, cities can find it difficult to adapt. At the institutional level, cities have varying capacity to identify these resilience and sustainability challenges and develop solutions commensurate with and capable of addressing them.

Solving these complex problems requires transformative change. Transformative change, or change that completely disrupts the structures, cultures, 
and practices that have contributed to and inhibit progress on sustainability and resilience problems is incredibly difficult to achieve (Olsson, Galaz, \& Boonstra, 2014a). In the urban context, institutions across scales must have the transformative capacity necessary to facilitate such changes. Transformative capacity can be understood as a collection of competencies, resources, and processes that aid transformations (Wolfram et al., 2019). Unfortunately, due to being entrenched in the systems that need to be changed, and the enormousness of the tasks, cities face major barriers to developing transformative capacity or solutions to complex problems on their own.

Recently, more attention is being given to the role of the university in urban transformations and transformative capacity-building, noting their importance as intermediaries for boundary-spanning collaboration (Wolfram et al., 2019). Universities can be strong partners for cities to build the knowledge and skills necessary to devise, test, and implement resilience and sustainability solutions. City-university partnerships (CUPs) oriented toward transformative capacity building: (i) impart knowledge and skills to city administrations; (ii) provide enthusiasm for resilience and sustainability solutions; and (iii) create new organizational infrastructure that can help cities overcome the structural limitations that impede comprehensively addressing these complex challenges (Keeler et al., 2019b; Wolfram et al., 2019). A CUP focused on capacity-building can play a critical role in transformative change - facilitating the development of the skills and knowledge that accelerates urban transitions via co-creation of practical and novel knowledge, and co-management of the design and implementation of interventions. 
As CUPs are gaining traction across the globe, numerous studies have emerged exploring individual CUP processes and outcomes. Case studies highlight several common challenges that CUPS face including lack of trust and understanding between city and university partners (Buys, 2016), inconsistent production of usable and useful outcomes for society (Trencher et al. 2017), and varying levels of the confidence, competence, commitment and power needed to build transformative capacity (Keeler et. al, 2018). Despite a growing body of research, an underlying logic of how CUPS serve as drivers of urban transformation, and thus how they should be managed for impact, remains poorly understood.

As the number of CUPs continues to grow, there is a pressing need to identify the underlying principles and practices that permit CUPs to be drivers of urban transformation. Research has shown that key contextual factors exist across CUPs that, when understood, provide guidance for the transfer of information between CUPs with different cultures, geographies, and demographics (Keeler et. al, 2018). These findings indicate that it is possible to understand CUPs at a deeper level, and distill their fundamental properties. In this article, we use a real-time evaluation method (Caughman et al, 2020) to monitor and adaptively manage five international CUP initiatives that are advancing transformative urban sustainability and resilience outcomes. The real-time evaluation is a participatory formative assessment method for data collection and analysis that facilitates learning, intervention design, and capacity building; meeting dual goals of studying the CUPs and managing them for impact. The results of one year of real-time evaluation data were compiled and used to develop and cross-compare five case-studies. 
Therefore, our research aims to answer the following question: What functional dynamics exist to describe why some CUPs become high-functioning and transformative, while others remain unimpactful or disintegrate? And, how can CUPs be appropriately designed and managed for transformative capacity building and impact?

In analyzing the CUPs and dissecting their distinct journeys, we derive a framework for understanding CUP dynamics and properties that are widely applicable to urban sustainability and resilience transformation. We demonstrate how the framework facilitated effective CUP management and how it supports transformative capacity building across several institutional and cultural contexts. Finally, we use insights from the framework to provide recommendations for other universities and cities interested in establishing such partnerships for urban sustainability and resilience transformation.

Methods

This paper inductively analyzes five sustainability and/or resilience-oriented cityuniversity partnerships (CUPs) in three countries. The five case studies are part of the CapaCities project, a network of CUPs funded by the Global Consortium for Sustainability Outcomes (GCSO) to (i) build capacity for transformational sustainability and resilience action in city administrations; and, (ii) transfer and scale insights across different cities and universities.

To analyze the CUPs, the CapaCities project team used assessment data collected throughout a full project cycle. The evaluation methodology followed the Foundation, Impacts, Action - Interpersonal Context and Empowering Supports (FAI-ICES) real-time 
evaluation framework developed by Caughman et. al (2020) that was specifically designed for the monitoring, evaluation, and adaptive management of sustainability and resilience focused transformative partnerships initiatives. Evaluation was conducted iteratively over the course of a year and consisted of consultative interviews, surveys, and site visits. Results of evaluation were compiled at three intervals and used for analysis, learning, and adjustment of CUP management.

The data generated from the real-time evaluation process was synthesized into results for each of the five case study sites and collaboratively cross-analyzed in three focus group sessions. The focus groups were held at two midpoints and an endpoint of the multi-site collaboration. At each session, researchers presented their findings from the analysis of each CUP, along with relevant contextual and site-specific information. Input from participants followed the framework developed by Keeler and colleagues (2016) and included a presentation and accompanying diagrams (timelines and scorecards) to facilitate synthesis and comparability of insights (figure 1) (Keeler et al., 2016). 


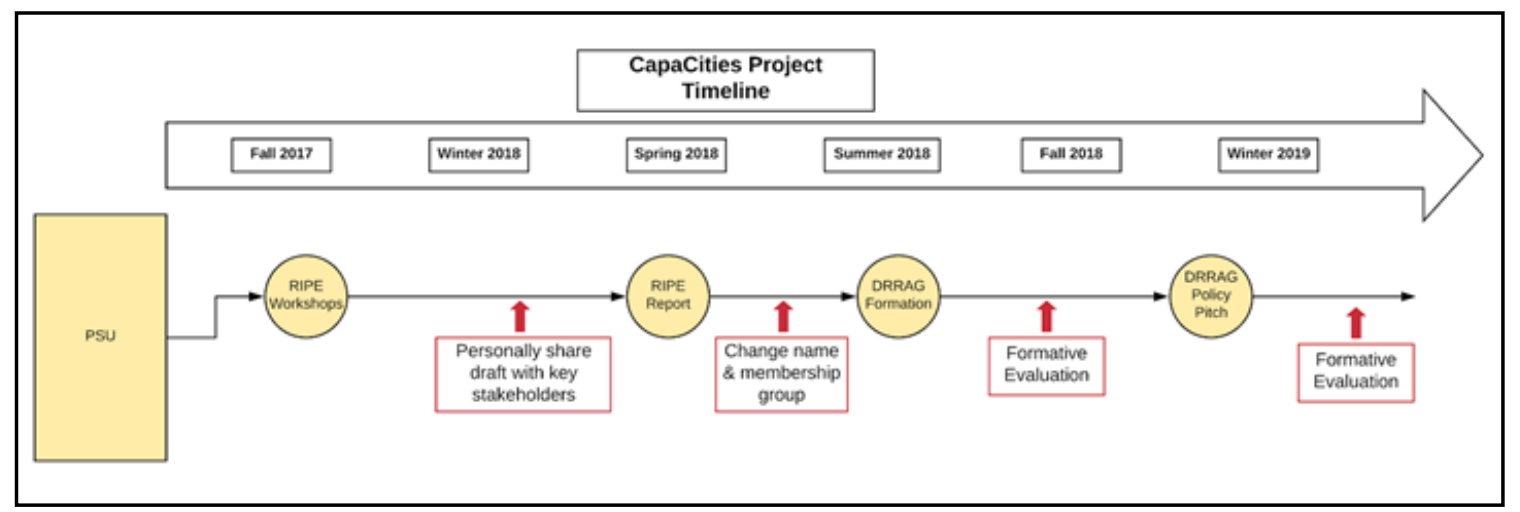

Partnership Diagnosis:

\section{Current}

S.tructures that empower

C.ollaborative history

R.esources committed

I.nterest to engage

M.otivation to engage

M.utual understanding of need

Overall SCRIMM Score
Previous

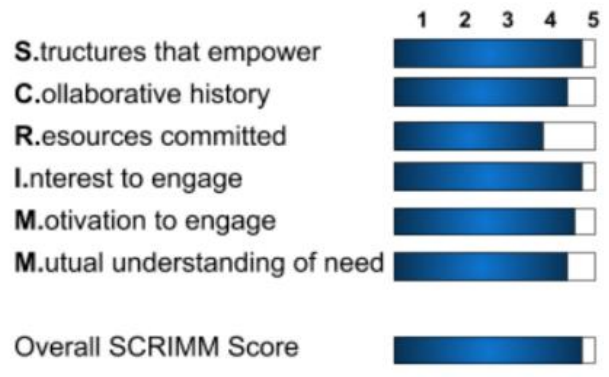

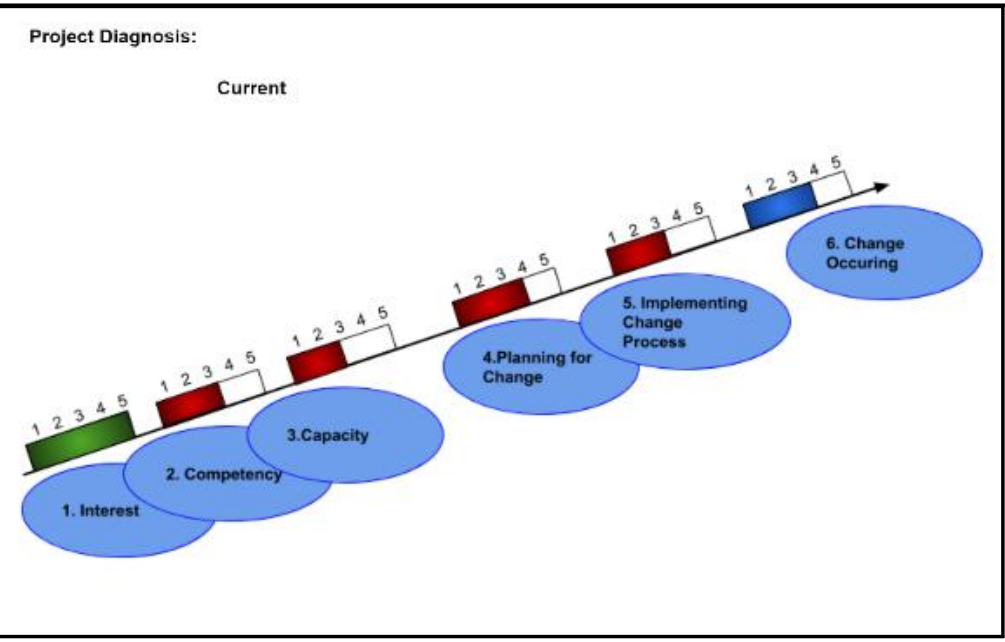

Figure 10. a) Example case study timeline; $b$ \& c) example case study "scorecards" where red indicates a decrease in the score, green indicates an increase in the score, and blue indicates no change. 
Five case studies of transformative sustainability and resilience CUPs are described below. In each focus group session, each university partner was asked to reflect on the results of the real-time evaluation, give a summary of the actors involved in the project, the project goals, project process, their concept of capacity building, and the broader context for their work (e.g., cultural, political, and geographic factors). Additionally, all participants were asked to reflect on the usefulness of the evaluation tool and to describe its impact on adaptive project management, collective learning, and knowledge transfer. Each partnership was focused on its own sustainability and/or resilience problem and developed a capacity-building solution, several of which included stakeholder engagement workshops. Table 1 summarizes each CUP involved in the GCSO collaboration and the embedded sustainability and resilience capacity-building research and action that was undertaken in the CapaCities collaboration.

\begin{tabular}{|l|l|l|}
\hline $\begin{array}{c}\text { City University } \\
\text { Partnership }\end{array}$ & \multicolumn{1}{|c|}{ Actors } & \multicolumn{1}{c|}{ Goals } \\
\hline $\begin{array}{l}\text { Arizona State } \\
\text { City of Tempe }\end{array}$ & $\begin{array}{l}\text { City of Tempe } \\
\text { administration, senior } \\
\text { department heads from all } \\
\text { departments, sustainability } \\
\text { manager, ASU researchers, } \\
\text { professors, and graduate } \\
\text { students }\end{array}$ & $\bullet \quad \begin{array}{l}\text { Increase sustainability literacy among senior } \\
\text { city officials. }\end{array}$ \\
Increase sustainability competence among \\
senior city officials.
\end{tabular}




\begin{tabular}{|c|c|c|}
\hline $\begin{array}{l}\text { Karlsruhe } \\
\text { Institute of } \\
\text { Technology - } \\
\text { City of } \\
\text { Karlsruhe }\end{array}$ & $\begin{array}{l}\text { Four city bureaus of } \\
\text { Karlsruhe, the Consortium } \\
\text { for Sustainability Outcomes } \\
\text { (CSO), KIT students and } \\
\text { three units of KIT,one } \\
\text { masters student as } \\
\text { accompanying research. }\end{array}$ & $\begin{array}{l}\text { - Support inter-bureau discourse on } \\
\text { sustainability and cooperation with external } \\
\text { partners. } \\
\text { - } \quad \text { Foster a broader understanding of } \\
\text { sustainability. } \\
\text { Make sustainability more visible in the KIT } \\
\text { and the City of Karlsruhe. } \\
\text { Contribute to long-term cooperation city- } \\
\text { KIT. }\end{array}$ \\
\hline $\begin{array}{l}\text { Leuphana } \\
\text { University - } \\
\text { City of } \\
\text { Lüneburg }\end{array}$ & $\begin{array}{l}\text { City Sustainability Manager; } \\
\text { individuals from four city } \\
\text { departments; a variety of } \\
\text { local actors (businesses, } \\
\text { community groups, } \\
\text { associations), local press; } \\
\text { university researchers }\end{array}$ & $\begin{array}{l}\text { City-wide visioning exercise for the year } \\
\text { 2030, facilitating conversations on the local } \\
\text { interpretation of Sustainable Development } \\
\text { Goals. } \\
\text { Cross-departmental conversation on } \\
\text { feasibility and adaptability of good practices. }\end{array}$ \\
\hline $\begin{array}{l}\text { National } \\
\text { Autonomous } \\
\text { University of } \\
\text { Mexico - } \\
\text { Mexico City }\end{array}$ & $\begin{array}{l}\text { Resilience Agency (new } \\
\text { official govt. office) in the } \\
\text { Environment Secretariat of } \\
\text { Mexico City; others at local } \\
\text { (borough) scale and across } \\
\text { other sectors of the city; } \\
\text { NGOs; researchers and } \\
\text { professors from UNAM }\end{array}$ & $\begin{array}{l}\text { - Assisting in capacity-building in themes } \\
\text { related to resilience for a greater } \\
\text { implementation of the Resilience Strategy of } \\
\text { Mexico City, with a focus in one case-study } \\
\text { where there is a planning process occurring } \\
\text { for better management of the area } \\
\text { (Xochimilco). } \\
\text { Capacity-building includes system, futures, } \\
\text { \& collaborative thinking. } \\
\text { Assisting the creation \& implementation of a } \\
\text { Reconstruction Plan after the September } 19 \\
\text { earthquake in the local case-study }\end{array}$ \\
\hline $\begin{array}{l}\text { Portland State } \\
\text { University - } \\
\text { City of Portland }\end{array}$ & $\begin{array}{l}\text { Four different bureaus } \\
\text { working on asset } \\
\text { management within the city. } \\
\sim 6 \text { other bureaus that support } \\
\text { asset management activities } \\
\text { and coordination; Institute } \\
\text { for Sustainable Solutions; } \\
\text { graduate students }\end{array}$ & $\begin{array}{l}\text { - Increasing inter-bureau } \\
\text { conversations/understanding related to asset } \\
\text { interdependencies under climate change and } \\
\text { seismic scenarios. } \\
\text { Empowering and activating individuals } \\
\text { within those bureaus to collaborate together } \\
\text { on cross-bureau planning and investments. }\end{array}$ \\
\hline
\end{tabular}

Table 7. Shows each CUP, the actors involved, and the stated goals.

\section{Case Studies}

Implementing the real-time evaluation tool allowed for a deep and longitudinal analysis of each CUP, capturing key decisions, obstacles, learning, and changes over 
time. A brief description of CUP goals, context, and progress is described for each CUP case study. Then a cross-cutting comparative analysis is undertaken to highlight key takeaways that expose the functioning and dynamics of transformative capacity-building CUPs across context.

National Autonomous University of Mexico (UNAM) and Mexico City, Mexico

The National Laboratory for Sustainability Science (LANCIS-IE), in the Ecology Institute at UNAM engaged in two years of active collaboration with the Mexico City Resilience Agency. The goal of the partnership was to conduct transdisciplinary research and facilitate sustainability education to link science and decision-making, supporting sustainability transitions in the country. Over two years the partners held several meetings, interviews, and presentations, as well as six participatory workshops. Other actors engaged in these interactions came from academia, city level and municipal governments, NGOs, the private sector, and the agricultural sector. Among the main products of these engagements were data sources, databases, references to other actors, conceptual and empirical baselines for indicators and indexes for integrated assessment models (i.e. multicriteria decision analysis), and validation of results. The policy-relevant outcomes of these engagements were two specific collaboration agreements between LANCIS-IEUNAM and the Mexico City Government. The purpose of those agreements was to: (a) build technical capacities in the city government agencies regarding sustainability (specifically the implementation of the Resilience Strategy of Mexico City); (b) provide analytical approaches and tools to evaluate the sustainability, vulnerability and adaptation 
of social-ecological systems, particularly urban and peri-urban areas and marginalized and poor communities; (c) compile and integrate databases of biophysical and socioinstitutional variables of Mexico City, through data acquisition, processing and integration mechanisms; and (d) reinforce collaborative governance mechanisms through technologies that enable the access to information by citizens.

In the beginning, participatory events were either focused on building capacities related to resilience and risk management (through game-based workshops) or addressing the consequences of the earthquake of September 19th, 2017. One of the main outcomes of these interactions were the two collaborative agreements between LANCIS-IE-UNAM and the Mexico City Resilience Agency to assist them in writing and implementing the Resilience Strategy for Mexico City, which directed subsequent work. Interactions were mainly part of the project called "A Socio-ecological Vulnerability Analysis of the World Heritage Site of Xochimilco, Milpa Alta and Tlahuac". Most of these interactions included information sharing and consultation, and consisted of presentations with government officials, interviews with key actors to elicit databases, and participatory workshops to generate the vulnerability models and indicators. It is worth noting that the smaller, less established collaboration interactions triggered deeper and more integrated interactions over time, either by means of workshops to communicate research and intervention or by specific collaboration agreements, that provided resources and formalized collaboration among actors.

The final reports for the formal agreements with the Resilience Agency were submitted at the same time as major political shifts in Mexico City. Simultaneously, the 
Mexico City government changed party and the Resilience Agency changed its administrative status and lost most of its staff. However, through real-time evaluation, these impending changes were recognized far before occurring, and specific strategies for overcoming the alterations were developed. Due to advanced planning and specific attention focused on the partnership, LANCIS-IE retained a relationship with the new staff of the Resilience Office and work is expected to continue into the future.

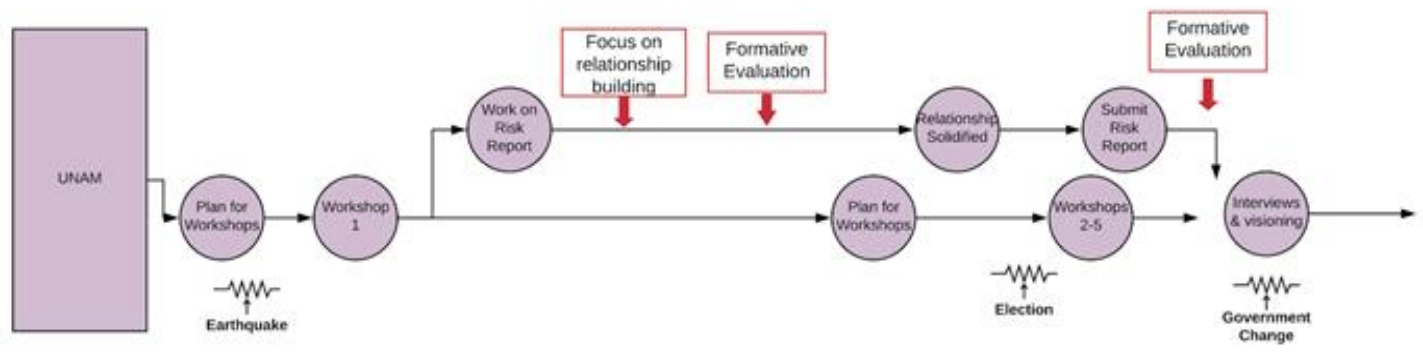

Figure 11. Overview of the UNAM/Mexico City CUP project timeline with key milestones and actions.

Leuphana University - City of Lüneburg

The city of Lüneburg and Leuphana University of Lüneburg (Faculty of Sustainability, Professorship for Transdisciplinary Sustainability Research, Lüneburg, Germany) engaged in a project to realize the UN Sustainable Development Goals on a local scale. Though the two institutions had worked collaboratively together many times in the past, this undertaking was the most comprehensive to date, and involved a variety of actors at the science-society interface, including the sustainability manager of the city, the environmental office, the planning department, representatives of the civil society, and the academic research team. The project aimed to address five core topics, namely (i) 
joint planning and decision making, (ii) facing climate change, (iii) joint economic collaboration, (iv) networking and provisioning, and (v) crafting city life.

In the first phase an initial visioning process was dedicated to developing a shared vision for the city for the year 2030 and beyond, engaging in a dialogue about the Sustainable Development Goals and their meaning for the city of Lüneburg. These findings were combined with research on international best-practices, culminating in the creation of Climate Adaptation Measures for Lüneburg. The second phase involved evaluation of the new Climate Adaptation Measures. Both phases utilized collaborative meetings, outreach events, research, workshops, surveys, and demonstrations.

Throughout the second phase of the project, difficulties arose between the city and university, especially when there seemed to be a lack of understanding and political support from the mayor, and staffing changes on all sides of the partnership. Application of the real-time formative evaluation tool helped CUP managers to see these challenges and create a plan for more vested relationship development, which in turn supported goal attainment. Assessment results indicated that the team needed to methodically shift to evaluate the Lüneburg partnership itself. This was achieved through the development and implementation of a participatory storyline-style interview approach that resulted in a better understanding of organizational components and skills of the group and informed what would shape a more productive partnership. Findings were integrated into the design of a gamified workshop that will be used to plan a stepwise procedure to institutionalize the partnership beyond the current project logic. 


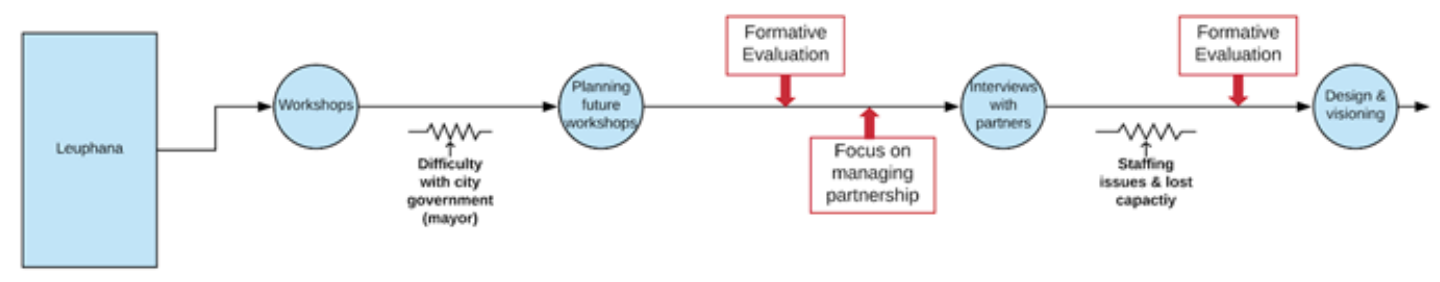

Figure 12. Overview of the Leuphana/Luneburg CUP project timeline with key milestones and actions.

Portland State University - City of Portland

The city of Portland has a long-standing commitment to sustainability, being the first US city to draft a climate action plan and the first to include an equity lens in climate action planning. Portland State University (PSU) also has a strong commitment to sustainability and has made sustainability a campus-wide learning outcome, with a goal of carbon neutrality by 2050. The City of Portland and PSU have a long history of collaboration on a wide range of topics, many which focus on sustainability and climate change. So, when the City of Portland realized they had a deficit in terms of infrastructure resilience planning, PSU was a natural partner. Together, PSU faculty, staff, and students associated with the Institute for Sustainable Solutions (ISS) worked with city staff from several bureaus to co-create a method for enhancing transformative capacity related to urban resilience. Through comprehensive pre-planning that included interviews, meetings, and analysis to understand city needs, the collaborative team developed and implemented two interactive extreme event scenario planning workshops. PSU convened the inter-departmental process and also provided staff and student time to enhance city capacity so that all departments came to the workshops having executed initial planning activities. PSU collaborated with city stakeholders to develop a synthesis 
report that was immediately used for advocacy and also as a work plan for a newly formed resiliency advisory group made up of key stakeholders from across the participating bureaus, and coordinated in partnership with PSU.

This new advisory group is convened by PSU and backed by university staff and numerous interns to support planning and implementation efforts. Real-time evaluation of the collaborative process showed the value of the university taking the time to listen to city needs, and attend to them; prioritizing relationship-building and tangible outcomes above academic publication. Additionally, the evaluation helped the team realize that in order to further the work the cross-bureau collaboration and knowledge sharing that occurred in the workshops would need to be both institutionalized within the city and bolstered by individual actors. Therefore, future work aims to continue the spirit of adhoc collaboration, while also aiming to produce policy to legitimize the work and funding to implement tangible projects. Additionally, this collaborative undertaking inspired the city and university to more intentionally formalize their relationship and they are beginning a process of identifying root-causes of sustainability and resilience problems that could be solved through deep partnership that transcends current organizational and operational structures. 


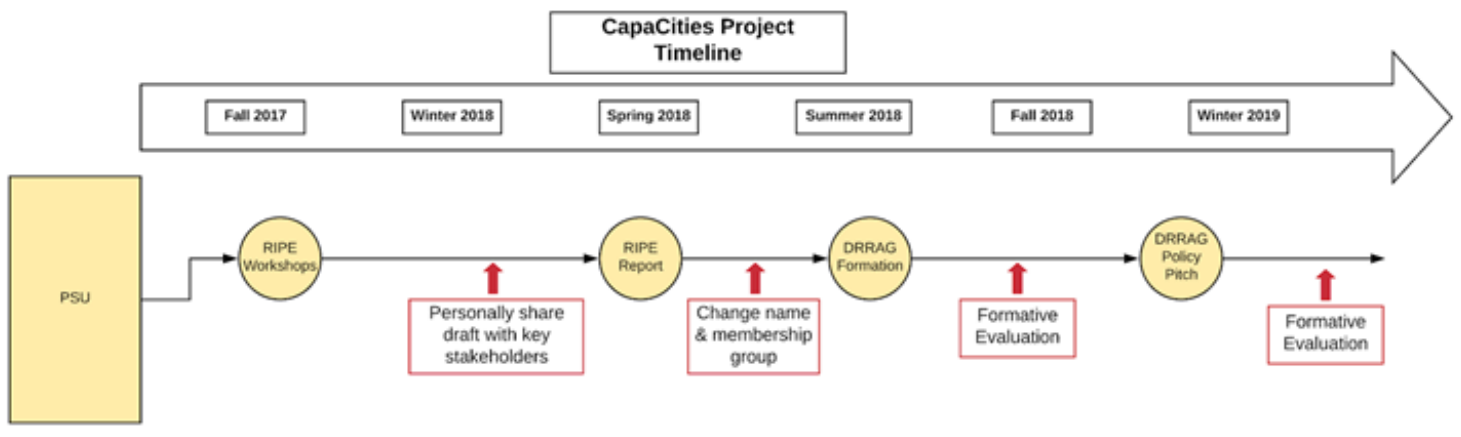

Figure 13. Overview of the PSU/Portland CUP project timeline with key milestones and actions.

Karlsruhe Institute of Technology and Karlsruhe, Germany

The Karlsruhe city government has developed an exemplary set of sustainability and climate protection documents and strategies and has a number of sustainability initiatives, for which it was voted the most sustainable city in Germany in 2015. However, implementation of existing strategies has remained the weak point. Across the municipality, the Karlsruhe Environmental Bureau is seen as the unit responsible for sustainability issues and the Karlsruhe Climate Protection and Energy Agency as the unit responsible for climate protection issues. The lack of co-responsibility for these issues across other municipal units as well as the lack of integrated understanding of sustainability actions beyond ecological aspects, and the quality of cooperation between bureaus and with further partners on sustainability and climate protection issues poses a significant roadblock to progress. Therefore, a partnership with the School of Sustainability at Karlsruhe Institute of Technology (KIT) was developed with the goal of building the capacity needed to mitigate these problems. The collaborative included work between KIT and several departments of city administration, with the Bureau of 
Environment and the Karlsruhe Energy and Climate Protection Agency (KEK) as the primary partners.

This project had two main phases. In the first phase, a city-wide sustainability walk was co-developed by researchers and partners to address abstract sustainability issues in a tangible, memorable way. This phase established a broad collective understanding of sustainability and strengthened cooperation between KIT and the city, but found limited success in supporting inter-bureau discourse. Therefore, phase two focused on the development of a culturally-specific serious gaming workshop that could be used to inspire cross-departmental collaborative planning.

University partners focused on developing and testing the workshop, but it soon became clear through real-time evaluation findings that the committed partnership needed to implement the workshops had deteriorated. Therefore, the university team began attempting to find an appropriate time and place to fit it into the city workflow. Several different departments and city teams took interest in the workshop, but each had their own changes they wanted to make, causing the university partners to constantly re-think the approach. During this time, staffing changes and inconsistencies on the university side of the partnership also slowed progress. As staffing regained consistency on the university side of the partnership, a useful framework for the workshop was developed and an appropriate time and place for the workshop to be utilized was scheduled. The newfound alignment of interests is likely an indicator of better collaboration in the future, if staffing consistency and commitment is achieved. 


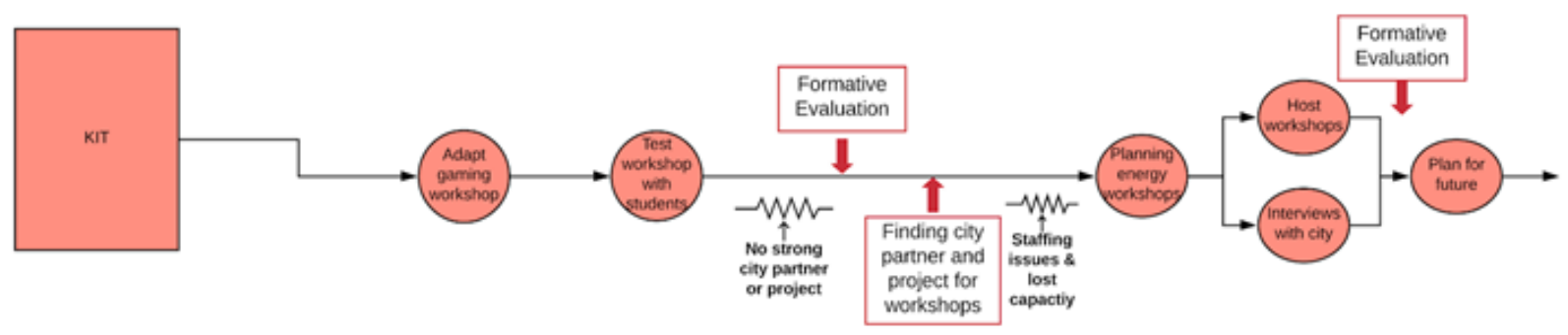

Figure 14.Overview of the KIT/Karlsruhe project timeline with key milestones and actions.

Arizona State University - Tempe, Arizona

Faculty from Arizona State University and the Sustainability Manager for the City of Tempe came together to create a mechanism to write the city's first ever Climate Action Plan and to grow the Sustainability Department. To do this, the partners conducted interviews with 41 city staff on potential actions for the climate action plan and the role of sustainability in the City of Tempe. From this, a report was produced with recommendations on how to structure the sustainability department at the City of Tempe.

Additionally, to support the development of the Climate Action Plan several engagements were co-developed and deployed, including: a stakeholder workshop on energy actions; a public forum on transportation actions; two expert forums on transportation actions; a scenario development workshop on the future of carbon neutrality in central Arizona; and a public forum on energy and resilience actions. Once the Climate Action Plan was created, the partners came together to conduct a public forum on all actions for the Climate Action Plan and even started to think ahead to future 
work with expert workshops on equity and energy efficiency programs and internal carbon pricing for Tempe's next iteration of climate action planning.

Collaboration between the ASU researchers and Tempe city staff proved to be consistent and productive throughout the entirety of the project timeline. However, formative evaluation revealed that the partnership between ASU and Tempe primarily existed between only one faculty member and one staff member. This highlighted that the partnership, although fruitful, was vulnerable to changes in staffing or political shifts. Therefore, the partners went beyond workshops alone, and used workshop planning as well as interviews with city staff to deepen relationships and widen the collaboration. Overall, the group felt that these efforts have helped propel the formalization and institutionalization of the CUP so that it will be durable for years to come.

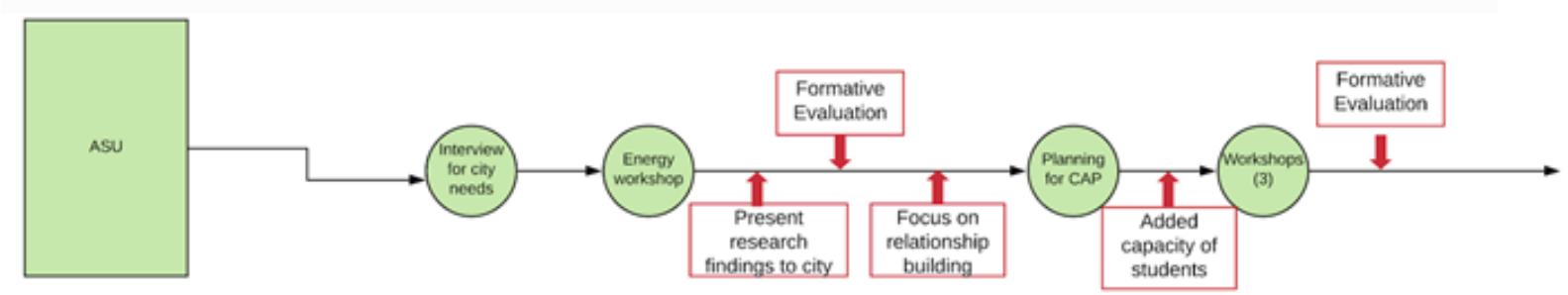

Figure 15. Overview of the ASU/Tempe CUP project timeline with key milestones and actions.

Findings and Discussion

CUPS and Transformative Capacity

This study monitored the ability of CUPs to take on increasingly complex problems and generate impactful solutions over time; these measures were used as a 
proxy for understanding changes to transformative capacity (as described in the FAIICES Real-time Evaluation (Caughman et al., 2020)). Findings from across the CapaCities case study sites indicate that CUPs themselves do not innately generate increased transformative capacity for sustainability and resilience transformations. However, results suggest that when the CUPs are functioning at a high level, transformative capacity seems to be improved, and when the CUPs are struggling, transformative capacity can stagnate, or even diminish.

Growth in transformative capacity can be best seen in the case of the PSU/Portland CUP. Here, successful collaboration in the planning, management, and implementation of resilience workshops led to the generation of a new co-managed working group aimed at making high level changes to governance systems and identifying and executing tangible city-wide resilience projects. Further, these CUP initiatives ignited the interest of city and university leadership, who are now working to explicitly define and build a path towards urban sustainability and resilience transformations that can be achieved through deeply integrated institutional partnership. Therefore, the ability of the CUP to tackle complex problems and produce impactful solutions is much greater now than it was at the conception of the CUP.

Stagnation or diminishment of transformative capacity was also noted. Unfortunately, in the case of the Leuphana/Luneburg CUP, the level of transformative capacity grew, waivered, and ultimately stagnated over time. In the beginning of the initiative, the perceived transformative capacity of the CUP was substantial, and the 
potential for increased transformative capacity was high. The institutions had a strong history of collaboration and shared goals for working together to envision the future of their community in the context of sustainable development goals. However, as the initiative concluded one phase and transitioned to the next, a lack of shared direction, evolving political context as well as leadership and staffing changes put a pause on shared CUP activities. This faltering of co-created CUP activities led to a diminishing ability of the CUP to take on complex problems and produce impactful solutions. However, the university team is exploring new ways to engage and partner with the city, and due to past successes, the overall transformative capacity is likely the same as it was at the conception of the CapaCities CUP.

\section{Understanding both the project and partnership side of each CUP}

Throughout the CapaCities project, CUP administrators routinely considered both project functioning and outcomes, as well as partnership stability and relationships. Interestingly, most of the CUP sites had never explicitly reflected on the state of their partnership in isolation from the state of their current project. Considering these two components individually, and then collectively, offered new insights to CUP managers, and significantly altered the trajectories of the CUPs. For example, the foundation of the ASU/Tempe CUP relied on only one city staff person and one university faculty member. Though they had an excellent history of collaboration and strong working relationship, real-time evaluation and cross-comparison between CUPs sites exposed their 
vulnerability to staffing changes or political whims. The CUP managers realized that they might be taking the stability of their partnership for granted, and that more specific attention needed to be paid to the growth and development of the partnership itself, despite generally successful project outcomes. The ASU/Tempe team realized that by expanding and ingraining the partnership further, they could undertake progressively more advanced and transformative project initiatives together, that would likely outlive the legacy of only two people. Through these, and several other similar observations, it became clear to all CapaCities members and the research team that project functioning impacts partnership development and partnership functioning impacts project outcomes.

\section{How projects impact partnerships}

Project functioning, defined by the interest, competencies, capacities, codevelopment, co-management, and ultimately, the outcomes from tangible projects showed to have immediate and lasting impact of the status and development of the partnership itself. This dynamic was seen across all five CUP case study sites; a selection of examples is shown in table 3. It was noted that when projects were functioning at high levels, there was a positive impact on the partnership; when projects were dysfunctional, the partnership was negatively affected.

\begin{tabular}{|l|l|l|}
\hline CUP Site & Project Functioning & Partnership Impact \\
\hline $\begin{array}{l}\text { Mexico City \& } \\
\text { UNAM }\end{array}$ & $\begin{array}{l}\text { Successful completion of project with } \\
\text { mutually expected outcomes }\end{array}$ & $\begin{array}{l}\text { Stronger collaborative history and interest } \\
\text { to engage solidified via formal written } \\
\text { agreement }\end{array}$ \\
\hline
\end{tabular}




\begin{tabular}{|l|l|l|}
\hline $\begin{array}{l}\text { Luneburg \& } \\
\text { Leuphana }\end{array}$ & $\begin{array}{l}\text { Project activities paused due to } \\
\text { personnel changes }\end{array}$ & $\begin{array}{l}\text { Desired reformatting of partnership } \\
\text { structure }\end{array}$ \\
\hline $\begin{array}{l}\text { Portland \& } \\
\text { PSU }\end{array}$ & $\begin{array}{l}\text { Co-management of the project } \\
\text { diminished as project focus shifted }\end{array}$ & $\begin{array}{l}\text { Less desire to contribute time and } \\
\text { resources }\end{array}$ \\
\hline $\begin{array}{l}\text { Karlsruhe \& } \\
\text { KIT }\end{array}$ & Project not being co-implemented & Reduced dedication towards partnership \\
\hline Tempe \& ASU & $\begin{array}{l}\text { Co-managed project produced } \\
\text { tangible and useful results }\end{array}$ & $\begin{array}{l}\text { Motivation to engage improved and } \\
\text { participation increased }\end{array}$ \\
\hline
\end{tabular}

Table 8. Chart showing how project functioning impacted the partnership across sites.

A clear example of project functioning impacting partnership can be seen via the work at KIT/Karlsruhe. In this case, there was an ill-defined project that was not being mutually managed or implemented. The university side of the CUP hoped to create workshops for use by the city, but created and tested their products within the university. Although well-intended, this one-sided implementation of the workshop made it difficult for the city partners to fully see themselves and their needs represented in the work. This led to a reduced level of motivation to continue partnering and less dedication to the partnership overall, from both city and university participants. Based on the findings from this study, the KIT/Karlsruhe partnership would be best served by the completion of a comanaged and jointly implemented project, to boost morale, and give the team a win.

How partnerships impact projects

In the previous section, results showed that successfully co-managed projects enhance feelings of partnership and failed joint-projects degrade feelings towards working together; surprisingly, we discovered that the status of the partnership itself also 
has a direct impact on project outcomes. Across all case studies, we found positive changes in partnerships functioning were seen to create positive outcomes for projects, just as dysfunction in the partnership resulted in negative project impacts. Examples of partnership functioning and their impacts on project outcomes are shown in the following table.

\begin{tabular}{|l|l|l|}
\hline CUP Site & Partnership Functioning & Project Impact \\
\hline $\begin{array}{l}\text { Mexico City } \\
\text { \& UNAM }\end{array}$ & $\begin{array}{l}\text { Partnership not solidified with } \\
\text { official documentation }\end{array}$ & $\begin{array}{l}\text { Increased uncertainty about ability to } \\
\text { tackle complex problems with extensive } \\
\text { projects in the future }\end{array}$ \\
\hline $\begin{array}{l}\text { Luneburg \& } \\
\text { Leuphana }\end{array}$ & $\begin{array}{l}\text { Strong collaborative history was } \\
\text { recognized and previous allies } \\
\text { convened }\end{array}$ & $\begin{array}{l}\text { Re-energized interest in project and } \\
\text { found place for project to be integrated } \\
\text { into city work }\end{array}$ \\
\hline $\begin{array}{l}\text { Portland \& } \\
\text { PSU }\end{array}$ & $\begin{array}{l}\text { Partnership roles and } \\
\text { responsibilities defined }\end{array}$ & Tangible project work-flows developed \\
\hline $\begin{array}{l}\text { Karlsruhe \& } \\
\text { KIT }\end{array}$ & $\begin{array}{l}\text { Lack of stable and consistent } \\
\text { partnership participants }\end{array}$ & Difficult to devise useful project \\
\hline $\begin{array}{l}\text { Tempe \& } \\
\text { ASU }\end{array}$ & $\begin{array}{l}\text { Motivation to engaged increased as } \\
\text { mutual understanding of need } \\
\text { improved }\end{array}$ & $\begin{array}{l}\text { More participation at workshops and } \\
\text { integration into city planning }\end{array}$ \\
\hline
\end{tabular}

Table 9. Chart showing how partnership functioning impacted the projects across sites.

Examining the Luneburg/Leuphana CUP shows this dynamic in action. At a certain point in the course of the study, the CUP began to stagnate and all involved were unsure of the path forward. However, by focusing on the previous strengths of the partnership and the strong collaborative history between the two institutions, partners from all sides were able to come together and consider future work. The team realized that the structure and configuration of their partnership needed to change to best suit their current context. Then, when the new form of the partnership was agreed upon, new 
opportunities for projects were quickly generated. All of the sites experienced times when the status of the partnership was either uncertain, or mis-matched with the goals of project, however, when focus shifted from managing the project to attending to partnership-related needs, the projects tended to naturally right themselves and improve.

\section{The Project-Partnership Cycle}

Taken together as a whole, our work reveals that city-university partnerships (CUPs) thrive when they are more than a series of one-off projects, and instead are intentionally formed with specific attention on the partnership itself and a shared vision of transformation. Our findings indicate that collaborative sustainability and resilience initiatives must equally prioritize partnership and project development (where historically projects dominate focus). This increased understanding prompts the development of a new framework for transformative CUPs, based on the observed positive feedback system of the project-partnership cycle (figure 16). The key assumption behind the model is that the strength of the partnership and the project are inseparable; both must be managed in tandem to have successful urban transformation outcomes and long-term viability. 


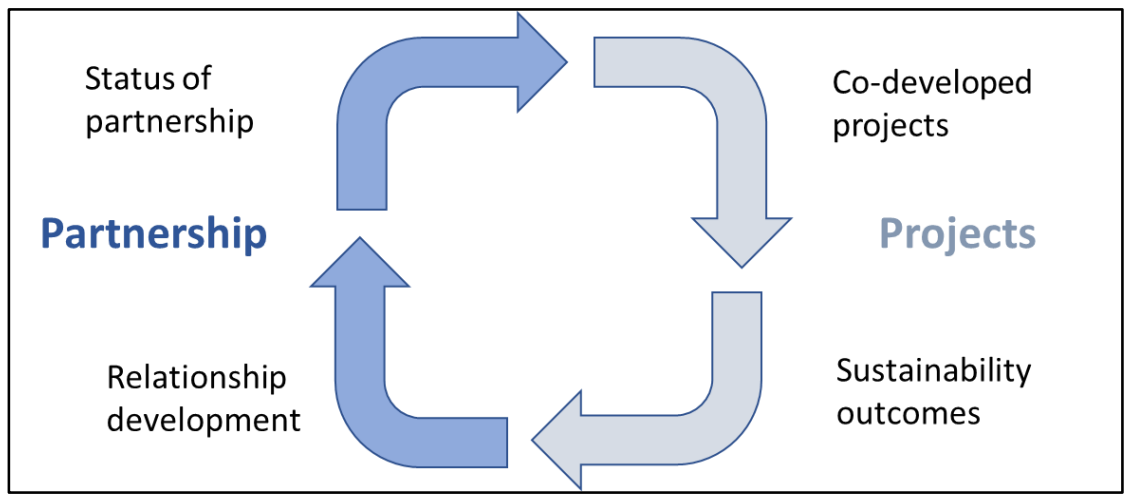

Figure 16. The partnership project cycle and positive feedback loop.

As shown in the figure, the partnership side and project side of a CUP deeply influence one-another. The status of the partnership (measure of motivation to partner, mutual understanding of needs, and level of partnership formalization) will influence the type and quality of projects (how well they are co-developed, co-managed, resourced, and implemented), which will subsequently determine project outcomes (goal attainment and real-world impact), and the nature of these project outcomes will reinforce the relationships between the individuals and institutions involved (developing them for better or for worse), which all leads to a new partnership status.

Further, as the cycle is repeated, the transformative capacity of the collective CUP evolves. Therefore, the project-partnership cycles itself progresses along a third axis, which indicates how the collective CUP is changing with respect to overall transformative capacity. When the cycle can be successfully completed, it moves in the positive direction, towards increased transformative capacity; when the cycle is broken, dysfunctional, or negatively reinforcing, it moves in the opposite direction indicating decreased transformative capacity (figure 17). 
a)

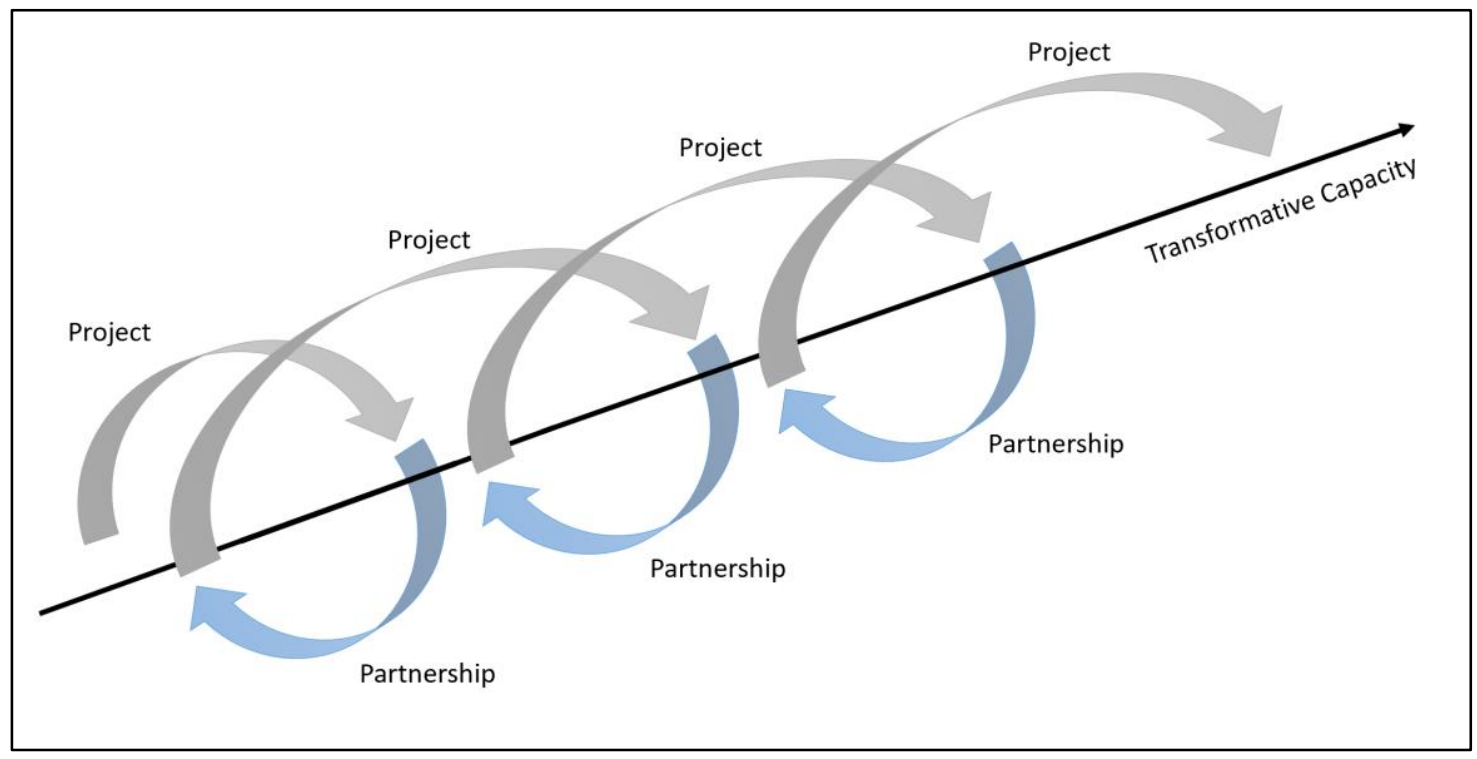

b)

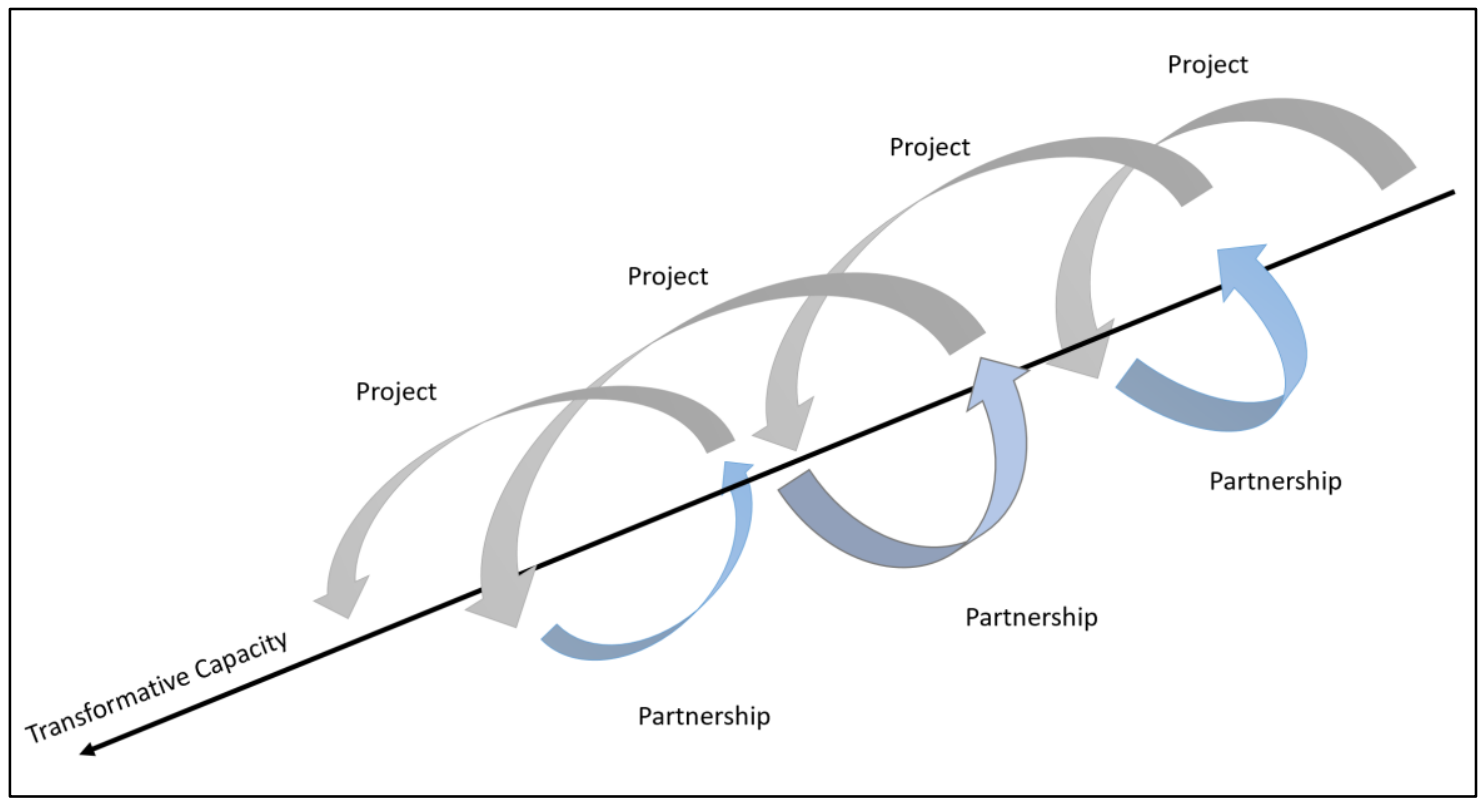

Figure 17. The project-partnership cycle spiraling towards changes in transformative capacity; a) Positive results from projects and partnerships reinforce each other and lead to positive gains in transformative capacity; b) Negative impacts from dysfunctional projects and partnerships reinforce each other and lead to negative change in transformative capacity. 
The reinforcing feedback loop formed by the project-partnership dynamics exists whether or not the CUP is being managed with attention paid to it; therefore it is suggested that real-time evaluation methods be utilized to best understand how the project-partnership cycle is unfolding for a given CUP so that intentional interventions can be applied and the functional dynamics can assist attainment of durable and impactful CUPs.

Project-Partnership Adaptive Management

Adaptative management of CUPs is enhanced when consideration of the projectpartnership cycle is combined with real-time evaluation techniques. Taken together, the partnership-process cycle and formative evaluation form a theoretical framework and operationalized tool for data collection, assessment, and management of transformative CUPS. This integrated approach allows researchers and CUP administrators to understand intricate details about each CUP, their specific socio-political contexts, and decisions made over the course of CUP activities. CUP managers can monitor movement across the project-partnership cycle and manage for impact. For the CapaCities project, each site had a unique experience, but the usefulness and applicability of the combined technique remained consistent and understanding the results in the context of the partnership-project cycle routinely informed CUP management strategies. Table 2 shows a selection of specific insights that were delivered through application of the approach, the management strategies it informed, and the subsequent outcome. 


\begin{tabular}{|l|l|l|l|}
\hline \multicolumn{1}{|c|}{ CUP Site } & \multicolumn{1}{|c|}{$\begin{array}{c}\text { Project-Partnership } \\
\text { Cycle Evaluation } \\
\text { Findings }\end{array}$} & \multicolumn{1}{|c|}{ Management Strategy } & Outcome \\
\hline $\begin{array}{l}\text { Mexico City } \\
\text { \& UNAM }\end{array}$ & $\begin{array}{l}\text { Government shift will } \\
\text { disrupt partnership }\end{array}$ & $\begin{array}{l}\text { Build relationships outside of } \\
\text { current configuration }\end{array}$ & $\begin{array}{l}\text { Partnership survived } \\
\text { government upheaval }\end{array}$ \\
\hline $\begin{array}{l}\text { Luneburg \& } \\
\text { Leuphana }\end{array}$ & $\begin{array}{l}\text { Uncertainty around city } \\
\text { priorities and feelings } \\
\text { towards CUP }\end{array}$ & $\begin{array}{l}\text { Conduct reflective interviews } \\
\text { with stakeholders }\end{array}$ & $\begin{array}{l}\text { Gamified workshops for } \\
\text { partnership development } \\
\text { created }\end{array}$ \\
\hline $\begin{array}{l}\text { Portland \& } \\
\text { PSU }\end{array}$ & $\begin{array}{l}\text { CUP is durable and } \\
\text { attained outcomes } \\
\text { enhanced trust and } \\
\text { capacity }\end{array}$ & $\begin{array}{l}\text { Formalize partnership with } \\
\text { enhanced cross-institutional } \\
\text { support and ambitious goals }\end{array}$ & $\begin{array}{l}\text { Assembled new } \\
\text { collaborative team of } \\
\text { empowered leaders at city } \\
\text { and university }\end{array}$ \\
\hline $\begin{array}{l}\text { Karlsruhe \& } \\
\text { KIT }\end{array}$ & $\begin{array}{l}\text { University desires and } \\
\text { nomenclature are not } \\
\text { meeting city needs }\end{array}$ & $\begin{array}{l}\text { Talk about the work in ways } \\
\text { that resonate with municipal } \\
\text { work-flow }\end{array}$ & $\begin{array}{l}\text { City more receptive to } \\
\text { interventions }\end{array}$ \\
\hline $\begin{array}{l}\text { Tempe \& } \\
\text { ASU }\end{array}$ & $\begin{array}{l}\text { Partnership is not robust } \\
\text { or resilient to change }\end{array}$ & $\begin{array}{l}\text { Involve more participants on } \\
\text { city and university side }\end{array}$ & $\begin{array}{l}\text { City and university jointly } \\
\text { planning future prolonged } \\
\text { engagement }\end{array}$ \\
\hline
\end{tabular}

Table 10. Chart showing how combined knowledge of the project-partnership cycle and application of realtime evaluation informed management strategies and produced specific outcomes across sites.

The reflexivity developed through this approach caught problems before they started and allowed CUP managers to look at their initiatives and interactions from a different perspective. For instance, partners at Mexico City and UNAM were able to think through various scenarios of how the impending governmental shift would impact their CUP work. They reflected upon the parts of their work would be most able to withstand change, and the parts that would likely become dismantled. While it was impossible to know how the elections would play out, they were able to think deeply about their network and strategically strengthen the informal bonds that supported their work, which in turn allowed them to develop formal agreement for continued collaboration. If the CUP had not completed thoughtful, iterative evaluation and 
consideration of the project-partnership cycle they may have simply finished their immediate projects and then disintegrated upon the governmental shift -- leaving any future work little foundation upon which to build. Instead, they were able to take control of the situation and weather the storm, coming out with a stronger partnership than ever before.

The project-partnership cycle combined with real-time evaluation also supported the kind of learning and innovation needed to enhance transformative capacity and ultimately impact urban sustainability and resilience transformations. It captured how actions made by CUP managers and how outcomes from different engagements impacted the state of the CUP and subsequent work. Such immediate feedback on decisions and occurrences sped-up learning and allowed for approaches to be tweaked as circumstances changed. This was often seen in the work between the City of Portland and PSU. Assessment showed that as the CUP transitioned from one phase of work (workshop planning and implementation) to another (formation of an advisory group seeking policy change) the dynamics of the CUP also shifted, with new divisions of labor, goal setting, and expectations needing to be defined. In those processes, lessons learned regarding what worked well and what didn't during the first phase of the project were able to be immediately applied. Additionally, the evaluation exposed that both the city and university were highly motivated to undertake more advanced and systemic urban sustainability and resilience problems, and therefore that a higher level group of empowered individuals from across institutions needed to come together and plan an integrated approach, outside of existing structural limitations. 
Conclusion

As cities rise to the challenge of attaining urban sustainability and resilience, they will need to build their transformative capacity and undergo massive transitions. No city government can accomplish this magnitude of change on their own. Municipalities face many barriers to solving complex issues; they are often deeply entrenched in the same systems that have created the problems in the first place, and often must make hard tradeoffs with limited resources. City-university partnerships (CUPs) have emerged as one strategy for breaking out of old cycles, enhancing learning, and accelerating progress towards solving complex problems. Over the past decade, the number of sustainability and resilience focused CUPs has been increasing rapidly; and while some of these initiatives are successfully enabling serious change, others fall flat. Research on CUPs has not yet developed a full understanding of what inhibits or propels CUP success.

This paper contributes to the understanding of CUP functioning and dynamics by closely monitoring five CUPs across three countries, and detailing how careful reflection and strategic decision-making impacted their experiences. Cross-analysis of the sites showed the value of utilizing real-time evaluation as a management technique, and highlighted that both the partnership and the project side of CUP initiatives play a critical role in overall CUP success. The relationship between partnership development and project outcomes (and vice-versa) was explored in-depth, and culminated in the discovery of the partnership-project positive-feedback cycle. This functioning of this cycle was seen across all five case study sites, as it amplified mishaps and reinforced positive changes. 
Additionally, the progression of the cycle leads CUPS towards improved or diminished transformative capacity, impacting their ability to tackle complex problems and implement impactful solutions. Therefore, it is recommended that CUPs manage themselves with the project-partnership cycle in mind. It proved to be especially prudent to use consistent real-time formative evaluation monitoring techniques to reflect upon project and partnership happenings, and adaptively manage for the best results.

\section{Works Cited}

Baker, I., Peterson, A., Brown, G., \& McAlpine, C. (2012). Local government response to the impacts of climate change: An evaluation of local climate adaptation plans. Landscape and Urban Planning, 107(2), 127-136.

https://doi.org/10.1016/J.LANDURBPLAN.2012.05.009

Bowen, G. (2009). Document Analysis as a Qualitative resear. Qualitative Research Journal. https://doi.org/10.3316/QRJ0902027

Dinshaw, A., Fisher, S., Mcgray, H., Rai, N., \& Schaar, J. (2014). Monitoring and Evaluation of Climate Change Adaptation METHODOLOGICAL APPROACHES. https://doi.org/10.1787/5jxrclr0ntjd-en

Fisher, S., Dinshaw, A., Mcgray, H., Rai, N., \& Schaar, J. (2015). Evaluating Climate Change Adaptation: Learning From Methods in International Development, (147). https://doi.org/10.1002/ev.20128 
Geels, F. W. (2010). Ontologies, socio-technical transitions (to sustainability), and the multi-level perspective. Research Policy, 39, 495-510.

https://doi.org/10.1016/j.respol.2010.01.022

Geels, F. W., \& Schot, J. (2007). Typology of sociotechnical transition pathways. Research Policy, 36, 399-417. https://doi.org/10.1016/j.respol.2007.01.003

Goddard, G., \& Farrelly, M. A. (2018). Just transition management: Balancing just outcomes with just processes in Australian renewable energy transitions. Applied Energy, 225, 110-123. https://doi.org/10.1016/J.APENERGY.2018.05.025

Guyadeen, D., \& Seasons, M. (2016). Plan Evaluation: Challenges and Directions for Future Research. Planning Practice \& Research, 31(2), 215-228. https://doi.org/10.1080/02697459.2015.1081335 Guyadeen, D., \& Seasons, M. (2018). Evaluation Theory and Practice: Comparing Program Evaluation and Evaluation in Planning. Journal of Planning Education and Research, 38(1), 98-110. https://doi.org/10.1177/0739456X16675930

Hansen, U. E., Nygaard, I., Romijn, H., Wieczorek, A., Kamp, L. M., \& Klerkx, L. (2018). Sustainability transitions in developing countries: Stocktaking, new contributions and a research agenda. Environmental Science \& Policy, 84, 198-203. https://doi.org/10.1016/J.ENVSCI.2017.11.009 
Healy, N., \& Barry, J. (2017). Politicizing energy justice and energy system transitions: Fossil fuel divestment and a “just transition.” Energy Policy, 108, 451-459. https://doi.org/10.1016/j.enpol.2017.06.014

Heffron, R. J., Mccauley, D., \& Heffron, R. J. (2017). Critical review What is the "Just Transition"? Geoforum, 88, 74-77. https://doi.org/10.1016/j.geoforum.2017.11.016

Helle, M., \& Scarenha S -Swan, M. A. (n.d.). The Case for a Just Transition. Retrieved from https://movementgeneration.org/wp-content/uploads/2018/08/Chapter-3-of-EnergyDemocracy-MG.pdf

Kemp, R., \& Loorbach, D. (2006). Reflexive Governance for Sustainable Development Google Books. Retrieved October 25, 2018, from https://books.google.com/books?hl=en\&lr=\&id=yYGZLbYKpxgC\&oi=fnd\&pg=PA103 $\& \mathrm{dq}=$ Transition + management $:+\mathrm{a}+$ reflexive + governance + approach \&ots $=\mathrm{kZdhdh} 25 \mathrm{UV} \&$ sig=N-FwMGn-uxGozGDZDY31ELrPQhk\#v=onepage $\& \mathrm{q}=$ Transition management $\% 3 \mathrm{~A}$ a reflexive govern

Kitzinger, J. (1995). Qualitative research. Introducing focus groups. BMJ (Clinical Research Ed.), 311(7000), 299-302. https://doi.org/10.1136/bmj.311.7000.299

Loorbach, D. (2010). Transition Management for Sustainable Development: A Prescriptive, Complexity-Based Governance Frameworkg ove_1471 161..184. Retrieved from www.senternovem.nl/energytransition 
Massey, A. P., \& Wallace, W. A. (1991). Focus groups as a knowledge elicitation technique: an exploratory study. IEEE Transactions on Knowledge and Data Engineering, 3(2), 193-200. https://doi.org/10.1109/69.87999

Nevens, F., Frantzeskaki, N., Gorissen, L., \& Loorbach, D. (2013). Urban Transition Labs: co-creating transformative action for sustainable cities. Journal of Cleaner Production, 50, 111-122. https://doi.org/10.1016/J.JCLEPRO.2012.12.001

Newell, P., \& Mulvaney, D. (2013). The political economy of the "just transition." https://doi.org/10.1111/geoj.12008

O’Leary. (2014). The Essential Guide to Doing Your Research Project - Zina O’Leary Google Books. Retrieved June 10, 2019, from https://books.google.com/books?hl=en\&lr=\&id=Xw5BDgAAQBAJ\&oi=fnd\&pg=PP1\& $\mathrm{dq}=$ The+essential+guide+to+doing+your+research + project $+\&$ ots=9Ff $2 \mathrm{~W} \times 1 \mathrm{hEA} \&$ sig=Dj lpUCWd8rs9P0qE1R3xiczTIdQ\#v=onepage \&q=The essential guide to doing your research project\&f=fal

Reed, M. S., Fraser, E. D. G., \& Dougill, A. J. (2006). An adaptive learning process for developing and applying sustainability indicators with local communities. Ecological Economics, 59(4), 406-418. https://doi.org/10.1016/J.ECOLECON.2005.11.008

Roorda, C., Frantzeskaki, N., Loorbach, D., Van Steenbergen, F., \& Wittmayer, J. (2012). Transition Management in Urban Context. Retrieved from www.drift.eur.nl 
Rotmans, J., Kemp, R., \& van Asselt, M. (2001). More evolution than revolution: transition management in public policy. Foresight, 3(1), 15-31. https://doi.org/10.1108/14636680110803003

Rotmans, J., Kemp, R., \& Van Asselt, M. (2001). Foresight More evolution than revolution: transition management in public policy Article information. https://doi.org/10.1108/14636680110803003

Scholz, R. (2017). The Normative Dimension in Transdisciplinarity, Transition Management, and Transformation Sciences: New Roles of Science and Universities in Sustainable Transitioning. Sustainability, 9(6), 991. https://doi.org/10.3390/su9060991 Shove, E., \& Walker, G. (2007). CAUTION! Transitions ahead: politics, practice, and sustainable transition management. Environment and Planning, 39, 763-770. https://doi.org/10.1068/a39310

Smith, J., Scott Frey, R., \& Gellert, P. K. (2018). Global climate justice activism: "the new protagonists" and their projects for a just transition. https://doi.org/10.1007/978-3$319-89740-0$

Sondeijker, S., Geurts, J., Rotmans, J., \& Tukker, A. (2006). Imagining sustainability: the added value of transition scenarios in transition management. Foresight, 8(5), 15-30. https://doi.org/10.1108/14636680610703063 
Sze, J., \& Yeampierre, E. (2017). Just transition and Just Green Enough: Climate justice, economic development and community resilience, 61-73. https://doi.org/10.4324/9781315229515-5

Tremblay, M. C., Hevner, A. R., \& Berndt, D. J. (2010). The Use of Focus Groups in Design Science Research (pp. 121-143). Springer, Boston, MA. https://doi.org/10.1007/978-1-4419-5653-8_10

van Welie, M. J., \& Romijn, H. A. (2018). NGOs fostering transitions towards sustainable urban sanitation in low-income countries: Insights from Transition Management and Development Studies. Environmental Science \& Policy, 84, 250-260. https://doi.org/10.1016/J.ENVSCI.2017.08.011

Villanueva, P. S. (n.d.). Learning to ADAPT: monitoring and evaluation approaches in climate change adaptation and disaster risk reduction-challenges, gaps and ways forward. Retrieved from www.csdrm.org Walker, G., \& Shove, E. (2007). Ambivalence, Sustainability and the Governance of Socio-Technical Transitions. Journal of Environmental Policy \& Planning, 9(3-4), 213225. https://doi.org/10.1080/15239080701622840

Withycombe Keeler, L., Wiek, A., Lang, D. J., Yokohari, M., van Breda, J., Olsson, L., ... Evans, J. (2016). Utilizing international networks for accelerating research and learning in transformational sustainability science. Sustainability Science, 11(5), 749762. https://doi.org/10.1007/s11625-016-0364-6 
Woodruff, S. C., \& Stults, M. (2016). Numerous strategies but limited implementation guidance in US local adaptation plans. Nature Climate Change, 6(8), 796-802.

https://doi.org/10.1038/nclimate3012 


\section{Chapter 5: Conclusion}

Climate change is upon us, and its most devastating impacts are closing-in fast. In this context, incremental changes to our interconnected social, environmental, and economic systems simply will not be enough. In order to rise to the occasion and face the complex challenges of sustainability and resilience, we must have rapid transformative change. This transformative change must encompass "radical, systemic shifts in values and beliefs, patterns of social behavior, and multilevel governance and management regimes" (Olsson et al., 2014b). Moreover, these rapid transitions must be done in equitable ways with just outcomes. Taken together as a whole, this is an incredibly difficult task, and with lack of federal and international leadership, much of this work is landing on the shoulders of urban communities and municipal governments.

In the United States, cities have taken the lead on climate change mitigation and adaptation efforts. This has occurred in part because the prevailing notion is that climate change planning and resilience initiatives should be local and context specific (Baker et al., 2012; Bassett \& Shandas, 2010). However, pressure for cities to plan for and respond to climate change has also mounted due to the lack of a coordinated federal level plan, and either missing or limited state plans. Therefore, cities and localized entities are tackling enormous challenges. It is critical for research to explore ways in which urban resilience and sustainability transformations can be achieved, and to deliver applicable strategies and practices that produce real results. 
The topics explored in this dissertation offer some insight into approaches that can be utilized in a just transition to resilient and sustainable cities. For example, Chapter 2 investigated the characterization of partnerships and collaboration in urban resilience plans. Analysis showed that partnerships and collaborations (P\&Cs) are highly sought after and popular approaches for implementing urban resilience work and are often considered positive for obtaining equity. However, in the planning documents the proposed P\&Cs were often ill-defined, and rarely mentioned or considered how they would be executed and monitored. Without clear strategies and appropriate evaluation, it is impossible to know how the $\mathrm{P} \& \mathrm{Cs}$ are performing, and if they are indeed reaching the desired outcomes of equity and increased resilience. This highlights the need for more research on $\mathrm{P} \& \mathrm{Cs}$ to better understand their structure and functioning, and how they should be managed for impact.

Chapters 3 and 4 help to fill some of these knowledge gaps by 1) articulating a real-time evaluation method for partnership-based resilience and sustainability work, and 2) developing a framework for understanding how collaborative projects function and relate to transformative capacity. Although focused on city-university partnerships, the tools and frameworks derived from these studies are widely applicable; very little about the real-time evaluation or project-partnership cycle is specific to universities or city governments (but further research is needed to fully understand how these relate to partnerships between other organizations). Real-time evaluation is likely useful for any collaboration, as it helps participants adaptively manage their work, increase flexibility, 
enhance learning, and ultimately reach their moving targets. It introduces a good practice of reflexivity, and operates on a more natural timeline, one which follows the ebbs and flows of the work. Ultimately, this approach can help partnership-based sustainability and resilience work evolve through ever-changing circumstances, while maintaining momentum towards their vision. Similarly, understanding of the project-partnership cycle offers sustainability and resilience project managers insight into the relationality of collaborative work, and how it impacts outcomes. The framework asks project managers to transcend the typical project timeline and instead look at how building integrative relationships across institutions can enhance transformative capacity and increase the ability to take on larger and more impactful work.

Insights from these chapters are particularly interesting when considering how just transitions to urban sustainability and resilience can be realized. While some scholars and practitioners have mentioned the usefulness of evaluation and collaboration to the actualization of equity (distributive, procedural, and recognitional/restorative) and urban transformation (sustainability and resilience) separately, the impact of collaboration and evaluation for equity and transformation collectively has not been explored. However, there is evidence to suggest that when combined, good practices around collaboration and evaluation could lead to an increase in just transformative capacity. Just transformative capacity can be defined as an assortment of processes, competencies, and resources that promote distributional, procedural, and restorative justice while aiding transformation. 
For swift and equitable urban sustainability and resilience transformations, individuals, organizations, and institutions require sufficient levels of just transformative capacity.

Collaboration and partnership can enhance just transformative capacity by bringing people together, dispersing power, and creating a third operating space, outside of existing and problematic institutional designs. This can accelerate the sharing of knowledge and resources and allow the collaborative groups to address problems impossible to tackle on their own. For this to have a positive impact on the overall just transformative capacity of the participants, attention must be paid to both the projects being undertaking, and the wellbeing of the partnership itself. As was seen with the project-partnership cycle (chapter 4), the ability of collaborative groups to take on increasingly complex challenges relies on successful completion of appropriately chosen initiatives, and activities that strengthen partnership relations. This is both aided and complemented by real-time evaluation.

Good practices for monitoring and evaluation, especially the application of realtime evaluation (chapter 3), can greatly increase just transformative capacity; without them there is little transparency and accountability to ensure that equitable processes and outcomes are being achieved, or if work is aligned with the overall transformations desired. Additionally, monitoring and evaluation delivers the practice of reflexivity, or awareness, reflection, and recognition of the ways in which project actions are affecting participants, stakeholders, and the world at large; integrating reflexivity has shown to promote trust, equity, integrity, and respect (Probst, 2015). In the context of partnership- 
based transformative resilience and sustainability work, as demonstrated in chapter 3, real-time evaluation provides check-ins and checkpoints to gauge progress on work, explore external and internal context, nourish relationships, and ultimately focus and refocus attention where it is needed. This can mitigate problems with disproportionate impacts, unfair processes, and unsuitable projects as they unfold, or even before they occur. This continuous feedback facilitates the quick learning and maneuverability that is needed to accelerate just transitions for urban sustainability and resilience transformations.

No previous studies have defined or explored the unified concept of just transformative capacity so it is unknown exactly how it should be understood in varying contexts, what exactly goes into its development, and how changing levels of just transformative capacity equate to the actualization of just transitions for urban resilience and sustainability transformation. However, the work contained in this dissertation, combined with the literature on just transitions, urban transformation, sustainability, and resilience, point to just transformative capacity as the natural next step at the nexus justice and climate change. Collaboration and evaluation are clear starting points for further investigating the concept, while simultaneously working to enact its principles. Future work should be done to more fully articulate the concept of just transformative capacity, relate it to specific collaborative and evaluative practices, and understand its role in achieving the massive systemic changes we need. 
Insights from this dissertation can help community organizers, private and public institutions, researchers, and all interested parties better understand the ways in which collaboration and evaluation can support equity and justice as we undertake transformations towards sustainable and resilient urban societies. From the development of just transformative capacity as a concept, to practical frameworks and tools for the management and evaluation of transformative partnerships, it is clear that both intellectual and tangible work must be done to accelerate progress towards a just, sustainable, and resilient future. 


\section{References}

Acosta, J. D., Burgette, L., Chandra, A., Eisenman, D. P., Gonzalez, I., Varda, D., \& Xenakis, L. (2018). How Community and Public Health Partnerships Contribute to Disaster Recovery and Resilience. Disaster Medicine and Public Health Preparedness, 12(5), 635-643. https://doi.org/10.1017/dmp.2017.130

Acuto, M., Parnell, S., \& Seto, K. C. (2018, January 1). Building a global urban science. Nature Sustainability. Nature Publishing Group. https://doi.org/10.1038/s41893017-0013-9

Adger, W. N., Arnell, N. W., \& Tompkins, E. L. (2005). Successful adaptation to climate change across scales. Global Environmental Change, 15, 77-86. https://doi.org/10.1016/j.gloenvcha.2004.12.005

Baker, I., Peterson, A., Brown, G., \& McAlpine, C. (2012). Local government response to the impacts of climate change: An evaluation of local climate adaptation plans. Landscape and Urban Planning, 107(2), 127-136. https://doi.org/10.1016/J.LANDURBPLAN.2012.05.009

Bassett, E., \& Shandas, V. (2010). Innovation and Climate Action Planning. Journal of the American Planning Association, 76(4), 435-450. https://doi.org/10.1080/01944363.2010.509703

Brand, F. S., \& Jax, K. (2007). Focusing the meaning(s) of resilience: Resilience as a descriptive concept and a boundary object. Ecology and Society. The Resilience 
Alliance. https://doi.org/10.5751/ES-02029-120123

Brown, L. D., Feinberg, M. E., \& Greenberg, M. T. (2012). Measuring Coalition Functioning: Refining Constructs Through Factor Analysis. Health Education \& Behavior, 39(4), 486-497. https://doi.org/10.1177/1090198111419655

Butcher, J., Bezzina, M., \& Moran, W. (2011). Transformational Partnerships: A New Agenda for Higher Education. Innovative Higher Education, 36(1), 29-40. https://doi.org/10.1007/s10755-010-9155-7

C40. (2020). Retrieved January 29, 2020, from https://www.c40.org/why_cities

Caughman, L. E. (n.d.). From theory to practice: Urban resilience partnerships and collaborations. In Prep.

Caughman, L. E. (2017). TRIBAL COLLEGE STUDENT PERSPECTIVES: SUSTAINABILITY EDUCATION CURRICULUM IN STEM.

Chi, G. C., Williams, M., Chandra, A., Plough, A., \& Eisenman, D. (2015). Partnerships for community resilience: perspectives from the Los Angeles County Community Disaster Resilience project. Public Health, 129(9), 1297-1300. https://doi.org/10.1016/j.puhe.2015.07.004

Coaffee, J., \& Clarke, J. (2015, June 11). Viewpoint: On securing the generational challenge of urban resilience. Town Planning Review. Liverpool University Press. https://doi.org/10.3828/tpr.2015.16 
Dinshaw, A., Fisher, S., Mcgray, H., Rai, N., \& Schaar, J. (2014). Monitoring and Evaluation of Climate Change Adaptation METHODOLOGICAL APPROACHES. https://doi.org/10.1787/5jxrclr0ntjd-en

Drakaki, M., \& Tzionas, P. (2017). Community-based social partnerships in crisis resilience: a case example in Greece. Disaster Prevention and Management: An International Journal, 26(2), 203-216. https://doi.org/10.1108/DPM-09-2016-0190

Evans, G., \& Phelan, L. (2016). Transition to a post-carbon society: Linking environmental justice and just transition discourses. Energy Policy, 99, 329-339. https://doi.org/10.1016/J.ENPOL.2016.05.003

Faehnle, M., \& Tyrväinen, L. (2013). A framework for evaluating and designing collaborative planning. Land Use Policy, 34, 332-341. https://doi.org/10.1016/j.landusepol.2013.04.006

Faulkner, L., Ayers, J., \& Huq, S. (2015). 6 Meaningful Measurement for CommunityBased Adaptation, (147). https://doi.org/10.1002/ev.20133

Ferraris, A., Santoro, G., \& Papa, A. (2018). The cities of the future: Hybrid alliances for open innovation projects. Futures, 103, 51-60. https://doi.org/10.1016/J.FUTURES.2018.03.012

Fisher, S., Dinshaw, A., Mcgray, H., Rai, N., \& Schaar, J. (2015). Evaluating Climate Change Adaptation: Learning From Methods in International Development, (147). https://doi.org/10.1002/ev.20128 
Fitzgibbons, J., \& Mitchell, C. L. (2019). Just urban futures? Exploring equity in "100 Resilient Cities." World Development, 122, 648-659. https://doi.org/10.1016/J.WORLDDEV.2019.06.021

Gajda, R. (2004). Utilizing Collaboration Theory to Evaluate Strategic Alliances. American Journal of Evaluation, 25(1), 65-77.

Goddard, G., \& Farrelly, M. A. (2018). Just transition management: Balancing just outcomes with just processes in Australian renewable energy transitions. Applied Energy, 225, 110-123. https://doi.org/10.1016/J.APENERGY.2018.05.025

Greenwald, H. P., \& Zukoski, A. P. (2018). Assessing Collaboration. American Journal of Evaluation, 39(3), 322-335. https://doi.org/10.1177/1098214017743813

Guyadeen, D., \& Seasons, M. (2018). Evaluation Theory and Practice: Comparing Program Evaluation and Evaluation in Planning. Journal of Planning Education and Research, 38(1), 98-110. https://doi.org/10.1177/0739456X16675930

Healy, N., \& Barry, J. (2017). Politicizing energy justice and energy system transitions: Fossil fuel divestment and a "just transition." Energy Policy, 108, 451-459. https://doi.org/10.1016/j.enpol.2017.06.014

Heffron, R. J., Mccauley, D., \& Heffron, R. J. (2017). Critical review What is the "Just Transition"? Geoforum, 88, 74-77. https://doi.org/10.1016/j.geoforum.2017.11.016

Helle, M., \& Scarenha S -Swan, M. A. (n.d.). The Case for a Just Transition. Retrieved from https://movementgeneration.org/wp-content/uploads/2018/08/Chapter-3-of- 


\section{Energy-Democracy-MG.pdf}

Keeler, L. W., Beaudoin, F., Wiek, A., John, B., Lerner, A. M., Beecroft, R., ... Forrest, N. (2019a). Building actor-centric transformative capacity through city-university partnerships. Ambio, 48(5), 529-538. https://doi.org/10.1007/s13280-018-1117-9

Keeler, L. W., Beaudoin, F., Wiek, A., John, B., Lerner, A. M., Beecroft, R., ... Forrest, N. (2019b). Building actor-centric transformative capacity through city-university partnerships. Ambio, 48(5), 529-538. https://doi.org/10.1007/s13280-018-1117-9

Kemp, R., \& Loorbach, D. (2006). Reflexive Governance for Sustainable Development Google Books. Retrieved October 25, 2018, from https://books.google.com/books?hl=en\&lr=\&id=yYGZLbYKpxgC\&oi=fnd\&pg=PA $103 \& \mathrm{dq}=$ Transition + management $:+\mathrm{a}+$ reflexive + governance + approach $\&$ ots $=\mathrm{kZdhdh}$ 25UV\&sig=N-FwMGn-uxGozGDZDY31ELrPQhk\#v=onepage\&q=Transition management $\% 3 \mathrm{~A}$ a reflexive govern

Kitzinger, J. (1995). Qualitative research. Introducing focus groups. BMJ (Clinical Research Ed.), 311(7000), 299-302. https://doi.org/10.1136/bmj.311.7000.299

Kula-Semos, M. (2009). Seeking transformative partnerships: schools, university and the practicum in Papua New Guinea. Retrieved from https://researchonline.jcu.edu.au/15463/

Lang, D. J., Arnim Wiek, B., Matthias Bergmann, B., Michael Stauffacher, B., Pim Martens, B., Peter Moll, B., ... Christopher Thomas, B. J. (n.d.). Transdisciplinary 
research in sustainability science: practice, principles, and challenges. https://doi.org/10.1007/s11625-011-0149-x

Lasker, R. D., Weiss, E. S., \& Miller, R. (2001). Partnership Synergy: A Practical Framework for Studying and Strengthening the Collaborative Advantage. Milbank Quarterly, 79(2), 179-205. https://doi.org/10.1111/1468-0009.00203

Loorbach, D. (2010a). Transition Management for Sustainable Development: A Prescriptive, Complexity-Based Governance Frameworkg ove_1471 161..184. Retrieved from www.senternovem.nl/energytransition

Loorbach, D. (2010b). Transition Management for Sustainable Development: A Prescriptive, Complexity-Based Governance Frameworkg ove_1471 161..184. Retrieved from www.senternovem.nl/energytransition

Lozano, R. (2007). Collaboration as a pathway for sustainability. Sustainable Development, 15(6), 370-381. https://doi.org/10.1002/sd.322

Luederitz, C., Sch, N., Wiek, A., Lang, D. J., Bergmann, M., Bos, J. J., ... Westley, F. R. (2017). Learning through evaluation e A tentative evaluative scheme for sustainability transition experiments. Journal of Cleaner Production, 169, 61-76. https://doi.org/10.1016/j.jclepro.2016.09.005

Luederitz, C., Schäpke, N., Wiek, A., Lang, D. J., Bergmann, M., Bos, J. J., ... Westley, F. R. (2017). Learning through evaluation - A tentative evaluative scheme for sustainability transition experiments. Journal of Cleaner Production, 169, 61-76. 
https://doi.org/10.1016/J.JCLEPRO.2016.09.005

MacKinnon, D., \& Derickson, K. D. (2013). From resilience to resourcefulness. Progress in Human Geography, 37(2), 253-270. https://doi.org/10.1177/0309132512454775

Marana, P., Labaka, L., \& Sarriegi, J. M. (2018). A framework for public-private-people partnerships in the city resilience-building process. Safety Science, 110, 39-50. https://doi.org/10.1016/J.SSCI.2017.12.011

Marek, L. I., Brock, D.-J. P., \& Savla, J. (2015). Evaluating Collaboration for Effectiveness. American Journal of Evaluation, 36(1), 67-85. https://doi.org/10.1177/1098214014531068

Margerum, R. D. (n.d.). A Typology of Collaboration Efforts in Environmental Management. https://doi.org/10.1007/s00267-008-9067-9

Massey, A. P., \& Wallace, W. A. (1991). Focus groups as a knowledge elicitation technique: an exploratory study. IEEE Transactions on Knowledge and Data Engineering, 3(2), 193-200. https://doi.org/10.1109/69.87999

Meerow, S. (2017). The Contested Nature of Urban Resilience: Meaning and Models for Green Infrastructure and Climate Change Adaptation Planning. Retrieved from https://deepblue.lib.umich.edu/handle/2027.42/138739

Meerow, S., \& Newell, J. P. (2016). Urban resilience for whom, what, when, where, and why? Urban Geography, 1-21. https://doi.org/10.1080/02723638.2016.1206395 
Meerow, S., Pajouhesh, P., \& Miller, T. R. (2019). Social equity in urban resilience planning. Local Environment, 24(9), 793-808. https://doi.org/10.1080/13549839.2019.1645103

Moloney, S., Scott, H., \& Macdonald, F. (2018). Tracking progress on climate change: Developing a tool for monitoring and evaluation for local governments How well are we adapting? View project Adaptation for Recovery project evaluation View project Tracking progress on climate change: developing a tool for monitoring and evaluation for local governments. Retrieved from https://www.researchgate.net/publication/327172586

Nauslar, N., Abatzoglou, J., \& Marsh, P. (2018). The 2017 North Bay and Southern California Fires: A Case Study. Fire, 1(1), 18. https://doi.org/10.3390/fire1010018

Nevens, F., Frantzeskaki, N., Gorissen, L., \& Loorbach, D. (2013). Urban Transition Labs: co-creating transformative action for sustainable cities. Journal of Cleaner Production, 50, 111-122. https://doi.org/10.1016/J.JCLEPRO.2012.12.001

Newell, P., \& Mulvaney, D. (2013). The political economy of the "just transition." https://doi.org/10.1111/geoj.12008

Nolan, R. H., Boer, M. M., Collins, L., Resco de Dios, V., Clarke, H., Jenkins, M., ... Bradstock, R. A. (2020). Causes and consequences of eastern Australia's 2019-20 season of mega-fires. Global Change Biology. Blackwell Publishing Ltd. https://doi.org/10.1111/gcb.14987 
Olsson, P., Galaz, V., \& Boonstra, W. J. (2014a). Sustainability transformations: A resilience perspective. Ecology and Society, 19(4). https://doi.org/10.5751/ES06799-190401

Olsson, P., Galaz, V., \& Boonstra, W. J. (2014b). Sustainability transformations a resilience perspective. Source: Ecology and Society, 19(4). https://doi.org/10.5751/ES-06799-190401

Plummer, R., \& Armitage, D. (2007). A resilience-based framework for evaluating adaptive co-management: Linking ecology, economics and society in a complex world. Ecological Economics, 61(1), 62-74. https://doi.org/10.1016/J.ECOLECON.2006.09.025

Polk, M. (2015). Transdisciplinary co-production: Designing and testing a transdisciplinary research framework for societal problem solving. Futures. https://doi.org/10.1016/j.futures.2014.11.001

Probst, B. (2015). The Eye Regards Itself: Benefits and Challenges of Reflexivity in Qualitative Social Work Research. https://doi.org/10.1093/swr/svu028

Ramaswami, A., Bettencourt, L., Clarens, A., Das, S., Fitzgerald, G., Irwin, E., ... Tabory, S. (2018). Sustainable Urban Systems: Articulating a Long-Term Convergence Research Agenda.

Reed, M. S., Fraser, E. D. G., \& Dougill, A. J. (2006). An adaptive learning process for developing and applying sustainability indicators with local communities. 
Ecological Economics, 59(4), 406-418.

https://doi.org/10.1016/J.ECOLECON.2005.11.008

Ritchie, H., \& Roser, M. (2018). Urbanization - Our World in Data. Retrieved February 28, 2020, from https://ourworldindata.org/urbanization

Rodríguez-Campos, L. (2012). Advances in collaborative evaluation. Evaluation and Program Planning, 35(4), 523-528.

https://doi.org/10.1016/J.EVALPROGPLAN.2011.12.006

Rotmans, J., Kemp, R., \& Van Asselt, M. (2001). Foresight More evolution than revolution: transition management in public policy Article information. https://doi.org/10.1108/14636680110803003

Salimova, T., Vatolkina, N., \& Makolov, V. (2014). Strategic partnership: Potential for ensuring the university sustainable development. Quality Innovation Prosperity, 18(1), 107-124. https://doi.org/10.12776/QIP.V18I1.320

Schlosberg, D. (2003). The Justice of Environmental Justice: Reconciling Equity, recognition, and participation in a political movement. Retrieved January 6, 2019, from https://books.google.com/books?hl=en\&lr=\&id=EumtnLONgAAC\&oi=fnd\&pg=PA 77\&dq=Schlosberg,+David+(2003).+The+Justice+of+Environmental+Justice:+Rec onciling+Equity,+recognition,+and+participation + in $+a+$ political+movement\&ots=b qc2jM6O77\&sig=L5ZayQ307KyZzbZ16q2hrh 
Scholz, R. (2017). The Normative Dimension in Transdisciplinarity, Transition Management, and Transformation Sciences: New Roles of Science and Universities in Sustainable Transitioning. Sustainability, 9(6), 991. https://doi.org/10.3390/su9060991

Seitanidi, M. M., \& Koufopoulos, D. N. (2010). Partnership Formation for Change: Indicators for Transformative Potential in Cross Sector Social Partnerships View project. Article in Journal of Business Ethics. https://doi.org/10.1007/s10551-011$0784-2$

Shove, E., \& Walker, G. (2007). CAUTION! Transitions ahead: politics, practice, and sustainable transition management. Environment and Planning, 39, 763-770. https://doi.org/10.1068/a39310

Simmons, V. N., Klasko, L. B., Fleming, K., Koskan, A. M., Jackson, N. T., NoelThomas, S., ... Tampa Bay Community Cancer Network Community Partners, T. B. C. C. N. C. (2015). Participatory evaluation of a community-academic partnership to inform capacity-building and sustainability. Evaluation and Program Planning, 52, 19-26. https://doi.org/10.1016/j.evalprogplan.2015.03.005

Smith, J., Scott Frey, R., \& Gellert, P. K. (2018). Global climate justice activism: "the new protagonists" and their projects for a just transition. https://doi.org/10.1007/978-3-319-89740-0

Sondeijker, S., Geurts, J., Rotmans, J., \& Tukker, A. (2006). Imagining sustainability: the 
added value of transition scenarios in transition management. Foresight, 8(5), 1530. https://doi.org/10.1108/14636680610703063

Spaans, M., \& Waterhout, B. (2016). Building up resilience in cities worldwideRotterdam as participant in the 100 Resilient Cities Programme Building up resilience in cities worldwide-Rotterdam as participant in the 100 Resilient Cities Programme. https://doi.org/10.1016/j.cities.2016.05.011

Spearman, M., \& McGray, H. (2011). Making Adaptation Count Concepts and Options for Monitoring and Evaluation of Climate Change Adaptation. Retrieved from www.giz.de.

Swartz, A. L., \& Triscari, J. S. (2011). A Model of Transformative Collaboration. Adult Education Quarterly, 61(4), 324-340. https://doi.org/10.1177/0741713610392761

Taras, M. (2005). Assessment - Summative and formative - Some theoretical reflections. British Journal of Educational Studies, 53(4), 466-478. https://doi.org/10.1111/j.1467-8527.2005.00307.x

Teitel, L. (2012). Childhood Education School/Uníversíty Collaboratíon: The Power of Transformative Partnerships. https://doi.org/10.1080/00094056.2009.10523067

Tierney, K. (2015). Resilience and the Neoliberal Project: Discourses, Critiques, Practices-And Katrina. https://doi.org/10.1177/0002764215591187

Tremblay, M. C., Hevner, A. R., \& Berndt, D. J. (2010). The Use of Focus Groups in Design Science Research (pp. 121-143). Springer, Boston, MA. 
https://doi.org/10.1007/978-1-4419-5653-8_10

Trencher, G., Bai, X., Evans, J., McCormick, K., \& Yarime, M. (2014). University partnerships for co-designing and co-producing urban sustainability. Global Environmental Change, 28, 153-165. https://doi.org/10.1016/J.GLOENVCHA.2014.06.009

Trencher, G. P., Yarime, M., \& Kharrazi, A. (2013). Co-creating sustainability: crosssector university collaborations for driving sustainable urban transformations. Journal of Cleaner Production, 50, 40-55. https://doi.org/10.1016/j.jclepro.2012.11.047

Warren, J. D., \& D., J. (2018). The North Carolina Policy Collaboratory: a Novel and Transformative Partnership for Decision-Relevant Science. American Geophysical Union, Fall Meeting 2018, Abstract \#PA43A-08. Retrieved from http://adsabs.harvard.edu/abs/2018AGUFMPA43A..08W

Whitmore, E. E. (1998). Understanding and Practicing Participatory Evaluation. New Directions for Evaluation. Retrieved from https://eric.ed.gov/?id=EJ580835

Who's in the Network - EPIC-N. (n.d.). Retrieved February 13, 2020, from https://www.epicn.org/whos-in-the-network/

Will Australia's forests bounce back after devastating fires? | Science News. (n.d.). Retrieved February 13, 2020, from https://www.sciencenews.org/article/australiaforest-ecosystem-bounce-back-after-devastating-fires 
Wilson, S., Campbell, D., Dalemarre, L., Fraser-Rahim, H., Williams, E., Wilson, S., ... Williams, E. (2014). A Critical Review of an Authentic and Transformative Environmental Justice and Health Community — University Partnership. International Journal of Environmental Research and Public Health, 11(12), 12817-12834. https://doi.org/10.3390/ijerph111212817

Withycombe Keeler, L., Beaudoin, F., \& Caughman, L. E. (n.d.). Transformative Parterships for Sustainability. In Prep.

Withycombe Keeler, L., Beaudoin, F., Lerner, A., John, B., Beecroft, R., Tamm, K., ... Lang, D. (2018). Transferring Sustainability Solutions across Contexts through City-University Partnerships. Sustainability, 10(9), 2966. https://doi.org/10.3390/su10092966

Withycombe Keeler, L., Wiek, A., Lang, D. J., Yokohari, M., van Breda, J., Olsson, L., ... Evans, J. (2016). Utilizing international networks for accelerating research and learning in transformational sustainability science. Sustainability Science, 11(5), 749-762. https://doi.org/10.1007/s11625-016-0364-6

Wolfram, M., Borgström, S., \& Farrelly, M. (2019). Urban transformative capacity: From concept to practice. Ambio, 48(5), 437-448. https://doi.org/10.1007/s13280-01901169-y

Woodland, R. H., \& Hutton, M. S. (2012a). Evaluating Organizational Collaborations. American Journal of Evaluation, 33(3), 366-383. 
https://doi.org/10.1177/1098214012440028

Woodland, R. H., \& Hutton, M. S. (2012b). Evaluating Organizational Collaborations. American Journal of Evaluation, 33(3), 366-383.

https://doi.org/10.1177/1098214012440028

Woodruff, S. C., \& Stults, M. (2016). Numerous strategies but limited implementation guidance in US local adaptation plans. Nature Climate Change, 6(8), 796-802. https://doi.org/10.1038/nclimate3012 
Appendix A: Personal and Academic Reflections

Coming to PSU to pursue my PhD, I really did not know what to expect. I knew that I had an interest in sustainability, and that I wanted to apply academic knowledge to the real world. But honestly, I had no clue what that would look like in practice, or how my previously gained knowledge and skills would fit in to this new endeavor. I only knew that I was going to arrive with an open mind and ambition to get involved making real change. What I came to experience at PSU was so much more than I could have ever imagined.

I started working as a Graduate Research Assistant at the Institute for Sustainable Solutions (ISS) on the PSU campus a few months before my first year of classes began. My first project involved working with the Portland Bureau of Parks and Recreation to develop a map of their most critical assets, enabling them to fully participate in a citywide resilience planning process. Throughout my experience working with Parks, I gained knowledge about the social, political, and economic context that resilience work must operate within. I saw so many of the barriers that practitioners face, and the shortcomings of the solutions academia provides; I also saw a lack of capacity for the city to take on complex problems and innovate new solutions, something that academia can do quite well. This planted the seeds in my heart and mind that my dissertation research should look at how cities and universities could would together to take on the challenges posed by climate change and build sustainable and resilient cities.

My role with the city's resilience work continued to evolve and I soon found myself coordinating a partnership between PSU and several city bureaus, aimed at building infrastructure resilience in the City of Portland. Through this work, I developed unique relationships with a variety of city staff members, learned about the Portlandspecific context, and became increasingly interested in how equity and social justice related to sustainability and resilience work. Through classes and independent study, I dove into the environmental justice literature, and became enamored with the idea of achieving Just Transitions. This led me to working with the Portland Bureau of Planning and Sustainability, where I used my newfound knowledge and academic skills to support Climate Action Planning, and integrate community defined priorities into city climate work (especially focused on underrepresented groups in Portland, like people of color, and low-income communities).

At the same time, I continued to explore ideas around city-university partnerships and was fortunate enough to work with the Global Consortium for Sustainability Outcomes (GCSO) as part of their CapaCities project. Here, I was tasked with creating and implementing a formative evaluation tool to better monitor and evaluate how these partnerships were operating, what made them work, and what made them fail. I spent a year coordinating calls, visits, and workshops with city and university partners in Portland, Oregon; Tempe, Arizona; Mexico City, Mexico; Luneburg, Germany; and 
Karlsruhe, Germany. The work afforded me the opportunity to do international travel that I had never been privileged to do before, including visiting Hamburg, Germany and Barcelona, Catalonia, Spain. Through these experiences, I not only conducted research to write my dissertation, but I also connected with an international group of academic peers for the first time and I was finally able to put myself and my work into a larger context. This was one of the crowning experiences of my time at PSU.

Soon, my combined interest and knowledge in city-university partnerships and just transitions, as well as joint-appointments at ISS and BPS, began affording me new opportunities. For one, I became a natural connection between combined academic and applied sustainability and resilience work in the City of Portland. This led me to becoming involved with the NSF Urban Resilience to Extremes Sustainability Research Network (UREx), where I developed working relationships with colleagues across the country and the world. Through these connections, I was able to join two different NSF sponsored workshops aiming to develop the future of Urban Sustainability Science. I attended meetings at University of Michigan and Arizona State University, where although consistently the youngest and earliest career researcher, I was able to contribute my opinions and knowledge, while learning about the state of sustainability as an applied and theoretical field. Again, this experience of connecting with my colleagues helped me understand that there is a real place for me in academia, and in the broader world of urban sustainability and resilience.

My committee always asked me where my work fit in, who I was talking to with my research, and questioned if it really had value (not in a demeaning way, but in a way that challenged me to explore my assumptions and justifications). It is quite hard doing interdisciplinary and applied work, especially in a field that is still considered new, and is rather amorphous. However, I finally know the worth of my work: I supply knowledge that bridges academia and the real world. My work is based on theory, research, and analysis, but is useful, applicable, and straight-forward. It offers ideas and pathways that are not meant to be scientific law, but thoughtful approaches to help work be done in better and less harmful ways. The work I produce should be able to immediately inform management and decision-making, being foundational enough to grow upon, but flexible enough to be beneficial for a wide range of the interconnected social and environmental problems we currently face.

As I move into my new faculty position at Northwest Indian College, I hope to continue and evolve this trajectory. I want to co-produce knowledge with my students and the tribal community that is useful for adapting to and thriving within our everchanging world. I hope to develop mechanisms for tribal community resilience and sustainability planning, while providing students the opportunity to grow their skills, and hopefully move into positions in their community where they have power to govern towards resilient and sustainable ends. Simultaneously, I hope to continue to grow my bonds within the wider sustainability and resilience academic community. 
Appendix B: Survey and Interview Questions

Example open-ended informal interview questions and guidelines and example openended and Likert style survey questions are available for reference:

Open ended interview

- Please describe the approach you are using for your collaborative project. Has your approach changed?

- Where would you like to be a year from now? Why? What do you need to get there?

- What are the impacts you envision from your project? From your partnership?

- Who do you work with at the city/university?

- What challenges are you currently facing? What opportunities do you see?

- What have you learned from using the real-time evaluation tool so far? What has been most helpful or hurtful and why?

Open ended survey

- What is your relationship to this project?

- What is the goal of this project?

- What are the primary actions being taken to support these goals?

- State the primary individuals and organizations involved in this project. Who are the leads?

- Please describe where you are currently at within the project timeline (i.e. phase 1 of a 3 phase project, or month 6 out of a yearlong project)

- Will this project have permanent sustainability impacts that endure after the project has been completed? Please explain.

- At the university, are there a variety of academic positions (including students, researchers, and faculty) are interested in the topic of this project? Please explain.

- At the city are there a variety of staff interested in the topic of this project? Please explain.

- At the university, how would you describe the level of understanding of the project topic? Do they have the skills and abilities needed to complete this project?

- At the city, how would you describe the level of understanding of the project topic? Do they have the skills and abilities needed to complete this project?

- Does the city have all of the resources (time, money, personnel, etc.) needed to undertake this project? Please explain.

- Does the university have all of the resources (time, money, personnel, etc.) needed to undertake this project? Please explain.

- Does the university have the ability to engage students in this work and/or provide them with related research opportunities? Please explain. 
- Does the university have experience working as a convener (i.e. bringing together multiple stakeholders)? Please explain.

- Please describe the level of trust between the city and university regarding this project.

- Please describe the level of communication between the city and university regarding this project.

- Please describe the level of commitment to this project. Are both sides of the partnership fully dedicated?

- Have the roles and responsibilities regarding project scoping and management been well defined, agreed upon, and co-created by both sides of the partnership? Please explain.

- Have the roles and responsibilities regarding fundraising and communications been well defined, agreed upon, and co-created by both sides of the partnership? Please explain.

- Have the roles and responsibilities regarding scheduling, meeting, and planning been well defined, agreed upon, and co-created by both sides of the partnership? Please explain.

- A reference document that memorializes the partnership has been created and agreed upon by both sides of the partnership.

- Before this project began, what actions had been taken by the city to work towards the topic of this project? i.e. City council announced that they would make a climate action plan

- Since this project began, what actions have been taken by the city to work towards the goal of this project? i.e. City officers have attended 2 workshops to start visioning the climate action process

- Before this project began, what actions had been taken by the university to work towards the topic of this project? i.e. multiple publications on climate mitigation strategies has been produced

- Since this project began, what actions have been taken by the university to work towards the goal of this project? i.e. University hired students to coordinate and facilitate climate action planning workshops

- Is the partnership structure being used to co-develop and design project activities? Please explain

- Based on your own personal understanding and assessment of the project, do you feel that the goals of this project have been achieved? Please explain.

- Do you envision future projects that build off this project and can utilize this partnership? Please explain.

- Do both sides have a desire to be partners with each other? Please explain.

- What drives the participation in the partnership? What do the partners hope to gain from partnering? 
- Do both sides of the partnership have enough motivation to enable dedication to the partnership? Please explain.

- Are both sides of the partnership willing to do what it takes to actively engage in the partnership? Please explain.

- Please rate your satisfaction with the level of motivation to partner and willingness to engage in partnership:

- Have you and your partner completed projects together in the past? Please explain.

- Were you satisfied with the outcomes of the past projects and your experience with the partner? Please explain.

- Are both sides of the partnership committing resources (time, money, personnel, etc.) to the development of the partnership itself? Please explain.

- Have roles and responsibilities in the partnership been outlined and agreed upon? Please explain.

- Are there documents that specifically state the goals and/or purpose of the partnership? Please explain.

- Would you describe both sides of the partnership as feeling empowered and valued in the partnership? Please explain.

- Do the partners have an understanding of each others needs? Please explain.

- Do the partners have an understanding of each others mission and priorities? Please explain.

- Does the partnership influence the internal strategies at both organizations? Please explain.

- Have the partners aligned their missions, in the context of the partnership? Please explain.

Likert scale 1 to 5

- Please rate your satisfaction with the sustainability impacts this project aims to produce:

- Please rate your satisfaction with the overall amount of interest in the topic of this project:

- Please rate your satisfaction with the level of capacity for this project:

- Please rate your satisfaction with the level of co-management for this project:

- Please rate your satisfaction with the actions that have been taken by this project:

- Please rate your current satisfaction with the outcomes and impacts that have been achieved by this project:

- Overall, rate your current level of satisfaction with the progress and functioning of the project:

- Please rate your satisfaction with the history of collaboration with your partner:

- Please rate your level of satisfaction with the resources that have been committed to the partnership: 
- Please rate your satisfaction with the level of mutual understanding in the partnership:

- Overall, rate your current level of satisfaction with the progress and functioning of the partnership:

- Please rate your level of satisfaction with the structure of the partnership overall: 